\title{
/ Feminismo y Movimiento de Mujeres Socialistas en la Revolución Rusa /
}

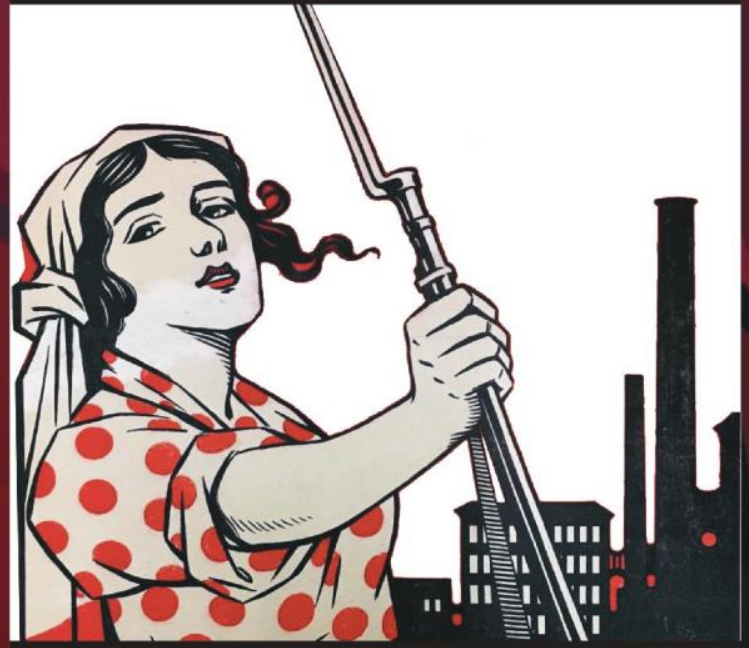

Cintia Frencia y Daniel Gaido 
Feminismo y movimiento de mujeres socialistas en la Revolución Rusa

Cintia Frencia - Daniel Gaido 
Feminismo y movimiento de mujeres socialistas en la Revolución Rusa

Cintia Frencia - Daniel Gaido

Primera Edición, agosto 2018

ISBN: 978-956-8416-63-8

Portada: Luis Thielemann

Ariadna ediciones

Laguna la invernada 0246

Estación Central, Santiago

Chile

www.ariadnaediciones.cl

DOI: http:/ /dx.doi.org/10.26448/9789568416638.12

Obra bajo Licencia Creative Commons Atribución-NoComercialSinDerivadas 4.0 Internacional.

\section{(cc) EY-NC-ND}

Impreso en Gráfica LOM que sólo actúa como impresora 


\section{Índice}

Introducción, p.7

1. Los orígenes del feminismo y del marxismo en Rusia hasta la revolución de 1905, p.11

Las organizaciones feministas en Rusia, p.11

El movimiento de mujeres socialistas en Rusia, p.18

2. Alexandra Kollontai y el Primer Congreso de Mujeres de Toda Rusia (1908), p. 25

Los fundamentos sociales de la cuestión femenina de Alexandra Kollontai, p.25

El Primer Congreso de Mujeres de Toda Rusia (diciembre de 1908), p.32

Balances mencheviques y bolcheviques del 1er Congreso de Mujeres, p.44

Feministas y socialistas durante el período de reacción (1907-1912), p. 46

3. Los orígenes socialistas del Día Internacional de la Mujer y el periódico Rabotnitsa, p.52

Los orígenes socialistas del Día Internacional de la Mujer, p. 52

El primer Día Internacional de la Mujer en Rusia (23 de febrero, 1913), p. 54

El Día Internacional de la Mujer de 1914 y el periódico bolchevique Rabotnitsa, p. 58

Las condiciones de las trabajadoras rusas según Rabotnitsa, p. 64

4. La revolución del 23 de febrero (8 de marzo) de 1917, p. 67

La Primera Guerra Mundial y la Conferencia de Berna, p. 67

El libro de Kollontai sobre el Seguro estatal de maternidad (1916), p. 70

El Día Internacional de la Mujer de 1917 y la Revolución de Febrero, p. 73

5. La organización de mujeres bolcheviques y la Revolución de Octubre, p. 79

Las asambleas de trabajadoras después de la Revolución de Febrero, p. 79

La manifestación feminista por el sufragio femenino, p. 83

Los esfuerzos bolcheviques por organizar las luchas de las trabajadoras, p.88

El relanzamiento de la revista Rabotnitsa, p. 93

Inessa Armand y la organización de las trabajadoras de Moscú, p. 97

La revolución bolchevique y la campaña electoral para la Asamblea Constituyente, p.101

Cierre: El gobierno bolchevique y la liberación de la mujer, p. 107 
Apéndice: Los bolcheviques y los soviets de lucha contra la prostitución, p. 111

August Bebel y Friedrich Engels sobre la prostitución, p. 111

La prostitución en Rusia antes de la Revolución de Octubre de 1917, p. 113

La regulación de la prostitución en la Rusia zarista, p. 115

La revolución bolchevique y la liberación de la mujer, p. 119

La prostitución bajo el comunismo de guerra (1918-1921), p. 120

La nueva definición legal de la prostitución, p. 123

Las Directrices para el Movimiento Comunista Femenino y la prostitución (1920), p. 124

La Nueva Política Económica y el resurgimiento de la prostitución, p.124

El decreto sobre las medidas de lucha contra la prostitución (26 de diciembre de 1922), p. 127

Los Soviets contra la prostitución y la revisión del Código Penal, p. 131

La milicia para combatir la prostitución, p. 134

La respuesta a la "Carta de la prostituta Tania" (1925), p. 136

Conclusión, p. 138

Referencias, p. 139 


\section{Introducción}

El movimiento de mujeres socialistas en Rusia tuvo como modelo al movimiento de mujeres socialistas en Alemania, de la misma manera que el Partido Obrero Socialdemócrata de Rusia (POSDR) tomó como modelo al Partido Socialdemócrata de Alemania (Sozialdemokratische Partei Deutschlands, SPD). A fines del siglo XIX, las socialistas alemanas, comenzaron a organizar política y sindicalmente a las mujeres trabajadoras. El movimiento de mujeres proletarias tenía como eje político y organizativo la idea de que el marxismo, como tendencia política revolucionaria dentro del movimiento obrero, y el feminismo ${ }^{1}$, como movimiento policlasista, eran incompatibles, y que por lo tanto, las mujeres proletarias tenían que tener sus propias organizaciones dentro de los partidos socialistas, que también incluían a los hombres de la clase trabajadora. Sobre la base de ese principio construyeron un movimiento de más de 170.000 trabajadoras. Los seis elementos que permitieron a las mujeres socialistas alemanas alcanzar esta notable hazaña política y organizativa fueron los siguientes:

1) La adopción de una política que su líder Clara Zetkin definió en 1894 como una "separación tajante" (reinliche Scheidung) entre las mujeres socialistas, como una tendencia dentro del movimiento obrero que aspiraba a la liberación de las mujeres mediante la conquista del poder político por parte de los trabajadores, y el feminismo. ${ }^{2}$ Según Zetkin, el feminismo y el marxismo no solo se diferencian por sus demandas y sus formas de organización, sino también por sus fundamentos teóricos: la teoría del derecho natural de las revoluciones burguesas, en un caso, y el materialismo histórico, en el otro. (Zetkin 1907, pp. 3-4).

2) La adopción de un programa, en el Congreso del SPD celebrado en octubre de 1896 en Gotha, que consideraba a la "cuestión de la mujer" como un producto de las transformaciones económicas producidas por el modo de producción capitalista. Este programa rechazó la creencia de que había un solo "movimiento de

\footnotetext{
${ }^{1}$ Frauenrechtlerei: una referencia peyorativa de la defensa de los derechos de las mujeres en el marco de la sociedad capitalista.

${ }^{2}$ La expresión proviene del artículo de Clara Zetkin, "Reinliche Scheidung", Die Gleichheit, 1894, Jg. 4, H. 8, p. 63, traducido íntegramente al español en Cintia Frencia y Daniel Gaido, El marxismo y la liberación de las mujeres trabajadoras: de la Internacional de Mujeres Socialistas a la Revolución Rusa, Santiago de Chile: Editorial Ariadna, 2016, pp. 32-34. http:/ / oapen.org/ search?identifier $=619630$
} 
mujeres". En su discurso programático, Zetkin afirmó que no existía una única "cuestión de la mujer" sino varias, correspondientes a las necesidades de las mujeres de las principales clases de la sociedad capitalista (la burguesía, la clase media y el proletariado). Las mujeres trabajadoras debían organizarse junto con los varones de su clase en el marco del partido socialista, ya que la emancipación de las proletarias no podía ser obra de las mujeres de todas las clases, sino sólo del accionar de todo el proletariado, sin distinción de sexo. ${ }^{3} \mathrm{El}$ programa concluía enumerando una serie de demandas para la organización de las mujeres trabajadoras, incluyendo la protección legal de su trabajo (especialmente para las mujeres embarazadas y las mujeres con niños pequeños), la introducción de inspectoras de fábrica, igual salario por igual trabajo sin distinción de sexo, etc. ${ }^{4} \mathrm{La}$ demanda del sufragio universal femenino, ya contenida en los programas de Gotha (1875) y de Erfurt (1891) de los socialistas alemanes, así como la igualdad jurídica de las mujeres, se transformó en la consigna central en torno a la cual las socialistas alemanas, y tras ellas las socialistas de todo el mundo, movilizaron y organizaron a las trabajadoras, como veremos más adelante.

3) La publicación de la revista quincenal Die Gleichheit ( $\mathrm{La}$ igualdad), editada por Zetkin en Stuttgart, que comenzó a aparecer en 1891 y alcanzó una circulación de 124.000 ejemplares en 1914, momento en el cual el movimiento de mujeres del SPD había llegado

${ }^{3}$ El discurso de Zekin en el congreso de Gotha aparece reproducido en Clara Zetkin, La cuestión femenina y la lucha contra el reformismo, Barcelona: Anagrama, 1976. La Resolución sobre la agitación entre las mujeres, adoptada por el congreso del Partido Socialdemócrata alemán celebrado en Gotha en octubre de 1896 en base al informe de Zetkin, aparece como apéndice a Cintia Frencia y Daniel Gaido, El marxismo y la liberación de las mujeres trabajadoras: de la Internacional de Mujeres Socialistas a la Revolución Rusa, Santiago de Chile: Editorial Ariadna, 2016, pp. 160-163.

http:/ / oapen.org/ search?identifier $=619630$

${ }^{4} \mathrm{Ya}$ en el tercer congreso de la Internacional Socialista, celebrado en Zúrich en 1893, tuvo lugar lo que la socialista alemana Ottilie Baader llamó "una ruptura oficial con la ideología feminista", cuando las marxistas alemanas llamaron a abandonar la noción de igualdad en la legislación y a adoptar leyes laborales protectoras del trabajo femenino y de las mujeres embarazadas y lactantes. La Resolución a favor de la introducción de legislación protectora del trabajo femenino aprobada por el Congreso de Zúrich en 1893 aparece traducida en Cintia Frencia y Daniel Gaido, El marxismo y la liberación de las mujeres trabajadoras: de la Internacional de Mujeres Socialistas a la Revolución Rusa, Santiago de Chile: Editorial Ariadna, 2016, pp. 27-28.

http:/ / oapen.org/ search?identifier $=619630$ 
a 174.754 miembros (aproximadamente un 17\% de la membresía del SPD).

4) La celebración, a partir del año 1900, de conferencias bianuales de mujeres socialistas inmediatamente antes de la apertura de los congresos del SPD. El SPD logró celebrar seis Frauenkonferenzen antes del estallido de la Primera Guerra Mundial.

5) Un trabajo de sindicalización sistemático, estrechamente vinculada a la construcción partidaria, como resultado del cual el número de mujeres trabajadoras sindicalizadas en Alemania creció exponencialmente: mientras que en 1892 la federación sindical alemana tenía 237.094 miembros, de los cuales sólo 4.355 (1,84\%) eran mujeres, poco antes del estallido de la Primera Guerra Mundial en 1914, el número de mujeres sindicalizadas en Alemania llegó a casi 216.000.

6) La creación del Movimiento de Mujeres Socialistas Internacional, que celebró su primera conferencia en Stuttgart en 1907 y fue responsable de la proclamación del Día Internacional de la Mujer en su segunda conferencia celebrada en Copenhague en 1910 (Frencia and Gaido 2018, p. 2). 


\section{Los orígenes del feminismo y del marxismo en Rusia hasta la revolución de 1905}

\section{Las organizaciones feministas en Rusia}

Antes de la revolución de 1905, la ausencia de derechos democráticos hizo que no existieran en Rusia organizaciones feministas en el sentido estricto de la palabra, de la misma manera que no existía su contraparte política, los partidos liberales. ${ }^{5}$ Las mujeres o bien dedicaban sus esfuerzos a exigir su admisión en la educación superior (en 1914 había 25.000 mujeres inscritas en carreras universitarias en diez ciudades, sobre todo en docencia y medicina, y tres de las cuatro organizaciones feministas en los años 1905-1917 fueron lideradas por doctoras), o bien su unían a las organizaciones revolucionarias, en las que llegaron a ocupar posiciones de liderazgo, como lo demuestra el ejemplo de Vera Figner en Narodnaia Volia y el de Vera Zasulich en el grupo Emancipación del Trabajo.

La principal organización protofeminista (filantrópica) que sobrevivió a la revolución de 1905 y jugó un rol importante luego de ella fue la Sociedad de Ayuda Mutua de las Mujeres Rusas (Русского Женского Взаимно-Благотворительного общества) creada en mayo de 1895 en San Petersburgo y dirigida por Anna Pavlovna Filosofova -quien más tarde se uniría al partido de la burguesía liberal, los kadetes- y Anna Nikitichna Shabanova. La Sociedad operaba dormitorios para mujeres, un centro de cuidado infantil para mujeres trabajadoras, una cafetería y un servicio de empleo, y organizaba cursos de teneduría de libros, mecanografía e idiomas extranjeros, así como series de conferencias. La Sociedad encabezó desde 1902 los esfuerzos para organizar un congreso de mujeres rusas, el cual finalmente tuvo lugar en 1908.

En 1899 Anna Filosofova fue elegida presidenta del Consejo Internacional de Mujeres (International Council of Women), una

\footnotetext{
${ }^{5}$ Los dos principales partidos burgueses, los Demócratas Constitucionalistas (kadetes) dirigidos por Pavel Miliukov y la Unión del 17 de octubre ("Octobristas") dirigidos por Alexander Guchkov, fueron creados en 1905. En inglés hay dos historias del feminismo en Rusia en el período en consideración: Linda Edmondson, Feminism in Russia: 1900-1917, Stanford University Press, 1984, y Rochelle Goldberg Ruthchild, Equality and Revolution: Women's Rights in the Russian Empire, 1905-1917, University of Pittsburgh Press, 2010.
} 
de las principales federaciones feministas, creada en 1888 en Washington D.C. bajo el liderazgo de las norteamericanas Elizabeth Cady Stanton y Susan B. Anthony, aunque el ICW no promovía activamente el sufragio femenino para no molestar a sus miembros más conservadores. Cuando Lili Braun, una representante del ala revisionista del Partido Socialdemócrata Alemán, desafió su énfasis estrecho en el trabajo de caridad y benevolencia y planteó el problema de la protección legal del trabajo femenino, las líderes de ICW respondieron con una resolución apoyando la "completa libertad de trabajo" y decidieron no invitar a las delegadas socialistas a su próximo congreso (Stites 1978, p. 176).

La Sociedad de Ayuda Mutua llegó a tener 1.600 miembros en 1899. Pero este resultó ser el pico de su influencia, y desde 1900 en adelante su membresía cayó bruscamente. En 1905, con sólo 716 miembros, la Sociedad había dejado de ser representativa de la opinión feminista, ya fuera en San Petersburgo o en Rusia en general. (Edmondson 1992, p. 80)

Poco después del Domingo Sangriento del 9 de enero de 1905, que dio inicio a la revolución de 1905, fue fundada en Moscú la segunda organización feminista de la época, la Unión Panrusa para la Igualdad de Derechos de las Mujeres (Всероссийский союз равноправия женщин), о Unión de Mujeres. Entre sus líderes se encontraban Zinaida Mirovich y Anna Kalmanovich en Moscú, y Liubov Gurevich y Maria Chejova en San Petersburgo.

El 10 de abril de 1905, la primera asamblea política de mujeres celebrada en Rusia se abrió en la sala del Instituto Educativo Tenishevsky de San Petersburgo, para lanzar oficialmente a la Unión Panrusa para la Igualdad de Derechos de las Mujeres. Asistieron más de mil personas: mujeres profesionales y filántropas de toda Rusia, así como algunas trabajadoras y socialdemócratas. Ariadna Tyrkova y Anna Miliukova (la esposa del futuro líder del partido kadete, Pavel Miliukov) las exhortaron a unirse en la lucha por el sufragio femenino y fueron calurosamente aplaudidas. Pero cuando la socialista Alexandra Kollontai se puso de pie para hablar, el decoro cesó por completo y sus palabras fueron interrumpidas por siseos y abucheos. Kollontai atacó la idea de que podía existir un movimiento de mujeres policlasista en un momento en que las huelgas se estaban extendiendo y se avecinaba una guerra de clases abierta. Según Kollontai, estaba claro por qué justamente en ese momento la Unión de Mujeres quería alejar a las trabajadoras del lugar que les correspondía, entre los socialdemócratas, que era los únicos que habían reconocido las causas económicas de la opresión de las 
mujeres y se habían comprometido a abolirlas. Sólo una persona apoyó el discurso de Kollontai, una trabajadora solitaria, mientras las feministas se abalanzaban sobre ella enfurecidas. Una gritó que estaba haciéndoles el juego a los antisemitas de las Centurias Negras del zar Nicolás II; otra, que estaba "despertando las pasiones bajas de las trabajadoras"; y otra, que no era más que una "provocadora". Una escritora llamada Krandievskaya se arrojó sobre ella gritando " ¡La horca es demasiado buena para ti!". (Kollontai 1921a). Las palabras de Kollontai resultaron proféticas: el 3 de junio de 1905, veintiocho mujeres y niños en Ivanovo-Voznesensk, un centro de la industria textil cercano a Moscú y sede del primer Soviet (consejo de diputados obreros) del 15 de marzo al 18 de julio de 1905, fueron asesinados cuando unas 11.000 trabajadoras textiles se declararon en huelga. Olga Gankina, una activista bolchevique, fue despedazada cuando fue descubierta con una maleta llena de armas por un grupo de matones de las Centurias Negras, y su ejemplo inspiró a otras mujeres a unirse a los grupos de lucha bolcheviques.

El programa de la Unión Panrusa para la Igualdad de Derechos de las Mujeres, adoptado en un congreso celebrado del 7 al 10 de mayo de 1905, afirmaba que "la lucha por los derechos de las mujeres es parte de la lucha por la liberación política de Rusia" y exigía "protección laboral para las trabajadoras y seguro obligatorio a la par con los trabajadores masculinos, apertura de todas las áreas del sector público y de servicios a las mujeres, coeducación y abolición de todas las leyes de prostitución" (es decir, del sistema de inspección médico-policial y de la "tarjeta amarilla", el pasaporte especial para las prostitutas), igualdad de derechos para las mujeres campesinas en todas las futuras reformas agrarias, igualdad jurídica entre hombres y mujeres, incluyendo las mujeres casadas, elección de una asamblea constituyente a través del sufragio universal femenino y masculino, plena vigencia de los derechos civiles, abolición de la pena capital y autonomía nacional. La membresía estaba abierta a mujeres y hombres. Las socialistas que buscaban un vínculo más explícito con una agenda revolucionaria fueron derrotadas en este congreso: una resolución que vinculaba la liberación de las mujeres con la abolición de la división de la sociedad en clases fue rechazada, así como una resolución mucho más modesta que reclamaba incluir en el programa la demanda de la jornada laboral de 8 horas (Ruthchild 2010, pp. 5051; Edmondson 1992, p. 87).

En julio de 1905, la Unión de Uniones, una suerte de federación de organizaciones liberales dirigida por Pyotr Struve y embrión del futuro Partido Constitucional Democrático (kadete), 
aceptó a la Unión de Mujeres como organización afiliada. El futuro líder de los kadetes, Pavel Miliukov, se opuso, aunque la Unión de Mujeres incluía entre sus líderes a su mujer, Anna Miliukova. Aunque la Unión de Mujeres fue finalmente aceptada, el primer congreso del Partido kadete, fundado en Moscú el 17 de octubre de 1905, incluyó el sufragio femenino en su programa por una mayoría de tan sólo 2 votos (sobre un total de 80), y esta demanda no fue hecha vinculante para sus miembros y diputados. Aun así, la feminista Ariadna Tyrkova se convirtió en miembro del Comité Central de los kadetes, y la demanda del sufragio femenino fue finalmente hecha vinculante para los miembros del partido kadete en su segundo congreso, celebrado en enero de 1906 -aunque tanto Miliukov como Peter Struve, otro prominente dirigente liberal, volvieron a oponerse a la misma (Ruthchild 2010, pp. 68-69).

El 17 de octubre de 1905, una huelga general y la creación del Soviet de diputados obreros de San Petersburgo arrancaron al autócrata ruso una serie de libertades democráticas, incluyendo la convocatoria a elecciones a un parlamento con facultades limitadas (la Duma), en el así llamado "Manifiesto de Octubre". Pero cuando el zar anunció sus planes para la nueva Duma, cerró la puerta a "personas del sexo femenino". No sólo eso, sino que las reglas para el personal estipulaban que "las mujeres serán empleadas en las oficinas de la Duma sólo como mecanógrafas, contables, bibliotecarias y taquígrafas" (Ruthchild 2010, p. 92).

La Unión de Mujeres presentó peticiones a las Dumas de las ciudades y a los zemstva (organizaciones municipales) para que se otorgase el derecho a voto a las mujeres. Cuando la Unión de Mujeres inició una campaña para presentar una petición ante la Primera Duma, luego de que ésta comenzara a sesionar en abril de 1906, para la adopción del sufragio femenino, los miembros más radicales de la Unión dirigieron su propia petición a los Trudoviques (Laboristas), la fracción del Partido Socialista Revolucionario que se negó a boicotear las elecciones. A principios de 1906 la Unión de Mujeres también abrió su propio club, el Club Político de las Mujeres, para promover esta campaña, y durante un tiempo atrajeron a un número importante de mujeres trabajadoras. Para marzo de 1906, la Unión de Mujeres había abierto cuatro clubes políticos femeninos, estaba enviando mujeres a las aldeas y a las fábricas para obtener firmas para su petición a la Duma, y estaba celebrando asambleas en todo el país. Pero en julio de 1906 el zar disolvió la primera Duma, y a fines del verano de 1906, la mayoría de los clubes de mujeres, incluyendo los afiliados a la Unión de Mujeres, habían 
sido cerrados por la policía._En 1904, en el congreso de Berlín del International Council of Women, se formó una organización separada para federar a las asociaciones sufragistas nacionales: la Alianza Internacional para el Sufragio Femenino (International Woman Suffrage Alliance), dirigida por las cautelosas Carrie Chapman Catt en los Estados Unidos y por Millicent Fawcett en Gran Bretaña, quienes rechazaban las tácticas militantes de las sufragistas inglesas. La Unión de Mujeres fue invitada a unirse a la International Woman Suffrage Alliance en 1905, y una delegación rusa participó en su tercer congreso celebrado en Copenhague en 1906.

En su apogeo en 1906, la Unión de Mujeres llegó a tener 8.000 miembros y 78 sucursales en 65 ciudades, lo que la transformó en la mayor organización feminista rusa. La Unión organizó campañas de peticiones en favor del sufragio femenino ante la primera y la segunda Duma, en las que se recolectaron decenas de miles de firmas. Según Alexandra Kollontai:

La mayoría de las cuarenta mil personas que firmaron las peticiones enviadas a la primera y segunda Dumas exigiendo que el sufragio se extendiera a las mujeres eran mujeres trabajadoras. Esto es evidencia de que las mujeres trabajadoras ya no eran indiferentes a su falta de derechos civiles y políticos. Las firmas recogidas por las organizaciones de mujeres burguesas, incluida la Unión para la Igualdad de Derechos de las Mujeres, provenían de las fábricas. Sin embargo, la buena disposición de estas mujeres para firmar peticiones organizadas por mujeres de otra clase muestra que su despertar político sólo había dado algunos pasos adelante y se había detenido a mitad de camino. Las mujeres trabajadoras comenzaron a sentir su condición política inferior en términos de su sexo, pero todavía no podían relacionar esto con la lucha general de su clase. Todavía tenían que encontrar el camino que llevaría a las mujeres proletarias a la liberación; todavía se aferraban a las faldas de las feministas burguesas. Las feministas utilizaron todos los medios para establecer contacto con las mujeres trabajadoras y ganarlas a su lado. Intentaron obtener su apoyo y organizarlas en sindicatos de mujeres que supuestamente estaban "por encima de las clases", pero que en realidad eran burgueses de principio a fin. Sin embargo, un sano instinto de clase y una profunda desconfianza hacia las "señoras" salvó a las mujeres trabajadoras de ser desviadas hacia el feminismo, y de cualquier conexión larga y permanente con las feministas burguesas (Kollontai 1920, p. 44). 
La Unión de Mujeres, o para ser más exactos algunas de sus integrantes bajo la dirección de Maria Chejova, comenzaron a publicar la revista mensual Unión de Mujeres (Союз женщин) en junio de 1907, pero su membresía se redujo rápidamente y finalmente la organización colapsó poco después del comienzo del periodo de reacción, en 1908. La revista misma la sobrevivió por casi dos años, hasta diciembre de 1909, pero sus contenidos se fueron derechizando cada vez más: mientras que uno de sus primeros números en octubre de 1907 afirmaba que la liberación total de las mujeres sería posible "sólo cuando se ponga fin a toda explotación de una persona por otra, es decir, bajo el socialismo", hacia el final de su existencia Unión de Mujeres llegó a publicar artículos en defensa de la propuesta de los Octubristas (el ala derecha de la burguesía, así llamada porque apoyaba el "Manifiesto de Octubre" del zar Nicolás II) en la tercera Duma de extender el sufragio calificado a las mujeres. ${ }^{6}$

La exclusión de las mujeres de las elecciones a la Duma en el "Manifiesto de Octubre" fue una de las razones para la creación en San Petersburgo, el 15 de diciembre de 1905 de una tercera organización feminista, mucho más pequeña: el Partido Progresista de las Mujeres (Женской прогрессивной партии) dirigido por Maria Ivanovna Pokrovskaia, quien un año antes, en septiembre de 1904, había comenzado a editar la revista El heraldo de la mujer (Женский вестник), la publicación feminista rusa de más larga trayectoria (1904-1917). ${ }^{7}$ El Partido Progresista de las Mujeres se convirtió en la segunda organización política feminista nacida como resultado de la revolución de 1905, aunque, como creyente en la existencia de una "esencia" femenina, Pokrovskaia deploraba la

${ }^{6}$ Rochelle Goldberg Ruthchild, Equality and Revolution: Women's Rights in the Russian Empire, 1905-1917, Pittsburgh: University of Pittsburgh Press, 2010, pp. 93-100. Una selección de artículos de la revista Unión de Mujeres aparece en Светлана Г. Айвазова, Русские женщины в кабиринте равноправия: очерки политической теории и истории: документальные материалы, М.: РИК Русанова, 1998. [Svetlana G. Aivazova, Las mujeres rusas en el laberinto de la igualdad: Ensayos sobre teoría política e historia: Materiales documentales, Moscú: RIK Rusanova, 1998.] Disponible online:

http://www.owl.ru/win/books/rw/index.htm

7 Una selección de artículos de la revista El heraldo de la mujer aparece en Светлана Г. Айвазова, Русские женщины в мабиринте равноправия: очерки политической теории и истории: документальные материалы, М.: РИК Русанова, 1998. [Svetlana G. Aivazova, Las mujeres rusas en el laberinto de la igualdad: Ensayos sobre teoría política e historia: Materiales documentales, Moscú: RIK Rusanova, 1998.] Disponible online:

http://www.owl.ru/win/books/rw/index.htm 
violencia revolucionaria como una característica masculina. Las mujeres, escribió en diciembre de 1905, durante la insurrección de Moscú, "sabemos que no es a través de la violencia y la matanza que podemos recrear la vida, sino sólo a través de una reforma pacífica" (Ruthchild 2010, p. 61). El programa del Partido Progresista se asemejaba al programa de la Unión de Mujeres en muchos detalles, con demandas similares de libertades civiles y políticas, de derecho al sufragio femenino, de igualdad de derechos en la familia, en el acceso a la tierra, en la educación y en el empleo, de coeducación, de igualdad jurídica de la mujer, de derecho al divorcio y de igualdad ante la ley de los hijos ilegítimos. Ambas organizaciones rechazaban la regulación estatal de la prostitución, el sistema de inspección médico-policial y el pasaporte especial para las prostitutas. Una integrante de la Sociedad de Ayuda Mutua desde su formación en 1895, y luego de la Unión de Mujeres, la Dra. Pokrovskaia había practicado la medicina durante muchos años entre las trabajadoras fabriles. Por su larga experiencia en el tratamiento de prostitutas, había desarrollado un poderoso desprecio por sus clientes, que había proyectado a todo el mundo de los hombres y de la política convencional. Mientras que la Unión de Mujeres abrió su membresía a los hombres, el Partido Progresista los excluyó.

El Partido Progresista de las Mujeres apoyaba una "monarquía constitucional democrática". Aunque exigía reformas para las trabajadoras, incluyendo la introducción de inspectoras de fábrica, una licencia por maternidad de diez meses, guarderías en las fábricas y salario igual por igual trabajo, se oponía a las huelgas. El Partido Progresista solicitó permiso legal para operar, y el gobierno le permitió abrir un club en San Petersburgo en diciembre de 1906, que se convirtió en el centro de sus actividades, pero nunca obtuvo apoyo serio fuera de la capital. Al igual que la Unión de Mujeres, el Partido Progresista de las Mujeres intentó presionar a los diputados de la Duma para que apoyaran los derechos de la mujer, aunque Pokrovskaia tenía menos ilusiones que los miembros de la Unión de Mujeres en los liberales rusos, llegando a declarar, ante las tácticas obstruccionistas de Miliukov en la Duma en relación al sufragio femenino: "Entiendo a las mujeres socialdemócratas, ipero no entiendo a las mujeres kadetes!" (Ruthchild 2010, p. 78).

\section{E1 movimiento de mujeres socialistas en Rusia}

El primer -y por una década el único- intento autóctono de las socialistas rusas de analizar la situación de las trabajadoras fue el 
panfleto de Nadezhda Krupskaya La mijer trabajadora, escrito en 1899, cuando solo tenía 20 años, y publicado por Iskra bajo el seudónimo "Sablina" en 1900.8 El folleto estaba destinado a demostrar que "las condiciones de la trabajadora son particularmente difíciles porque es miembro de la clase trabajadora, sus condiciones están estrechamente ligadas a las condiciones de toda la clase trabajadora, y sólo la victoria de la clase trabajadora, del proletariado, puede liberar a las mujeres". La primera sección, titulada "La mujer como miembro de la clase trabajadora", recordando que la ley de 2 de junio de 1897 había fijado la jornada laboral máxima en 11 horas y media diarias, describía en detalle las condiciones laborales de distintas secciones de las trabajadoras. La segunda sección, titulada "Las condiciones de las mujeres trabajadoras en la familia", analizaba la situación de dependencia tradicional de la mujer con relación al padre y al marido, y cómo esa situación estaba siendo alterada por el crecimiento del trabajo asalariado entre las mujeres. Esto sentaba las condiciones para relaciones más igualitarias entre los sexos, pero también, en aquellas ramas de la producción en los que los salarios de las mujeres no cubrían su subsistencia, para el florecimiento de la prostitución, abiertamente fomentada por los empleadores como un "suplemento" al salario. La tercera sección, titulada "Las mujeres y la crianza de los niños", describía las terribles condiciones en las que los niños eran criados en las aldeas y en las barriadas obreras rusas y recordaba que los socialistas defendían la educación social de los niños, lo cual significaba "que la sociedad proporcionará al niño no sólo los medios de existencia, sino que cuidará de que tenga todo lo necesario para que se desarrolle completamente y en todos los sentidos", mediante la creación de jardines de infancia y de escuelas ligadas al trabajo productivo. ${ }^{9}$

${ }^{8}$ Existe una biografía de Krupskaya en inglés: Robert H. McNeal, Bride of the Revolution: Krupskaya and Lenin, Ann Arbor, Michigan: The University of Michigan Press, 1972.

${ }^{9}$ En un artículo de 1909, titulado “¿Se deben enseñar 'cosas de mujeres' a los niños?", Krupskaya afirmaba que "La escuela libre lucha contra todos los prejuicios que dañan la vida de las personas. El prejuicio de que las tareas domésticas son sólo dignas de seres con necesidades inferiores socava las relaciones entre hombres y mujeres, introduciendo en ellas un principio de desigualdad... La escuela libre, al enseñar trabajos manuales, no debe diferenciar entre niños de distintos sexos. Es preciso que los niños y las niñas aprendan de la misma forma a hacer todo lo necesario en el trabajo doméstico, y que no consideren indigno realizarlo”. Krupskaya concluía afirmando: "Es claro que sería ridículo esperar grandes consecuencias de enseñar 'cosas de mujeres' a los niños, pero se trata de uno de esos detalles 
Como ya vimos, en el tercer congreso de la Internacional Socialista celebrado en Zúrich en 1893 había tenido lugar la ruptura oficial de las socialistas con la ideología feminista, cuando Clara Zetkin introdujo la demanda de legislación protectora para el trabajo femenino. Al final de su folleto, Krupskaya sintetizaba las demandas de legislación protectora del trabajo femenino adoptadas en el congreso de Zúrich (jornada laboral de ocho horas diarias y de 44 horas semanales, con un descanso de al menos 42 horas seguidas, licencia por maternidad de ocho semanas antes y ocho semanas después del parto, igualdad salarial para mujeres y hombres que realizaran el mismo trabajo, etc.). Dado que la agitación por tales medidas era imposible en la situación de ausencia de libertades vigente entonces en Rusia, el folleto concluía con un llamado a las trabajadoras a volverse políticamente conscientes y a tomar parte activa en todas las luchas de su clase. Los trabajadores demandaban el sufragio universal que les permitiría enviar a sus propios representantes al parlamento, así como la libertad política, y las trabajadoras debían asumir un rol activo en esta lucha por los derechos políticos: "A fin de obtener una verdadera protección laboral, los trabajadores deben conquistar la libertad política, como lo han hecho sus hermanos, los trabajadores europeos. La lucha política es la única forma en que los trabajadores pueden lograr mejorar en su condición. En la lucha por mejores condiciones de trabajo, por la libertad política y por un futuro mejor, la trabajadora irá del brazo del hombre trabajador."

La obra de Krupskaya, una de las principales constructoras, junto con Lenin, del Partido Bolchevique, también ofrece información reveladora sobre las causas de la prostitución en Rusia y su relación con la esclavitud asalariada de las obreras, a las cuales los patrones incitaban abiertamente a prostituirse para complementar sus salarios de hambre:

Recientemente, en mayo de 1899, hubo una gran agitación laboral en Riga Estas perturbaciones comenzaron con el hecho de que las mujeres de la fábrica de yute exigían un aumento de salarios. Fueron al gobernador para quejarse de la administración de la fábrica. En el camino, las mujeres fueron detenidas y encerradas en la prisión Alexander. Los trabajadores de la planta de Fénix y otros comenzaron a liberar a las mujeres detenidas. El

que corresponden al espíritu general de la escuela libre a los cuales es preciso prestar atención” (Schneider 2017, pp. 90-91). 
gobernador ordenó que se desplegaran las tropas y, del 5 al 15 de mayo, Riga se convirtió en un campo de batalla: las tropas dispararon a los trabajadores, los trabajadores arrojaron piedras a las tropas, rompieron las ventanas y prendieron fuego a los edificios. Pero la principal furia de los trabajadores se dirigió a las casas de tolerancia; en una noche 11 prostíbulos fueron destruidos. ¿Por qué los trabajadores se apresuraron a destruir los burdeles? ¿Cuál fue la relación con la huelga y la agitación de los trabajadores? ¿Cuál era la conexión con los prostíbulos? La conexión era directa, porque cuando los trabajadores reclamaron ante la imposibilidad de que sus esposas e hijas sobrevivieran con sus salarios, las autoridades cínicamente respondieron que sus esposas e hijas podían hacer dinero extra en los burdeles. ¡Por lo tanto, la prostitución fue señalada abiertamente como la única manera que tenía una trabajadora de sobrevivir con su miserable salario! ¿Quién puede entonces culpar a una mujer forzada a venderse? ¿Quién puede culpar a una mujer forzada a elegir el único ingreso disponible ante la perspectiva de una existencia miserable de semi-inanición o directamente de hambre? Este ingreso está lejos de ser obtenido "fácilmente". Hay que escuchar cuán arrogantemente hablan los burgueses bien alimentados y sus esposas acerca de la "corrupción" de las mujeres y de las niñas de las fábricas. Estas señoras que nunca han experimentado la necesidad- pronuncian la palabra "prostituta" son disgusto hipócrita.

¡Los profesores burgueses no se avergüenzan en declarar que las prostitutas no son esclavas, sino que, voluntariamente eligen su camino! Es la misma hipocresía repugnante que les hace declarar que nada impide a un trabajador salir de la fábrica donde no puede respirar debido al polvo, los humos tóxicos, el calor, etc. Él también permanece allí "voluntariamente" y continúa trabajando "voluntariamente" entre 16 y 18 horas por día. ${ }^{10}$

Haciéndose eco del programa desarrollado por los socialistas alemanes, el Programa del Partido Obrero Socialdemócrata

10 Надежды Константиновны Крупской, Женщина-работнича (1899) // Педагогические сочинения. Том I. Автобиографические статьи. Аореволючионныге работы, Москва: Издательство Академии педагогических наук, 1957, С. 88-89. [Nadezhda Konstantinovna Krupskaya, La mujer trabajadora (1899), reproducido en Krupskaya, Obras pedagógicas, Vol. I: Artículos autobiográficos. Obras prerrevolucionarias, Moscú: Editorial de la Academia de Ciencias Pedagógicas, 1957, pp. 88-89.] 
de Rusia, adoptado en el segundo congreso celebrado en julio-agosto de 1903 - congreso en el que tuvo lugar la escisión entre bolcheviques y mencheviques por cuestiones organizativas (ambas tendencias compartieron el mismo programa hasta 1905)—, incluía la demanda del sufragio universal para ambos sexos, y estos dos puntos específicos sobre la protección de las trabajadoras:

6. Prohibición del trabajo de la mujer en todas las ramas de la producción nocivas para la salud de la mujer; relevar del trabajo a las mujeres durante ocho semanas antes y ocho semanas después del parto [es decir, licencia por maternidad].

7. Instalación de guarderías para niños de pecho y de corta edad y de salas para la lactancia en todas las fábricas y otras empresas en que trabajen mujeres; las madres, durante la lactancia, estarán autorizadas a suspender el trabajo durante media hora, con intervalos no mayores de tres horas. ${ }^{11}$

Hasta el año de la primera revolución rusa, en 1905, el movimiento de mujeres trabajadoras rusas fue principalmente de carácter económico: las trabajadoras participaron en numerosas huelgas desde finales del siglo XIX, pero hesitaban ante la idea en sumarse al Partido Socialdemócrata en grandes cantidades (Kollontai 1920, pp. 39-41). ${ }^{12}$ La revolución de 1905 permitió por primera vez el

11 El Proyecto de Programa del Partido Obrero Socialdemócrata de Rusia redactado por Lenin en abril-mayo de 1917 hacía los siguientes agregados (en cursiva) a las demandas de protección laboral de las mujeres incluidas en el programa adoptado por los marxistas rusos en 1903: “6. Prohibición del trabajo de la mujer en todas las ramas de la producción nocivas para la salud de la mujer; probibición del trabajo nocturno; relevar del trabajo a las mujeres durante ocho semanas antes y ocho semanas después del parto, sin pérdida del salario y con asistencia médica y medicinas gratuitas." A la demanda siguiente, se agregaba al final: "concesión de subsidio por lactancia a estas madres y reducción de su jornada de trabajo a seis horas". (Lenin, "Materiales sobre la revisión del programa del partido", abril-mayo de 1917, en Obras completas, Madrid: Akal, 1977, tomo 25 , p. 459.)

12 Beate Fieseler calculó que unas 2.100 mujeres fueron socialdemócratas activas antes de 1905, y que las militantes del POSDR constituían entre el 11\% y el 15\% de la membresía total del partido antes de 1917 (Fieseler 1989, pp. 195-196). Ver las biografías de 545 mujeres que se unieron al Partido Bolchevique hasta fines de la guerra civil en 1921 en Barbara Evans Clements, Bolshevik Women, Cambridge University Press, 1997. Sin embargo, la autora atribuye, arbitrariamente y contra toda evidencia, el mote de 
surgimiento tanto de organizaciones feministas como de organizaciones especiales de obreras en Rusia —además de conducir a la adopción del sufragio femenino en Finlandia (el primer país del mundo en hacerlo) en julio de 1906.13 En abril de 1907 comenzaron a celebrarse asambleas de trabajadoras bajo los auspicios del Partido Obrero Socialdemócrata de Rusia, pero éstas fueron prohibidas poco después por la policía en el marco de la represión general: el 3 de junio de 1907 fue disuelta la Segunda Duma, que se había reunido en febrero, y los 56 diputados socialdemócratas fueron arrestados y en su mayoría condenados a largos periodos de prisión y trabajos forzados. Ante esta situación, el comité del Partido Socialdemócrata de San Petersburgo decidió apoyar la celebración de asambleas legales de mujeres en los clubes de trabajadoras.

El primer club patrocinado por las socialistas para el proletariado femenino fue abierto en San Petersburgo en 1907, cerca de la sede del Sindicato de Trabajadores Textiles. Utilizando un nombre filantrópico inofensivo que encajaba dentro de la rúbrica de las actividades centradas en las mujeres aprobadas por el gobierno, la Sociedad de Ayuda Mutua de las Trabajadoras (общество Взаимопомощь работниц) obtuvo la aprobación de su estatuto con bastante rapidez, en un mes y medio. Sus organizadoras incluyeron tanto a Kollontai (quien militó en las filas del bolchevismo en 1904 y 1905, pasó al menchevismo de 1906 a 1914 y retornó finalmente al Partido Bolchevique en 1915), como a un grupo de mujeres trabajadoras. Sus actividades incluyeron conferencias y una biblioteca; estaba abierto todas las noches y tenía entre doscientos y trescientos miembros. La Sociedad de Ayuda Mutua de las Trabajadoras deliberadamente no se identificó con ninguna de las facciones socialdemócratas. Tanto los bolcheviques como los mencheviques la frecuentaron; Vera Zasulich asistió a su primera asamblea. No todo no fue sencillo: el club era una iniciativa de "frente único" entre las distintas facciones del Partido Socialdemócrata, lo cual causó fricciones, y algunos de sus miembros fundadores, como Kollontai, tuvieron que pasar a la clandestinidad y luego al exilio. Sin embargo, el club continuó sus actividades hasta 1913, cuando fue cerrado por

feministas a las militantes bolcheviques, un procedimiento que ya había utilizado en su biografía de Kollontai: Barbara Evans Clements, Bolshevike Feminist: The Life of Aleksandra Kollontai, Bloomington: Indiana University Press, 1979.

13 Ver al respecto el artículo de Eric Blanc, "Finlandia 1906: Las raíces revolucionarias del sufragio femenino", Sin Permiso, 08/03/2015. old.sinpermiso.info/articulos/ficheros/femhis.pdf 
la policía. Muchos de sus miembros fueron obligados a abandonar San Petersburgo.

Hemos visto que las marxistas rusas seguían los lineamientos de las socialistas alemanas, cuya política se vio plasmada en el plano internacional en la resolución a favor del sufragio universal femenino adoptada por la Primera Conferencia de la Internacional de Mujeres Socialistas celebrada en Stuttgart en agosto de 1907, conferencia a la cual Alexandra Kollontai asistió como la delegada por Rusia. ${ }^{14}$ Antes de participar en la Conferencia de Stuttgart, Alexandra Kollontai asistió a la Conferencia de Mujeres (Frauenkonfereñ) del Partido Socialdemócrata alemán celebrada en Mannheim en septiembre de 1906, que sirvió para prepararla. Allí conoció a las principales líderes del movimiento de mujeres socialistas alemán: Clara Zetkin, Luise Zietz y Ottilie Baader. Kollontai confiaba en que sus camaradas rusos podían ser persuadidos de aceptar el modelo alemán, basado en "la fusión de las mitades masculinas y femeninas de la clase trabajadora en la organización del Partido, conservando la autonomía de la agitación entre las mujeres de la clase trabajadora". ${ }^{15}$

Alexandra Kollontai estuvo presente en la Primera Conferencia de la Internacional de Mujeres Socialistas celebrada en Stuttgart en agosto de 1907. Kollontai fue la única delegada rusa en esta asamblea de 58 delegadas de los partidos socialistas de catorce países. La principal organizadora la Conferencia de Stuttgart fue Clara Zetkin, quien invitó a Kollontai y a Rosa Luxemburg a hospedarse en su casa. Las delegadas tuvieron sólo dos días, del 17 al 19 de agosto de 1907, para elaborar las resoluciones sobre el sufragio

14 Sobre la historia de la Internacional de Mujeres Socialistas ver Cintia Frencia y Daniel Gaido, El marxismo y la emancipación de la mujer trabajadora: De la Internacional de Mujeres Socialistas a la Revolución Rusa, Universidad de Santiago de Chile: Editorial Ariadna, 2016, pp. 68-101, y la tesis no publicada de Jürgen Kirchner, Herausbildung und Geschichte der Sozialistischen Fraueninternationale und zu den Anfängen des Internationalen Frauentages. Ein Beitrag zur Geschichte der II. Internationale, Dresden, Pädagogische Hochschule, Diss. B, 1983.

15 Alexandra Kollontai, Women Workers Struggle for Their Rights (1919), 1. The Socialist Movement of Women Workers in Different Countries, London: Falling Wall Press, 1971. La Resolución de la cuarta conferencia de mujeres socialistas alemanas celebrada en Mannheim sobre el sufragio femenino (23 de septiembre de 1906) aparece como apéndice a Cintia Frencia y Daniel Gaido, El marxismo y la liberación de las mujeres trabajadoras: de la Internacional de Mujeres Socialistas a la Revolución Rusa, Santiago de Chile: Editorial Ariadna, 2016, pp. 163-166. http:/ / oapen.org/search?identifier $=619630$ 
universal femenino y sobre la creación de un Buró internacional de mujeres socialistas para presentar ante el Congreso de la Segunda Internacional celebrado en Stuttgart inmediatamente después de la Conferencia. Kollontai apoyó las mociones de Zetkin en la Conferencia de Stuttgart y en su intervención dijo lo siguiente sobre las características del movimiento de mujeres socialistas en Rusia:

No hemos tenido hasta ahora en Rusia un movimiento específico de trabajadoras o de mujeres. Las trabajadoras con conciencia de clase han tomado parte en el movimiento de liberación al lado de los varones, en el mismo marco [organizativo]. La Socialdemocracia rusa también ha representado siempre los intereses de las trabajadoras, y las mujeres rusas con conciencia de clase se han unido en gran número al Partido Socialdemócrata y a los sindicatos - sobre todo a los sindicatos, que han crecido muy rápidamente. Ahora, sin embargo, tenemos que pasar por un momento difícil en Rusia. El movimiento de mujeres proletarias ha encontrado un nuevo enemigo en el movimiento de mujeres burgués, del cual no existían trazos hace tan solo tres años atrás [es decir, antes del estallido de la revolución de 1905]. Ahora ha brotado como un hongo después de la lluvia. Hay mujeres kadetesradicales que son políticamente muy decididas, pero totalmente atrasadas en lo que concierne a la legislación social. También hay mujeres progresistas, y finalmente una "Unión de Mujeres auténticamente rusas" [patrocinada por la emperatriz] que están ávidas de beber la sangre de nuestros abnegados luchadores revolucionarios. ¡Una bella organización del bello sexo! Ahora debemos luchar contra todas estas mujeres burguesas, y así proseguimos la lucha contra el absolutismo, hombres y mujeres juntos. ¡Las vamos a derrotar, y esta derrota será una victoria para todo el mundo! (fuertes aplausos) (Erste Internationale Konferenz Sozialistischer Frauen, Stuttgart 1907, pp. 131132).

Alexandra Kollontai fue la figura dominante del movimiento de mujeres socialistas en Rusia desde la revolución de 1905 hasta la publicación de Rabotnisa en 1914. Pero Kollontai no actuaba sola en este sentido en Rusia, sino que estaba acompañada por un círculo de mujeres socialistas que incluía a trabajadoras como Marusya Burko, Anna Semenova y Maria Antonova, a quienes se sumaron, a principios de 1907, Anna Osipova, una trabajadora textil bolchevique; una enfermera bolchevique llamada Efremova; Klavdia 
Nikolaeva, un tipógrafa que se había unido a los bolcheviques a la edad de catorce años en 1905, y las también bolcheviques Konkordia Samoilova y Praskovia Kudelli. ${ }^{16}$

\section{Alexandra Kollontai y el Primer Congreso de Mujeres de Toda Rusia (1908)}

\section{Los fundamentos sociales de la cuestión femenina de Alexandra Kollontai}

La revolución rusa de 1905 fue seguida por un período de reacción que comenzó en 1907 y se extendió hasta 1912. En este marco, que entre otras cosas condujo a la disolución de la principal organización feminista de la época, la Unión de Mujeres, tuvo lugar en San Petersburgo el Primer Congreso Panruso de Mujeres (Первый всероссийский женский съезА) del 10 al 16 de diciembre de 1908. El Comité Organizador del Congreso reflejaba toda la gama de grupos feministas, incluyendo a representantes de la Sociedad de Ayuda Mutua (Anna Shabanova, Anna Filosofova, Olga Shapir, Evgeniia Chebysheva-Dmitrievna y Evgeniia Avilova), activistas de la Unión de Mujeres como Liudmila von Ruttsen, Maria Chejova, Ekaterina Shchepkina y Maria Blandova, y la Dra. Maria Pokrovskaia de Partido Progresista. El Congreso se llevó a cabo bajo supervisión

16 Alexandra Kollontai, "Aus meinem Leben und aus meiner Arbeit", Proletarskaja Rewoluzija, Nr. 3, 1921 (mit dem Titel „Autobiographischer Abriss"), in Kollontai, „Ich babe viele Leben gelebt": Autobiographische Aufzeichnungen, Berlin: Dietz Verlag, 1980, S. 115-163. [Alexandra Kollontai, "De mi vida y de mi trabajo", Revolución proletaria, No 3, 1921 (publicado originalmente con el título "Esbozo autobiográfico"), en Kollontai, "He vivido muchas vidas": Apuntes autobiográficos, Berlin: Dietz Verlag, 1980, pp. 115-163.] Este esbozo autobiográfico de Kollontai contiene la mejor descripción de su trabajo entre las mujeres socialistas, en particular en torno al Congreso de diciembre de 1908. Sólo fue traducido al alemán y no debe ser confundido con su "Autobiografía" de julio de 1926, traducida al castellano en Kollontai 1976, pp. 67-117. Después de la revolución bolchevique Kudelli editó un folleto sobre el rol de la trabajadoras de la capital en la revolución de 1905: Прасковья Ф. Кудемли,, Работница в 1905 г. в С.-Петербурге. Сборник статей и воспоминаний. Сост. П. Ф. Куделми. Аенинград: Рабочее издательство "Прибой", Сектор "Работница и крестьянка", 1926. - 88 с. Praskovia F. Kudelli, La mujer trabajadora en 1905 en San Petersburgo: Colección de artículos y memorias. Comp. P. F. Kudelli. Leningrado: Editorial de trabajo Priboy, Sector "Trabajadora y mujer campesina", 1926. 88 p.] 
policial (en cada sesión hubo al menos un policía, y a veces varios) con el lema "el movimiento de mujeres no debe ser ni burgués ni proletario, sino un movimiento de todas las mujeres".

Kollontai decidió usar este lema para alentar a las mujeres trabajadoras a desafiar, en una intervención organizada, la idea de que un solo movimiento podía unir a mujeres cuyos intereses de clase eran tan diametralmente opuestos. Fue apoyada por Lyubov Gurevich, Olga Volkenstein, y la menchevique, Margarita MarguliesAitova, las socialistas con quienes había asistido a la primera asamblea de fundación de la Unión de Mujeres el 10 de abril de 1905, y luego de una oposición inicial, también fue apoyada por los bolcheviques, quienes enviaron como representante a Vera Slutskaya y Praskoviia Kudelli, junto con un delegado identificado como "camarada Sergei". Entre octubre y diciembre de 1908, Kollontai trabajó para garantizar que todas las mujeres trabajadoras de la capital conocieran el congreso: habló en 52 asambleas preparatorias, disfrazadas de círculo de costura y charlas sobre la nocividad de los corsés.

Antes del congreso, y para preparar las intervenciones de las trabajadoras, Kollontai escribió un libro de 437 páginas titulado Bases sociales de la cuestión de la mujer, que incluía una polémica detallada con las organizaciones feministas existentes entonces en Rusia (sobre todo con la Unión de Mujeres, por ser la más grande y la que más esfuerzos hacía por atraer trabajadoras a sus filas) desde un punto de vista socialista. ${ }^{17} \mathrm{El}$ libro consta de cuatro capítulos: "La lucha por la independencia económica de las mujeres"; "El matrimonio y el problema de la familia"; "La protección de las mujeres embarazadas y parturientas"; y "La lucha de las mujeres por los derechos políticos". En cada uno de ellos Kollontai enfatizaba el abismo de clase que separaba a las feministas del movimiento de mujeres trabajadoras, aun cuando sus demandas inmediatas, como el sufragio femenino, coincidieran, ya que apuntaban a objetivos finales diametralmente opuestos: apuntalar o destruir la sociedad capitalista.

En la introducción Kollontai señalaba que el libro había sido escrito con vistas al congreso de diciembre de 1908, ya que el mismo había "sacudido el hormiguero feminista": "El eslogan

17 El libro fue finalmente impreso después del congreso, en 1909, y está actualmente disponible online. Александра Комлонтай, Сочиальные основы женского вопроса. СПб.: ИзА. т-ва "Знание", 1909. - 437. [Alexandra Kollontai, Fundamentos sociales de la cuestión de la mujer, San Petersburgo: Editorial "Conocimiento", 1909. 437 pp.] http://books.eheritage.ru/book/10072576 
elegido para el próximo congreso es el grito de guerra feminista tradicional: la unión de todas las mujeres en una lucha por derechos e intereses puramente femeninos ... Una tras otra, feministas como Pokrovskaia, Kalmanovich, Shchepkina, Vajtina y otras pronunciaron discursos y conferencias cuyo contenido podría resumirse en el mismo llamado al congreso de mujeres: 'iMujeres de todas las clases de la población, uníos!' Por muy tentador que suene este eslogan 'pacífico', por mucho que parezca prometerle a la pobre hermana menor de la mujer burguesa -la mujer trabajadora-, es precisamente este eslogan tan querido por las feministas el que nos obliga a detenernos y examinar en mayor detalle el próximo congreso de mujeres, y a someter sus objetivos y aspiraciones fundamentales a una evaluación cuidadosa desde el punto de vista de los intereses de las mujeres de la clase trabajadora."

Kollontai resumía de la siguiente manera sus postulados teóricos generales (tomados de los marxistas alemanes): "Los partidarios del materialismo histórico reconocen plenamente las diferencias naturales existentes entre los sexos y exigen sólo una cosa: que, a cada individuo, hombre o mujer, se le dé la posibilidad real de lograr la autodeterminación más libre y plena, que tenga las mayores oportunidades posibles para el desarrollo y la aplicación de todos sus talentos naturales. $\mathrm{Al}$ mismo tiempo, los partidarios del materialismo histórico niegan la existencia de cuestiones específicamente femeninas aparte del problema social general de nuestros días. Ciertos factores económicos llevaron a la posición subordinada de la mujer, y sus características naturales jugaron un papel puramente secundario. Sólo la desaparición total de esos factores económicos, sólo la evolución de aquellas formas económicas que en el pasado causaron la esclavización de las mujeres, puede producir un cambio radical en su posición social. En otras palabras, las mujeres sólo pueden llegar a ser verdaderamente libres e iguales en un mundo transformado que se base en nuevos principios sociales y económicos.

"Esta afirmación, sin embargo, no excluye la posibilidad de una mejora parcial en la vida de las mujeres en el marco del sistema existente, aunque una solución verdaderamente radical de la cuestión del trabajo sólo es posible con la reestructuración completa de las relaciones de producción existentes. No obstante, tal visión de la situación no debe actuar como un freno al trabajo de reforma destinado a satisfacer los intereses inmediatos del proletariado. Por el contrario, cada nuevo avance de la clase trabajadora es un 
peldaño en la escalera que lleva a la humanidad al reino de la libertad y de la igualdad social; cada nuevo derecho obtenido por las mujeres las acerca a su objetivo: la emancipación total."

Citando a Clara Zetkin, Kollontai definía al feminismo como "el último eco de la lucha por la emancipación del Tercer Estado" -es decir, como una lucha por hacer extensivos a las mujeres los "derechos del hombre y del ciudadano" proclamados por la revolución burguesa en Francia en 1789. Kollontai ofrecía el siguiente resumen de la historia del feminismo en Rusia, cuyo origen databa de las transformaciones sociales operadas por la abolición de la servidumbre en 1861: "El feminismo en Rusia es indiscutiblemente un fenómeno nuevo. La primera publicación feminista, La causa de las mujeres (Женское deло) apareció en 1899. Durante muchos años el deseo de emancipación de parte de las mujeres rusas se limitó al llamado a la igualdad de oportunidades educativas. Desde la década de 1860, cuando la cuestión de las mujeres se planteó por primera vez en Rusia, hasta el presente, el movimiento de mujeres no ha sido otra cosa que la historia de la lucha por mejorar y ampliar el nivel de educación femenina, y principalmente la educación superior. En los éxitos obtenidos en esta esfera, las mujeres de las clases burguesas vieron, y no sin razón, uno de los principales métodos para extender la esfera del trabajo femenino profesional, la base de su independencia económica... Naturalmente, una vez completada su educación superior, las mujeres exigieron el libre acceso al empleo estatal y privado."

Dicho movimiento de la mujer tenía, según Kollontai, "una naturaleza claramente burguesa: involucraba sólo a un círculo bastante reducido de mujeres, principalmente de la nobleza, con algunos representantes de las nuevas 'clases medias' (разночинцы). Ningún ideal socialista encontró expresión en las demandas presentadas por las principales campeonas de la igualdad femenina en Rusia. Aunque cada año la industria rusa empleaba a miles de mujeres proletarias, parecía que un abismo insalvable separaba a las mujeres emancipadas y educadas de las obreras, y que no era posible ningún contacto entre ellas. Las mujeres de estos dos campos sociales opuestos se pusieron en contacto sólo a través de la actividad filantrópica."

Todo había cambiado después de la revolución desatada por el Domingo Sangriento el 9 de enero de 1905. "Las feministas, hasta hace poco tan modestas en sus demandas, se dieron cuenta de que la regeneración de Rusia y el establecimiento de un nuevo sistema 
estatal eran los requisitos previos esenciales de la emancipación femenina." Esto, por supuesto, no sucedió sin fricción: mientras que el ala izquierda en las organizaciones de mujeres insistía en la necesidad de definir claramente el credo político del movimiento de mujeres y daba prioridad a la lucha por la igualdad política de las mujeres, el ala derecha se mantuvo fiel a las viejas tradiciones, no deseando incorporar a la "política" en sus aspiraciones estrechamente feministas. En abril de 1905, los elementos más izquierdistas formaron la Unión Panrusa para la Igualdad de Derechos de las Mujeres, la primera organización de mujeres en Rusia en adoptar una plataforma política clara. Mientras tanto, los derechistas continuaron concentrándose en torno a la Sociedad de Ayuda Mutua de las Mujeres Rusas y al periódico El heraldo de la mијеr (Женский Вестник), defendiendo la idea de un feminismo políticamente neutral. La Unión de Mujeres estableció una amplia red de sucursales en toda Rusia, y tan solo un año después, en mayo de 1906, su oficina estimó su membresía en alrededor de 8.000. Según Kollontai, "la Unión de Mujeres esperaba congregar a mujeres de todas las clases sociales sobre la base de sus vagas consignas, y así como los kadetes, en sus primeros días, hablaron en nombre de todo el pueblo, la Unión de Mujeres declaró que estaba expresando las necesidades de todas las mujeres rusas." Pero esta unidad ilusoria no duró, y ya en la primavera de 1906, la regional de la Unión de Mujeres en San Petersburgo se dividió en dos partes: las feministas de "izquierda" que se alinearon, como resultado de sus convicciones políticas, con los partidos revolucionarios, y las de "derecha", lideradas por Maria Pokrovskaia, fundaron el Partido Progresista de las Mujeres, el cual expresaba "las demandas y los requisitos de la gran burguesía." La Unión de Mujeres, en tanto, representaba a la oposición liberal de tipo kadete y estaba compuesta sobre todo por mujeres de la pequeña burguesía, principalmente miembros de la intelectualidad.

¿Por qué la Unión de Mujeres, que se había atrevido a plantear la necesidad de celebrar elecciones a una Asamblea Constituyente, no apoyaba a los tradicionales defensores del sufragio femenino, a los socialdemócratas? Porque "a pesar de todo su radicalismo político, nuestras sufragistas continúan basándose en las aspiraciones de su propia clase burguesa... Nuestras feministas, como sus hermanas en el exterior, no van más allá de la demanda de igualdad política. Los amplios horizontes abiertos por las doctrinas de la socialdemocracia son, para ellas, ajenos e incomprensibles. Las feministas luchan por la igualdad dentro del marco de la sociedad de clases existente, sin socavar de ninguna manera sus cimientos; están 
luchando por sus prerrogativas femeninas sin esforzarse por lograr la abolición de todas las prerrogativas y de todos los privilegios existentes..."

Como Zetkin, Kollontai no tenía objeción alguna a que las feministas operaran "dentro del marco de la estructura existente de clases sociales", siempre que organizaran a mujeres de su propia clase social, pero rechazaba de plano los intentos de las feministas de organizar en un marco policlasista a las mujeres trabajadoras, que debían organizarse dentro del partido socialista. Según Kollontai: "El mundo de las mujeres, como el mundo de los hombres, se ha dividido en dos bandos: uno, por sus objetivos, aspiraciones e intereses, está del lado de las clases burguesas, mientras que el otro está estrechamente vinculado al proletariado, cuya aspiración a la libertad también involucra la solución de la cuestión de la mujer en todos sus aspectos. Estos dos grupos de mujeres combatientes difieren en sus objetivos, intereses y métodos de lucha, a pesar de que ambos actúan sobre la base del lema común de 'la emancipación de la mujer'. Cada uno de estos grupos militantes procede inconscientemente sobre la base de los intereses de su propia clase, lo que da un carácter de clase específico a sus aspiraciones y objetivos. Una mujer individual puede ser capaz de elevarse por encima de los intereses de su propia clase y de ignorarlos en nombre del triunfo de los objetivos de otra clase, pero esto es imposible para una organización de mujeres unida que refleje todas las necesidades y los intereses reales del grupo social que la fundó. Por muy radicales que puedan parecer las demandas de las feministas, no debe olvidarse que, en virtud de su posición de clase, las feministas no pueden luchar por lograr una reestructuración fundamental de la actual estructura económica de la sociedad, y que sin esto la emancipación de las mujeres no puede ser completa.

"Mientras que en casos individuales los objetivos inmediatos de las mujeres de todas las clases coinciden, los objetivos últimos que determinan la dirección del movimiento y la táctica misma a utilizar difieren totalmente. Para las feministas, el logro de la igualdad de derechos con los hombres en el marco del mundo capitalista contemporáneo es un 'fin en sí mismo' concreto; para las mujeres proletarias, la igualdad de derechos es simplemente un medio para ser utilizado en la lucha continua contra la esclavización económica de la clase trabajadora. Para las feministas, el enemigo inmediato son los hombres como tales, que se han arrogado todos los derechos y privilegios y han dejado a las mujeres solo esclavitud y obligaciones. Cada victoria de las feministas significa que los 
hombres deben ceder parte de sus prerrogativas a favor del 'bello sexo'. La mujer proletaria, sin embargo, tiene una actitud completamente diferente ante su posición [de opresión]: a sus ojos, el trabajador no es su enemigo y opresor, sino, por el contrario, ante todo un camarada que comparte con ella un triste destino común, y un compañero leal en la lucha por un futuro mejor. Las mismas relaciones sociales esclavizan tanto a la trabajadora como a su camarada masculino; las mismas condiciones brutales del capitalismo los oprimen y los privan de la felicidad y de los placeres de la vida. Es cierto que ciertas características específicas del sistema actual pesan doblemente sobre la mujer; también es cierto que las condiciones del trabajo asalariado a veces transforman a la mujer trabajadora en un amenazante rival del hombre. Sin embargo, la clase trabajadora sabe quién tiene la culpa de estas desafortunadas condiciones." Kollontai concluía que "la trabajadora está atada a su camarada de sexo masculino por mil hilos invisibles, mientras que los objetivos de la mujer burguesa le parecen extraños e incomprensibles", porque la obrera era consciente de que la igualdad política en el contexto de la retención del régimen de explotación capitalista no podía liberar a la mujer trabajadora.

En cuanto a la necesidad de una nueva forma de familia que asegurara la igualdad entre los sexos, una demanda sobre la que parecía existir una coincidencia entre las feministas y las mujeres trabajadoras, Kollontai señalaba que "la cuestión de la maternidad plantea muchas preguntas para la mujer que lucha por la libertad. ¿Es posible el 'amor libre'? ¿Puede realizarse como un fenómeno común, como la norma generalmente aceptada en lugar de la excepción individual, dada la estructura económica de nuestra sociedad? ¿Es posible ignorar el elemento de propiedad privada en el matrimonio contemporáneo? ¿Es posible, en un mundo individualista, ignorar el contrato formal de matrimonio sin dañar los intereses de las mujeres? Porque el contrato matrimonial es la única garantía de que no caerán sobre la mujer solamente todas las dificultades de la maternidad. ¿No le sucederá ahora a la mujer lo que una vez le sucedió al artesano? La eliminación de las normas de las guildas, sin el establecimiento de nuevas reglas que rigieran la conducta de los maestros, le dio al capital el poder absoluto sobre los trabajadores. El eslogan tentador 'libertad de contrato para el trabajo y el capital' se convirtió en un medio para la explotación desmedida del trabajo por parte del capital. $\mathrm{El}$ 'amor libre', introducido consistentemente en la sociedad de clases contemporánea, en lugar de liberar a la mujer de las dificultades de la vida familiar, seguramente les agregaría una nueva carga: la tarea de 
cuidar, sola y sin ayuda, de sus hijos... La cuestión de las relaciones matrimoniales dejaría de ser tan dolorosa para la mayoría de las mujeres si la sociedad se hiciera cargo de todos los pequeños cuidados domésticos que son inevitables hoy en día, dada la existencia de economías domésticas dispersas, si asumiera la responsabilidad por la generación más joven, protegiera a la maternidad y diera a la madre la oportunidad de cuidar de su niño por lo menos durante los primeros meses después del nacimiento."

La conclusión de Kollontai -una vez más, parafraseando a Zetkin en el congreso de Gotha de 1896- era que "la emancipación de la mujer proletaria no puede ser el resultado del esfuerzo de las mujeres de todas las clases. Esta tarea solo puede lograrse mediante el esfuerzo común de todo el proletariado sin distinción de sexo."18

\section{E1 Primer Congreso de Mujeres de Toda Rusia (diciembre de 1908)}

De las 1.053 mujeres y hombres que se inscribieron en el Primer Congreso Panruso de Mujeres, celebrado en de San Petersburgo en diciembre de 1908, la gran mayoría provenía de la capital y eran estudiantes y profesionales, especialmente médicas y profesoras. No asistieron mujeres campesinas. El "grupo obrero" inclúa a no más de 35 activistas sindicales y afiliadas al Partido Socialdemócrata elegidas en asambleas de mujeres; el grupo hizo diez presentaciones en el Congreso, de un total de 160 discursos. El proceso de selección de las delegadas del grupo obrero enfatizó la participación y el control sindical. Cada grupo de veinte trabajadoras afiliadas a un sindicato eligió una delegada; ésta delegada podía ser aprobada o rechazada por su sindicato. Veinte delegadas fueron elegidas de esta manera; diez más fueron seleccionadas por clubes de trabajadoras, y algunas vinieron de Vilna y Moscú. Kollontai jugó un papel importante en la preparación de sus charlas. Se eligieron diez temas, todos sobre economía y política, que iban desde las mujeres y el activismo político hasta las condiciones de trabajo en industrias específicas y la necesidad de una legislación protectora del trabajo.

\footnotetext{
18 "Por lo tanto, la lucha de liberación de la mujer proletaria no puede ser una lucha como la de la mujer burguesa contra el hombre de su clase; por el contrario, es la lucha con el hombre de su clase contra la clase capitalista... La mujer proletaria lucha contra la sociedad capitalista de la mano con el hombre de su clase (Hand in Hand mit dem Manne ihrer Klasse kämpft die proletarische Fran gegen die kapitalistische Gesellschaft)." (Zetkin 1896, p. 163).
} 
Casi todas las charlas fueron preparadas colectivamente (Ruthchild 2010, p. 110).

El Primer Congreso Panruso de Mujeres fue significativo sobre todo como una arena de debate que mostró claramente las diferencias entre las organizaciones feministas y el movimiento de mujeres socialistas en Rusia. ${ }^{19}$ La noche anterior al inicio del congreso, las mujeres del grupo obrero recibieron una visita de las feministas, quienes, alarmadas ante la idea de que sus elaborados preparativos fueran saboteados por la intervención de este grupo de trabajadoras, les advirtieron que no se dejasen engañar por los socialdemócratas y por la "influencia alemana" de Alexandra Kollontai (Porter 1980, p. 145).

Según Linda Edmondson, las trabajadoras del grupo obrero "fueron notorias desde el principio por su apariencia física: mal alimentadas y vestidas con ropas baratas, presentaban un marcado contraste con las mujeres bien vestidas de las clases altas. Acentuaron su carácter distintivo al mantenerse juntas en un rincón de la sala (en el lado izquierdo), lejos de las organizadoras del congreso. Casi todas ellas trabajaban en fábricas y talleres. Las trabajadoras domésticas, cuyos trabajos liberaban a sus señoras de las tareas diarias para que tuvieran una vida más interesante fuera del hogar, fueron notables por su ausencia. Las socialistas aprovecharon al máximo este hecho. La dependencia de las mujeres de clase media y alta de la continua inferioridad de sus sirvientes resultó ser un arma valiosa para exponer los lemas 'burgueses' de la igualdad de derechos como una farsa hipócrita" (Edmondson 1976, pp. 131-132).

En la noche del 10 de diciembre de 1908, en el Salón Aleksandrovskii de la Duma de la Ciudad, Shabanova abrió el congreso reafirmando que su propósito era llamar a la unidad entre las mujeres. Barbara Ivanova Volkova respondió en nombre del grupo obrero, afirmando que las mujeres trabajadoras estaban allí para representar a su propia clase y que nunca serían separadas del proletariado organizado. El grupo obrero había venido a destruir la ilusión de que las mujeres trabajadoras eran las "hermanas menores" de las feministas y que necesitaban su protección. Estaban decididas a demostrar la imposibilidad de la cooperación a través de las barreras de clase. Sus armas fueron una exposición de la vida de las

19 Las minutas del congreso fueron publicadas como Tpуды Первого Всероссийского женского съезда при Русском женском обществе в Санкт-Петербурге, 10-16 декабря 1908 г. СПб., 1909. [Actas del Primer Congreso de Mujeres de toda Rusia en la Sociedad de Mujeres Rusas en San Petersburgo, del 10 al 16 de diciembre de 1908. San Petersburgo, 1909]. 
mujeres de fábrica, y un análisis de los fundamentos teóricos de la explotación que soportaban a manos de las mismas mujeres que afirmaban desear su liberación (Edmondson 1976, pp. 135-136, 139).

Zinaida Mirovich, de la Unión de Mujeres, "derramó aceite sobre las llamas" al afirmar que, en el último congreso de la Internacional Socialista en Stuttgart, varios hombres se habían retirado cuando se sometió a votación la cuestión del sufragio femenino. Sus palabras produjeron un gran revuelo. Kollontai intentó refutar los "ataques difamatorios" de Mirovich, pero fue acallada y la sesión se detuvo temporalmente. (Edmondson 1976, p. 140).

La intervención de Anna Kalmanovich, una de las líderes de Unión de Mujeres, titulada "El movimiento de mujeres y la relación de los partidos hacia él", también fue un ataque en regla a los partidos políticos, tanto liberales como conservadores, pero, sobre todo, socialdemócratas, por no defender realmente los derechos de la mujer, en particular el derecho al sufragio. La autora declaraba: "ansío convencer a las mujeres de que no deben esperar la libertad de los hombres, no importa cómo ellos se llamen: liberales, conservadores o socialdemócratas. En cuanto el hombre tenga la oportunidad de oprimir y humillar a la mujer, lo hará". Kalmanovich creía que "el movimiento feminista no es partidario" porque "los hombres de todos los grupos y de todas las clases sociales están vitalmente interesados en la esclavitud de la mujer". Kalmanovich centró sus ataques contra los marxistas, acusándolos de hipocresía y poniendo como ejemplo los casos de Bélgica y Austria (criticados en su momento por las socialdemócratas alemanas), donde los partidos socialistas habían accedido a que el sufragio se ampliara a los obreros, pero no a las mujeres. Poniendo el acento en estas flaquezas, la autora afirmó que "en todo lugar son las mujeres las que están organizando a sus hermanas proletarias, y no los hombres". Siguiendo este razonamiento, desestimó la significación de la celebración del Primer Congreso de la Internacional de Mujeres Socialistas en Stuttgart en 1907 y atribuyó la adopción de una resolución en favor del sufragio universal (no calificado) femenino por dicho Congreso a "la influencia del así llamado movimiento feminista burgués". Como hemos visto, en realidad, la demanda por el sufragio universal ya estaba contenida en los programas de Gotha (1875) y de Erfurt (1891) de los socialistas alemanes. Igualmente engañosa era la referencia a la réplica de Kautsky al cuestionario sobre la defensa de la igualdad de las mujeres enviado por la Revue socialiste a una serie de líderes socialdemócratas europeos, ya que 
Kautsky apoyó sin cortapisas la defensa del sufragio femenino. ${ }^{20} \mathrm{La}$ conclusión de Kalmanovich era que "las mujeres no deben depositar esperanzas en ningún partido. Deben organizarse entre ellas, como hacen las inglesas, y reclutar amigos entre todos los partidos, dondequiera que ellos se encuentren." Su intervención fue criticada no sólo por las delegadas obreras sino también por la feminista y dirigente kadete Ariadna Tyrkova, quien acusó a Kalmanovich de intentar dividir el mundo en dos campos opuestos de hombres y mujeres. ${ }^{21}$

Si las feministas hicieron de Austria el talón de Aquiles de las socialistas, las socialistas hicieron lo mismo con las feministas señalando el ejemplo de las sufragistas en Inglaterra. En ese momento Inglaterra era un campo de batalla clave en la lucha por los derechos de las mujeres. Las sufragistas militantes de la Women's Social and Political Union, dirigidas principalmente por Emmeline Pankhurst y su hija Christabel, revitalizaron el movimiento inglés e hicieron que las feministas de todo el mundo reexaminaran sus tácticas. Pero incluso estas defensoras militantes del sufragio femenino habían decidido exigir primero el sufragio calificado. Las socialistas atacaron esta posición como una indicación de la naturaleza de clase del movimiento de mujeres burgués. Una vez que las mujeres propietarias obtuvieron el voto, argumentaron, los intentos de extender la franquicia serían abandonados. Kollontai afirmó que "el sufragio limitado, apoyado por las feministas burguesas, es utilizado por la burguesía como un antídoto contra las demandas democráticas de la clase trabajadora" (Ruthchild 2010, p. 131).

La ponencia de Maria Pokrovskaia, la fundadora del Partido Progresista de las Mujeres, se titulaba "Cómo las mujeres deben luchar contra la prostitución", cuya eliminación definía como "el tema más urgente para las mujeres que aspiran a la igualdad de

20 Karl Kautsky, "Le droit de suffrage pour les femmes : doit-on leur accorder immédiatement et sans transition ? ", La revue socialiste, tome XLIV, $\mathrm{N}^{\circ} 260$, Août 1906, pp. 145-166. Disponible online en Gallica.

21 Кальманович А., Женское Авижение и отношение партий к нему // Светлана Г. Айвазова, Русские женщины в мабиринте равноправия: очерки политической теории и истории: Аокументальные материалы, М.: РИК Русанова, 1998. [Anna Kalmanovich, "El movimiento de las mujeres y la actitud de los partidos hacia él”, reproducido en Svetlana G. Aivazova, Las mujeres rusas en el laberinto de la igualdad: Ensayos sobre teoría política e historia: Materiales documentales, Moscú: RIK Rusanova, 1998.] Disponible online: http://www.owl.ru/win/books/rw/t2_3.htm Versión portuguesa en Schneider 2017, pp. 21-38. 
derechos". Pokrovskaia mencionó los datos del censo llevado a cabo en 1889 de las prostitutas "registradas" y sujetas a la inspección médico-policial, según el cual había en Rusia 17.603 prostitutas, de las cuales la mayoría eran de origen campesino, el $87,4 \%$ eran huérfanas de padre o madre y el $43 \%$ habían sido empleadas domésticas. Su tesis central era que la sociedad contemporánea conducía a "un desarrollo excesivo del instinto sexual masculino", y que las mujeres que deseaban la aniquilación de la prostitución debían exigir "una moral sexual idéntica". Esto debía ser acompañado de una lucha contra la pornografía a fin de "dominar la bestia que habita en la persona". Para esto era necesaria "una reforma escolar radical", a fin de "conservar en el corazón del joven esas inclinaciones nobles que la madre le inculca y, por otro lado, enseñarle a refrenar sus instintos sexuales. Pero para que tal reforma tenga lugar, las mujeres precisan tener derechos legislativos". La autora sostenía que la prostitución regulada por el estado ejercía una "influencia corruptora" y contribuía "al aumento del número de prostitutas". Pokrovskaia concluía reafirmando que "la falta de derechos constituye para las mujeres un obstáculo enorme en la lucha contra la prostitución. Por eso, conquistar para sí los derechos legislativos es la tarea más importante para aquellas que realmente desean la aniquilación de ese mal. Las mujeres deben dirigir sus esfuerzos a conseguir el derecho a votar en la representación popular". ${ }^{22}$

Los límites del abolicionismo liberal en relación a la prostitución se volvieron evidentes desde el momento en que Pokrovskaia no mencionaba la división de la sociedad en clases como causa de la prostitución y pensaba que podía ser erradicada mediante medidas legislativas en el marco de la sociedad capitalista. Nada de esto satisfizo a las mujeres del grupo obrero, para las cuales la crisis en la familia y el crecimiento de la prostitución eran síntomas de la proletarización de las mujeres y de las desigualdades sociales

22 Покровская М. Как женщины Аолжны бороться с проституцией // Светлана Г. Айвазова, Русские женщины в мабиринте равноправия: очерки политической теории и истории: Аокументальные материалы, М.: РИК Русанова, 1998. [Maria Pokrovskaia, "Cómo deberían las mujeres luchar contra la prostitución”, reproducido en Svetlana G. Aivazova, Las mujeres rusas en el laberinto de la igualdad: Ensayos sobre teoría política e historia: Materiales documentales, Moscú: RIK Rusanova, 1998.] Disponible online: http://www.owl.ru/win/books/rw/t5_1.htm

Versión portuguesa en Schneider 2017, pp. 52-60. 
inherentes al capitalismo -una postura compartida por Lenin. ${ }^{23} \mathrm{La}$ prostitución estaba creciendo como resultado de la desocupación y de los salarios miserables de las trabajadoras. El grupo obrero se opuso a los "paliativos" propuestos por las mujeres burguesas. En la sociedad del futuro, las mujeres serían valoradas como trabajadoras productivas iguales a los hombres, mientras que la responsabilidad por el cuidado de los niños recaería sobre la comunidad (Edmondson 1976, p. 143).

La bolchevique Anna Gurevich ofreció una presentación sobre "La protección de la infancia", en la que se refirió a las condiciones de trabajo de las mujeres y de los niños en las fábricas. Gurevich propuso una resolución que abogaba por la prohibición del trabajo infantil, la educación obligatoria entre los seis y dieciséis años, la prohibición de trabajos peligrosos para los adolescentes, períodos obligatorios de descanso diario y el control permanente del saneamiento y la inspección de fábricas en todas las industrias que empleaban mano de obra infantil (Rutchchild 2010, p. 125).

Una posición a medio camino entre el socialismo y el feminismo fue la de Ekaterina Kuskova, la autora del famoso "Credo" economicista denunciado publicado por primera vez por Lenin y denunciado por él en su famoso libro de 1902 ¿Qué hacer?24 En su informe sobre el congreso, publicado en la revista Unión de las Mujeres y titulado "La mujer y la igualdad", Kuskova hizo un recuento del progreso experimentado por las mujeres bajo el capitalismo ("nos alegramos por las diputadas en el parlamento finlandés, simpatizamos con las insistentes y apasionadas sufragistas inglesas, leemos con alegría el telegrama sobre la señorita Jousselin, de Francia, que fue seleccionada para el cargo de jueza en París, siendo la primera en ocupar este puesto") y concluyó reivindicando "el manifiesto para las mujeres escrito por Olympe de Gouges" y el sufragio femenino. ${ }^{25} \mathrm{La}$

23 "Mientras exista la esclavitud asalariada, la prostitución es inevitable" (Lenin, "El capitalismo y el trabajo de la mujer", Pravda, No. 102, 5 de mayo de 1913, en Obras completas, Madrid: Akal, 1971, tomo 19, p. 277).

24 Lenin publicó el "Credo" revisionista-economicista de Kuskova en diciembre de 1899, acompañado de una "Protesta de los socialdemócratas de Rusia", en una separata de la revista Rabocheye Dyelo, No. 4-5, en Lenin, Obras completas, Madrid: Akal Editor, 1976, Tomo IV: 1899-abril de 1901, pp. 169184. Alexandra Kollontai indicó posteriormente que "E. D. Kuskova, con dos o tres seguidoras más, intentó hacer las paces entre las feministas de tipo cadete y el grupo de mujeres trabajadoras" (Kollontai 1920, p. 57).

25 Кускова Е., Женщины и равноправие, Союз женщин, 1908 г., № 12. // Светлана Г. Айвазова, Русские женщины в кабиринте равноправия: 
presencia de Kuskova en el grupo obrero fue muy desagradable para las socialdemócratas, quienes la acusaron de tratar de "seducir" a las mujeres trabajadoras para que se alejaran de la política revolucionaria, ya que en el congreso Kuskova tendió a adoptar una posición intermedia entre las revolucionarias y las burguesas (Edmondson 1976, p. 138, nota 66).

A pesar de que la primera oradora instó a todas las "disidentes" a irse, a medida que se discutía cada tema de la agenda el sufragio femenino, el trabajo femenino, las mujeres en los partidos políticos-, una representante del grupo obrero daba un paso al frente y con creciente audacia leía su propia declaración. Kollontai, que tenía orden de captura desde septiembre de 1908 por agitación en el sindicato de trabajadoras textiles y por propugnar un "levantamiento armado", no quiso arriesgarse a ser arrestada por hablar y asistió a las sesiones desde el fondo de un pasillo cuando se abrió el congreso. Pero el debate sobre el seguro por enfermedad causó un gran alboroto, e hizo que las feministas silbaran y patearan en la plataforma, y que las mujeres del grupo obrero gritaran: "¿Qué saben ustedes de nuestras vidas, dando vueltas en carruajes mientras a nosotras nos salpica el barro?" Cuando una feminista replicó que, precisamente porque las mujeres burguesas no tenían que soportar vidas tan miserables, estaban mejor calificadas para luchar por la igualdad de derechos, Kollontai no pudo resistirse a tomar la palabra para responderle. Su apariencia causó una gran sensación, por lo que sólo pudo asistir a la mitad del Congreso antes de huir al extranjero para evitar su arresto (cruzó la frontera a fines de diciembre de 1908 y pasó los ocho años siguientes en el exilio), y su informe fue presentado in absentia por la trabajadora Barbara Ivanova Volkova.

En su intervención, titulada "La mujer trabajadora en la sociedad contemporánea", Kollontai lanzó un ataque frontal contra el eslogan de "libertad de trabajo" reivindicado por las feministas y planteó un programa de defensa de la protección laboral de la mujer, en consonancia con la posición de las socialdemócratas alemanas y de la Internacional Socialista de Mujeres creada el año anterior. Afirmó que "el trabajo femenino se ha convertido en un factor importante y

очерки политической теории и истории: Аокументальные материалы, М.: РИК Русанова, 1998. [Ekaterina Kuskova, "La mujer y la igualdad", Unión de mujeres, 1908, № 12, reproducido en Svetlana G. Aivazova, Las mujeres rusas en el laberinto de la igualdad: Ensayos sobre teoría política e historia: Materiales documentales, Moscú: RIK Rusanova, 1998.] Disponible online: http://www.owl.ru/win/books/rw/s1_14.htm

Versión portuguesa en Schneider 2017, pp. 134-137. 
necesario en la vida económica", pero esto se debía a que "el capital necesita de trabajadores baratos y por ello atrae a más y más fuerza de trabajo femenina nueva". En el sistema capitalista moderno de producción, "el trabajo no fue un liberador para las mujeres trabajadoras, las cuales tomaron sobre sus hombros débiles una nueva carga, que se ha añadido a sus responsabilidades como esposas y madres: la carga de trabajo asalariado. Bajo el peso de esta nueva carga insoportable, cientos de miles de mujeres se inclinan y perecen. No existe un trabajo repugnante, una labor dañina en la que las trabajadoras no se encuentren en abundancia". Kollontai se preguntaba sarcásticamente: " ¿Y ésta es la libertad de trabajo para la mujer sobre la que las feministas tanto alborotan? Estas mujeres imaginan que encontraron la clave para la felicidad de las mujeres. ¿Qué les ofrecen a las proletarias? ¿Qué hicieron para proteger a la mujer de la clase trabajadora de la sobrecarga de trabajo?”

En cuanto a la prostitución, citando el libro del líder socialista alemán August Bebel, La mujer y el socialismo, Kollontai afirmó que "el matrimonio es la cara visible de la medalla de la cuestión sexual, la otra es la prostitución", a la cual describió como "un complemento inevitable de la familia burguesa moderna, que es un producto necesario del sistema de explotación". Las medidas propuestas por las feministas para luchar contra la prostitución se limitaban "en el mejor de los casos, a la lucha contra la regulación", y eran completamente incapaces de erradicarla. "En esta cuestión, como en todos los aspectos tenebrosos de su vida, la mujer sólo puede esperar su liberación del poder creciente de la clase trabajadora... Luchar contra la prostitución significa no solamente destruir su regulación, no, significa luchar contra los cimientos del sistema capitalista, significa luchar para destruir la división en clases de la sociedad".

Algo similar sucedía con la demanda del sufragio femenino, "esta culminación de las pasiones feministas". Los derechos políticos de las mujeres representaban un paso adelante, y el movimiento de mujeres trabajadoras se ponía el frente de la lucha por conseguirlos, pero por sí mismos eran incapaces de "liberar a la proletaria de los abismos de sufrimiento y de los males que la agobian, no sólo como mujer, sino como vendedora de su fuerza de trabajo".

Kollontai refutó las acusaciones de las feministas contra los socialistas, según las cuales se éstos se limitaban a adoptar una actitud pasiva ante la opresión de la mujer en espera de la revolución social, y propuso el siguiente programa de reformas para la protección y movilización de las mujeres trabajadoras: 
Obviamente, eso no significa que los partidarios del socialismo científico "aplazan" la solución del tema de la igualdad de derechos de las mujeres hasta el advenimiento del socialismo, como los acusan de hacerlo las feministas; no significa que ellos no quieren luchar por la emancipación de la mujer, en la medida en que eso es posible, en el marco del mundo burgués contemporáneo. Por el contrario, no hay un solo partido en el mundo que haya dedicado más atención a los intereses de las mujeres y que haya hecho tanto para su liberación en todos los aspectos como el partido de los trabajadores, basado en el punto de vista del socialismo científico Profundamente convencido de que la emancipación total de las mujeres sólo será posible en una sociedad fundamentalmente reformada, este partido, sin embargo, para satisfacer las necesidades inmediatas de las mujeres, demanda:

1. La derogación de todas las leyes que subordinan a la mujer al hombre;

2. El derecho a elegir y ser elegida en todas las instituciones legislativas y órganos de autogobierno local, sobre la base del sufragio universal, igualitario, secreto y directo;

3. Protección legislativa del trabajo:

a) Extensión de la legislación protectora del trabajo a todas las ramas de la industria, así como al trabajo agrícola, al trabajo a domicilio y al servicio doméstico;

b) Establecimiento de una jornada laboral máxima de 8 horas en la industria y el comercio y de 10 horas para el trabajo agrícola en el verano;

c) Descanso semanal completo (de al menos 42 horas);

d) Descanso de medio día los sábados;

e) Abolición del trabajo nocturno y de las horas

extras;

f) Prohibición del trabajo femenino en actividades particularmente dañinas para el cuerpo femenino: en industrias donde se usa mercurio, fósforo, plomo y otras sustancias venenosas;

g) Mejora de las condiciones higiénicas y sanitarias y de las técnicas de trabajo en los talleres;

h) Prohibición de métodos de trabajo que sean perjudiciales o peligrosos para la madre y la descendencia (levantar objetos pesados, operar máquinas a pedal, etc.);

i) Expansión de la inspección de fábricas a todas las ramas del trabajo, incluyendo al trabajo a domicilio y al 
trabajo doméstico. Nombramiento de mujeres como inspectoras de fábrica. Participación en la inspección de representantes electos de trabajadoras y trabajadores;

4. Protección de la maternidad:

a) Establecimiento del descanso obligatorio [licencia por maternidad] para las mujeres embarazadas, 8 semanas antes y 8 semanas después del parto, percibiendo el salario normal de las cajas de seguro estatal;

b) Atención médica y obstétrica gratuita durante el período de gestación y durante el parto;

c) Licencia [para amamantar] para las trabajadoras con niños de pecho por un período de media hora, cada dos horas;

d) Asignación de un espacio en las grandes empresas para la alimentación de los niños lactantes y para guarderías; las empresas pequeñas deben proporcionar conjuntamente dichos locales en cada distrito;

e) Administración de las guarderías por las madres;

f) Organización de cursos para enseñar a las madres a cuidar de los niños;

g) Creación de locales para mujeres embarazadas y para mujeres que dieron a luz, donde se distribuya gratuitamente leche saludable para las madres que no puedan amamantar a sus hijos.

5. En el ámbito de las relaciones familiares y de la lucha contra la prostitución, exigimos:

a) Abolición de la regulación de la prostitución y lucha contra ésta mediante la mejora de la condición económica de la clase trabajadora y de la amplia participación de las mujeres en el movimiento de clase del proletariado;

b) Otorgamiento de un permiso de residencia separado para la esposa, hasta que se revoque el sistema de pasaporte [regia entonces en Rusia un sistema de pasaporte único para las parejas casadas, expedido por el estado al esposo];

c) Asignación a las administraciones locales rurales y urbanas de la responsabilidad por la construcción de hogares baratos y saludables para las familias de los trabajadores y para los trabajadores y trabajadoras solteros [planes de viviendas];

d) Desarrollo de un movimiento cooperativo que facilite el trabajo de las obreras.

Un requisito previo para la implementación de todas las demandas presentadas es la total libertad de 
asociación, de asamblea, de prensa, de expresión y de huelga.

Kollontai concluyó afirmando que "el mundo femenino, así como el masculino, está dividido en dos bandos: uno de ellos, por sus objetivos, aspiraciones e intereses, está ligado a las clases burguesas; el otro está estrechamente relacionado con el proletariado, cuyas aspiraciones de liberación abarcan también la solución de la cuestión de la mujer en su totalidad. Y los objetivos, intereses y medios de lucha son diferentes para ambas categorías de mujeres que luchan por su emancipación". ${ }^{26}$

El informe de Kollontai fue recibido con aplausos por el grupo obrero y con gritos de “¡No queremos escuchar! ¡Váyanse!” por la mayoría feminista. El grupo obrero propuso entonces una resolución en la que se afirmaba que un único movimiento de mujeres que abarcara a todas las clases sociales no tenía sentido. Sorprendentemente, la mayoría del comité político estuvo de acuerdo y apoyó la moción, pero el comité organizador, insistiendo en su prerrogativa de redactar la resolución política del congreso, envió a la kadete Ariadna Tyrkova de vuelta al comité político con una resolución alternativa, que terminó imponiéndose. De manera similar, durante el debate sobre la posición económica de las mujeres, el congreso aprobó una resolución propuesta por el grupo obrero que establecía que el requisito previo para mejorar las condiciones de las trabajadoras era el reconocimiento de los derechos de asociación y de expresión y de la libertad de prensa, lo cual sólo era posible "con la democratización total del sistema estatal". Esto, sin embargo, fue eliminado por la comisión de edición y no apareció en las resoluciones del Congreso.

Pero no fue hasta la última sesión, el 16 de diciembre de 1908, que el grupo obrero se retiró del congreso. El conflicto sobre el sufragio precipitó el choque final entre las feministas y el grupo obrero en el Congreso de Mujeres. En la tercera sesión de la sección

26 Комлонтай А. Женщина-работница в современном обществе // Светлана Г. Айвазова, Русские женщины в мабиринте равноправия: очерки политической теории и истории: документальные материалы, М.: РИК Русанова, 1998. [Alexandra Kollontai, "La mujer trabajadora en la sociedad contemporánea", reproducido en Svetlana G. Aivazova, Las mujeres rusas en el laberinto de la igualdad: Ensayos sobre teoría politica e historia: Materiales documentales, Moscú: RIK Rusanova, 1998.] Disponible online: http://www.owl.ru/win/books/rw/t4_2.htm

Versión portuguesa en Schneider 2017, pp. 150-159. 
política, el 13 de diciembre, se presentaron dos resoluciones que representaban los puntos de vista socialista y feminista sobre el sufragio. La comisión de edición, dominada por feministas con vínculos con los kadetes, propuso una resolución que abogaba por la igualdad de derechos y el sufragio limitado. Zinaida Mirovich introdujo la propuesta feminista, que exigía "la reforma de las leyes injustas relativas a las mujeres, equiparando a ambos sexos en lo referente a la tierra, la herencia y los derechos familiares" y "otorgando inmediatamente a las mujeres rusas la misma participación que los hombres poseen en los gobiernos locales, estatales y municipales, y también el mismo derecho al sufragio activo y pasivo que los hombres para la elección de la Duma del Estado" (es decir, manteniendo el sufragio calificado por "curias" vigente desde las elecciones a la tercera Duma). El grupo obrero, por el contrario, presentó una resolución que apoyaba el sufragio universal, argumentando que "el sufragio universal femenino es una de las principales armas en la lucha de las mujeres por la liberación completa". (Ruthchild 2010, p. 132)

Ambas propuestas de resolución fueron presentadas ante la comisión de edición, que decidió proponer su propia resolución "política general", la cual supuestamente "expresaba los sentimientos de la mayoría del Congreso". Naturalmente, la delegación obrera se negó a votar la nueva propuesta de resolución debido a la ausencia de una referencia al sufragio universal no calificado, pero el Congreso finalmente la aprobó. Ante esto, el grupo obrero decidió retirarse del congreso, no sin antes leer una declaración en la que afirmaba la imposibilidad de la cooperación entre clases hostiles. (Edmondson 1976, pp. 140, 147-148). Pero el triunfo de las organizadoras contra las socialistas fue una victoria pírrica, porque el congreso fue incapaz de lograr la unidad de las mujeres o, aunque más no fuera de las feministas rusas.

\section{Balances mencheviques y bolcheviques del Primer Congreso de Mujeres}

Dado que la intervención del grupo obrero en el Primer Congreso de Mujeres de Toda Rusia fue una iniciativa de frente único, en la que participaron tanto bolcheviques como mencheviques y delegadas sindicales, sus resultados dieron lugar a evaluaciones contradictorias. La apreciación de Kollontai, publicada bajo el seudónimo "Mijailova", apareció en un artículo titulado "La mujer 
trabajadora en el primer congreso feminista de Rusia", publicado en el periódico menchevique Golos sotsial-demokrata de marzo de 1909. Para Kollontai, el Congreso fue significativo porque, "en un contexto de reacción triunfante", había mostrado que, aunque "en la superficie todo está tranquilo, en las profundidades de la sociedad un trabajo incansable y fructífero, consciente y determinado, está teniendo lugar". Kollontai cuestionó el momento de la retirada del grupo obrero, argumentando que una protesta contra el intento de las feministas de crear una organización unificada de mujeres rusas independientemente de la clase y del partido hubiera sido más efectiva. Sin embargo, para Kollontai las trabajadoras habían logrado sus objetivos: habían utilizado al Congreso como un foro de agitación y habían puesto de manifiesto "ese antagonismo de clase... que divide el mundo de las mujeres, como lo hace con el de los hombres, en dos campos hostiles", estableciendo una clara distinción entre el movimiento de mujeres burguesas y el movimiento de mujeres proletarias.

Un segundo artículo, publicado con el pseudónimo de "W" en el mismo periódico menchevique, fue mucho más crítico con la intervención del grupo obrero. El autor o la autora criticaba el fuerte énfasis del grupo obrero en las cuestiones económicas y su insistencia en la estricta "demarcación de límites de clase", lo cual había hecho imposible concertar "incluso alianzas temporarias y momentáneas con todo el congreso o con su mayoría". El autor culpaba de esta rigidez a los bolcheviques, citando la gran cantidad de bolcheviques entre las líderes del grupo obrero-aunque como vimos la dirigente más importante del grupo obrero fue Kollontai, quien por entonces militaba en las filas del menchevismo. Pero "W" también culpó a la inexperiencia de las propias trabajadoras. Lo que le preocupaba era que la intervención del grupo obrero había alejado de las filas de la socialdemocracia a mujeres burguesas o de clase media alienadas por las tendencias "octubristas" de las líderes del Congreso. Dichas mujeres eran, en opinión del autor, aliadas potenciales; habían expresado su simpatía con las trabajadoras a través de sus aplausos, conversaciones privadas y promesas de votar con el grupo obrero, pero estos acercamientos no prosperaron debido al carácter militante de la intervención de las trabajadoras. El grupo obrero había hecho imposible que se desarrollara una coalición de elementos socialdemócratas y liberales, que era el eje de la política menchevique.

Los editores del periódico menchevique Golos sotsialdemokrata agregaron sus propios comentarios después de los dos artículos antes mencionados, acordando con "W" y criticando a 
Kollontai / Mijailova. En el futuro, escribieron, las activistas socialdemócratas en el movimiento de mujeres trabajadoras debían ir más allá de la "oposición elemental entre las saciada y las hambrientas' y hacer que la trabajadora promedio participe activa e independiente en la lucha democrática general, todavía inconclusa" ("Ot redaktsii," p. 9).

En la edición del 3 de abril de 1909 del periódico bolchevique Sotsial-Democrat, dos artículos evaluaron el Congreso de Mujeres. El primero, escrito por un miembro del Comité de Petersburgo del POSDR ("Chlen P.K."), analizó los conflictos dentro del grupo obrero y la "ruptura demostrativa" final del grupo con la mayoría del Congreso. El segundo artículo, sin firma, evaluó el significado del Congreso y la crítica menchevique a la intervención del grupo obrero, señalando que el grupo definió con éxito la situación especial, los objetivos y las tácticas de las mujeres proletarias, y que la táctica de Kollontai no había recibido el apoyo de sus compañeros mencheviques. ${ }^{27}$ En general, concluyó el corresponsal de Sotsial-Democrat, los bolcheviques podrían estar satisfechos, porque esto mostraba "el abismo entre la tendencia real del desarrollo proletario y la prédica de los elementos oportunistas" dentro de la Socialdemocracia.

Aunque el grupo obrero no duró mucho más allá del Congreso de Mujeres, disolviéndose poco después, su intervención en el Congreso había puesto en claro la necesidad de hacer de la organización de las trabajadoras una prioridad y de prestar especial atención a las necesidades del proletariado femenino. El grupo obrero ayudó a establecer un Comité de Mujeres dentro de la Oficina Central de Sindicatos y sugirió que cada organización de trabajadores estableciera un comité especial para el trabajo entre las mujeres. Varios miembros del partido querían organizar un "grupo dentro del

${ }^{27}$ Kollontai explicó esta situación anómala por Kollontai en su autobiografía de la siguiente manera: "En el año 1908 pertenecía yo a los mencheviques, porque la postura de los bolcheviques frente a la Duma, un seudoparlamento convocado por el zar para calmar los espíritus insurrectos de la época, me obligaba a ello. Con los mencheviques defendí la tesis de que incluso un seudoparlamento debía ser utilizado como tribuna para nuestro partido y de que las elecciones de la Duma deberían emplearse como instrumento de unificación de la clase trabajadora. Sin embargo, difería de los mencheviques en lo tocante a la coordinación de las fuerzas trabajadoras con las liberales para acelerar el derrocamiento del absolutismo. En este punto pertenecía yo realmente a la izquierda radical y hasta fui calificada de «sindicalista» por mis camaradas de partido" (Kollontai 1976, p. 82). 
partido para el trabajo entre las mujeres", similar al existente en Alemania (Ruthchild 2010, pp. 140-142).

En su informe a la segunda conferencia de la Internacional de Mujeres Socialistas celebrada en Copenhague en 1910, Kollontai señaló que las socialistas habían desarrollado una activa propaganda con motivo del Congreso panruso de mujeres de 1908. En opinión de Kollontai, "al desacuerdo interno entre el feminismo burgués (bürgerlichen Frauenrechteler) y el incipiente movimiento de mujeres proletarias salió claramente a la luz. Tuvo lugar una polémica, que proporcionó estímulo y esclarecimiento a las proletarias. Luego de la conclusión del congreso, la cuestión de la mujer fue discutida en asambleas de trabajadoras en Petersburgo y en las provincias. Algunos sindicatos, como la federación de trabajadores textiles y gráficos de Petersburgo, las trabajadoras textiles y costureras en Bakú y las costureras en Moscú decidieron crear comisiones especiales de agitación entre las mujeres, a fin de impulsar el desarrollo ulterior del movimiento de mujeres proletario y de ganar a las trabajadoras para el partido y para los sindicatos" (Kollontai 1910, pp. 74-75).

\section{Feministas y socialistas durante el período de reacción (1907-1912)}

La brutal represión de la insurrección de Moscú en diciembre de 1905, que arrojó más de mil muertos, dio comienzo a un período de reacción, el cual, dada la abundancia de revueltas de campesinos y de motines de soldados y marineros en 1906, es generalmente datado desde la disolución de la Segunda Duma el 7 de junio de 1907. Durante el periodo de reacción fue creada la cuarta y última organización feminista existente en Rusia antes de la revolución bolchevique: la Liga Panrusa por la Igualdad de Derechos de las Mujeres (Всероссийская мига равноправия женщин). El estatuto de la Liga fue aprobado por el gobernador de la ciudad de San Petersburgo el 6 de marzo de 1907. Sus fundadoras provenían de la clase dominante, siendo generalmente esposas, viudas o hijas de funcionarios. Como lo indicaba su estatuto, el propósito de la Liga era "el logro por parte de todas las mujeres de derechos políticos y civiles idénticos a los derechos de los ciudadanos varones rusos, con el objetivo de mejorar la situación legal y económica de las mujeres".

Aunque los miembros de la Liga recogieron en 1907 firmas para peticiones que exigían el sufragio femenino a la Segunda Duma, no fue hasta después del Congreso de Mujeres de diciembre de 1908 que la Liga dio señales reales de vida. En ese momento, muchas ex- 
activistas en la Unión Panrusa para la Igualdad de Derechos de la Mujer se unieron a la Liga y alcanzaron prominencia en ella, incluyendo a Ekaterina Shchepkina, que se convirtió en directora de la oficina de oradores de la organización, Anna Kalmanovich, Zinaida Mirovich, Liudmila Ruttsen, Ariadna Tyrkova y Olga Volkenshtein. Maria Chejova, fundadora de la Unión de Mujeres y editora de su revista, se unió a la Liga y se convirtió en presidenta de la sección de San Petersburgo en enero de 1909. Chejova se mudó a Moscú en 1910, donde fue creada una sección de la Liga bajo su presidencia ese mismo año. La nueva presidente de la Liga, Polixena Shishkina-Iavein, una médica, dirigió la sección de San Petersburgo hasta su desaparición después de la Revolución de Octubre.

La Liga era una organización pequeña, de entre 1.500 y 2.000 miembros (es decir, la cuarta parte de la Unión de Mujeres), centrada principalmente en las secciones de Moscú y San Petersburgo, con secciones más pequeñas en Jarkov y Tomsk. En 1911 se produjo una escisión en la Liga cuando Maria Raij, de la sucursal de Moscú, acusó a Zinaida Mirovich de antisemitismo, lo que hizo que Mirovich y sus aliadas, respaldadas por la sección de San Petersburgo, abandonaran la Liga de Moscú. Esto coincidió con una escisión en el partido kadete en 1912 que condujo a la formación del Partido Progresista, centrado en la burguesía de Moscú: dicha escisión estuvo acompañada de rumores acerca de una supuesta influencia judía dentro de los kadetes (los derechistas atacaban al periódico kadete Rech como un "diario judío") y los disidentes lanzaron un nuevo periódico, editado por Tyrkova y Peter Struve, que sin embargo duró sólo un año (Ruthchild 2010, pp. 190-192). La Liga luego desempeñó un rol destacado en la política liberal en 1917, como veremos más adelante.

Durante el punto álgido del período de reacción, una de las principales arenas de debate entre las feministas y las socialistas fue el "Primer congreso de toda Rusia para combatir la trata de mujeres y sus causas" celebrado en San Petersburgo del 21 al 25 de abril de 1910 y presidido por Anna Filosofova, la dirigente de la Sociedad de Ayuda Mutua, quien para entonces se había unido al partido de la burguesía liberal, los kadetes. ${ }^{28} \mathrm{El}$ congreso comenzó con un

28 Ver la reseña del debate, desde un punto de vista feminista hostil al socialismo, en Laurie Bernstein, Sonia's Daughters: Prostitutes and Their Regulation in Imperial Russia, Berkeley: University of California Press, 1995, Chapter 6: Saving Fallen Women: Salvationists and Socialists. Las minutas del congreso están disponibles online como Трудв первого всероссийского съезда по борьбе с торгом женщинами и его причинами, происходивщего в С.-Петербурге с 
"Discurso de Su Alteza la Princesa Elena Georgievna SaxenaAltenburgskaya" (la presidenta de la "Sociedad Rusa para la Defensa de las Mujeres", la sociedad filantrópica que organizó el congreso) y contó con las figuras más destacadas del feminismo ruso de entonces, incluyendo a Anna Shabanova de la Sociedad de Ayuda Mutua, Polixena Shishkina-Iavein de la Liga Panrusa por la Igualdad de Derechos de las Mujeres, Ariadna Tyrkova-Williams, también dirigente de la Liga y del Comité Central de los kadetes pero presentada como miembro del "Club de Mujeres de San Petersburgo", Zinaida Mirovich, dirigente de la difunta Unión de Mujeres y ahora de la Liga, presentada como miembro del "Primer Club de Mujeres de Moscú", Maria Pokrovskaia del Partido Progresista de las Mujeres, presentada como miembro del "Consejo Editorial de EL Heraldo de la Mujer", etc.

Las invitaciones oficiales al congreso al principio incluyeron solamente a representantes de organizaciones filantrópicas y médicas, universidades, sociedades de templanza, consejos municipales y de distrito, así como a propietarios de fábricas y talleres, ya que éstos tenían la "posibilidad de mejorar el saneamiento de las trabajadoras a través de medidas juiciosas". El comité organizador se reservó el derecho de invitar a otras personas, pero las categorías aprobadas no dejaron lugar para trabajadoras o sindicalistas, quienes recibieron permiso para asistir sólo dos semanas antes de la apertura del congreso. Kollontai exhortó a las organizaciones sindicales a protestar por su exclusión inicial, señalando cáusticamente que los organizadores del congreso parecían decididos a arreglar las cosas de manera tal "que la inquietante voz de la vida no viole la imparcialidad de su erudición burocrática". La policía y los obstáculos burocráticos finalmente permitieron que participaran en el congreso solamente cinco delegados de la clase trabajadora: Zinaida M. Ivanova y Georgii M. Bek, del sindicato de sastres, costureras y peleteros de Moscú; Zinaida A. Golovacheva, una representante sindical de Moscú; Petr G. Goncharov, del sindicato de empacadores de té; y Pavel S. Pavlov, secretario del sindicato de los trabajadores gráficos de Moscú, en medio de casi 290 miembros de orígenes aristocráticos, burgueses y pequeñoburgueses.

21 nо 25 Апреля 1910 года. С.-Петербург: Типо-Аитография С.Петербургской ОАиночной Тюрьмы, 1911. [Actas del Primer Congreso de toda Rusia sobre la lucha contra la trata de mujeres y sus causas, que tuvo lugar en San Petersburgo del 21 al 25 de abril de 1910. San Petersburgo: Typo-litografía de la prisión única de San Petersburgo, 1911.] http://istmat.info/node/37476 
Los representantes sindicales de Moscú, a pesar de su pequeño número, libraron una feroz batalla ideológica, argumentando que, dado que la prostitución era un componente integral del capitalismo, no podía eliminarse mediante ninguna medida filantrópica sino sólo mediante la eliminación de todo el sistema social, político y económico que le daba origen. Pero los trabajadores necesitaban la libertad de organizarse en defensa de sus intereses para lograr esto, y por lo tanto tenían que protestar contra las políticas represivas del estado autocrático de Rusia. En consecuencia, los delegados de Moscú utilizaron el Congreso como una plataforma para denunciar las restricciones a la libertad de expresión, de asociación y de prensa, y para exigir el derecho de los trabajadores a formar una federación nacional de sindicatos con lazos internacionales. ${ }^{29}$ Presentaron una resolución, rechazada por los organizadores del congreso, para eliminar el trabajo infantil para los menores de 15 años, instituir la educación obligatoria, elegir a los inspectores de fábrica en el seno de la clase trabajadora e instituir una jornada laboral de ocho horas. Los representantes de los trabajadores rechazaron el concepto mismo de una organización obrera compuesta exclusivamente por mujeres, denunciándola como una "invención de señoras burguesas".

Por su parte, la feminista Ariadna Tyrkova enajenó a los trabajadores cuando se pronunció a favor del sufragio calificado, siempre y cuando incluyera a las mujeres. Pero Tyrkova apoyó la propuesta de los trabajadores de prohibir el empleo de mujeres en trabajos peligrosos para su salud, mientras que feministas como Mirovich y Mariia Pokrovskaia afirmaron que tal práctica restringiría aún más las opciones laborales de las mujeres. La prohibición del trabajo nocturno de las mujeres, por otro lado, sólo encontró una sola objeción: la de Pokrovskaia. Su deseo de ver una única legislación laboral para hombres y mujeres la colocó junto con los miembros más conservadores del Congreso. La negativa de la presidencia del congreso de someter a votación sus resoluciones (la resolución demandado libertad de sindicalización fue rechazada por ser "política") hizo que los cinco representantes del grupo obrero

29 Como resultado de la revolución de 1905, el gobierno zarista se vio obligado a autorizar legalmente a los sindicatos, intentando al mismo tiempo encorsetarlos con disposiciones extremadamente restrictivas, mediante la promulgación, el 4 de marzo de 1906, de un decreto titulado "Reglas provisorias sobre las sociedades y las uniones", el cual "limitaba las posibilidades de unión de los sindicatos a nivel de la ciudad, de la provincia y del país" (Hocax 2001, p. 49). 
finalmente abandonaran el congreso en el tercer día de sus sesiones, el 23 de abril de 1910.

En su informe a la segunda conferencia de la Internacional de Mujeres Socialistas celebrada en Copenhague en 1910, Kollontai señaló que, igual que el movimiento obrero y la izquierda en su conjunto, el movimiento de mujeres proletarias había sufrido los golpes de la reacción que siguió a la revolución de 1905. "Pero el Congreso para la lucha contra la prostitución que tuvo lugar en abril de 1910 en San Petersburgo reavivó la actividad de los círculos de trabajadoras en Petersburgo y Moscú. Asambleas públicas y secretas tuvieron lugar, e incluso fue enviada como delegada al congreso una representación de las trabajadoras de Moscú". Kollontai concluía presentando estadísticas parciales que mostraban que "el número de trabajadoras organizadas en una forma $u$ otra en Rusia es muy pequeño, tanto en términos absolutos como en proporción al número de trabajadores varones organizados, aunque todas las organizaciones proletarias tienen miembros femeninos y las mujeres están incorporadas al Partido Socialdemócrata clandestino, a los sindicatos legales y semi-legales, a las asociaciones de educación de los trabajadores, etc.” (Kollontai 1910, pp. 74-75).

Durante el período de reacción, la Liga Panrusa por la Igualdad de Derechos de las Mujeres centró sus esfuerzos en hacer lobby en la Tercera Duma para mejorar la situación jurídica de las mujeres. Las mujeres casadas rusas tenían mayores derechos de propiedad que las mujeres en la mayoría de los otros países, pero aun así la ley clave sobre la herencia, el artículo 1.130 del Código Civil, estipulaba que las hijas debían recibir solo una fracción de la parte correspondiente a los hijos varones de los bienes inmuebles (una decimocuarta parte) y muebles (una octava parte). Además, existían dos excepciones al control de su propiedad: las mujeres casadas no podían obtener créditos o contratar trabajadores asalariados sin el consentimiento de sus maridos. Por la ley del 3 de junio de 1912, la proporción de la herencia correspondiente a las hijas fue elevada de la decimocuarta a la séptima parte de los bienes inmuebles. Este cambio carecía en gran medida de significado para las mujeres de la clase trabajadora.

En términos de derechos personales, la esposa rusa no tenía derecho a obtener su propio pasaporte o a vivir separada de su esposo sin su consentimiento; él tenía el derecho de elegir su lugar de residencia, y ella estaba legalmente obligada a vivir allí. Las mujeres fueron finalmente autorizadas a obtener sus propios pasaportes el 12 de marzo de 1914. Las mujeres casadas que vivían separadas ya no 
necesitaban el permiso de su esposo para obtener un trabajo, ingresar al servicio público o trabajar en instituciones educativas. Esta ley, de mayor alcance que la anterior, era más significativa para las trabajadoras, pero no modificaba significativamente su situación, entre otras cosas por la mayor prevalencia de parejas de hecho entre el proletariado.

En todos los otros planos los esfuerzos de las feministas fracasaron, incluyendo dos proyectos de ley para extender el voto calificado a las mujeres. Las mujeres sólo obtuvieron el derecho al sufragio universal y a ejercer la abogacía (otro proyecto de ley presentado por las feministas que fue originalmente rechazado), así como igualdad de condiciones con los hombres en los puestos educativos estatales, después de la Revolución de Febrero, como veremos más adelante. ${ }^{30}$

La Liga utilizó también otras oportunidades legales para reunir apoyo, organizando asambleas y congresos. El más importante de ellos fue el Primer Congreso de toda Rusia sobre la educación de las mujeres (Первый Всероссийский съезА по образованию женщин), celebrado en San Petersburgo del 26 de diciembre de 1912 al 4 de enero de 1913, cuatro años después del Primer Congreso de Mujeres de toda Rusia. Pero esta vez no hubo debates entre las feministas y las representantes del movimiento de mujeres socialistas: a fin de evitar polémicas como las que tuvieron lugar en el congreso de 1908, el comité organizador prohibió la participación de una delegación de trabajadoras y censuró él mismo todos los debates. Las resoluciones aprobadas en el Congreso incluyeron llamados a la coeducación, a la autonomía de las instituciones educativas y a la eliminación de las restricciones por nacionalidad (Ruthchild 2010, pp. 172-193).

30 Rochelle Goldberg Ruthchild, Equality and Revolution: Women's Rights in the Russian Empire, 1905-1917, Pittsburgh: University of Pittsburgh Press, 2010, pp. 160-162 para los cambios en las leyes sobre la herencia y el pasaporte, pp. 167-171 sobre los proyectos para extender el sufragio a las mujeres presentados ante la tercera y la cuarta Duma. 


\section{Los orígenes socialistas del Día Internacional de la Mujer y el periódico Rabotnitsa}

\section{Los orígenes socialistas del Día Internacional de la Mujer}

El Día Internacional de la Mujer fue proclamado por la Segunda Conferencia Internacional de Mujeres Socialistas celebrada en Copenhague en 1910. La invitación a la misma dejaba en claro su carácter de clase: "Invitamos a las mujeres socialistas organizadas de todos los países -sin distinción del grupo o del partido al que pertenezcan- a enviar representantes a la conferencia, así como a todas las organizaciones de trabajadoras que reconozcan el principio de la lucha de clases". 31

El informe de las delegadas estadounidenses mencionaba que el 28 de febrero de 1909 "tuvo lugar por primera vez el 'Día de la Mujer', un evento que ha despertado la atención de nuestros enemigos." En 1908, el Partido Socialista de los Estados Unidos había nombrado un Comité Nacional de Mujeres para la Campaña por el Sufragio y les había pedido que organizaran manifestaciones. Ansiosa por comenzar, la Seccional Número 3 de la Sociedad de Mujeres Socialdemócratas de la Ciudad de Nueva York celebró una asamblea masiva a favor del sufragio femenino el 8 de marzo de 1908. Las socialistas norteamericanas declararon al último domingo de febrero como el Día Nacional de la Mujer. Al año siguiente, el 23 de febrero de 1909, la asamblea principal en Nueva York tuvo lugar en el Murray Hill Lyceum en la Trigésima cuarta y Tercera Avenida. Dos mil personas escucharon a Leonora O'Reilly y otras explicar los principios de la igualdad de derechos y exigir el voto para las mujeres. ${ }^{32}$ La manifestación de Nueva York el año siguiente tuvo lugar el 27 de febrero de 1910, y se inauguró con una asamblea en el Carnegie Hall. La audiencia cantó la Marsellesa y luego Rose Schneiderman, Charlotte Perkins Gilman y Metta I. Stern explicaron cómo las mujeres socialistas alemanas abrieron el camino en Stuttgart

\footnotetext{
31 "Zweite Internationale Sozialistische Frauenkonferenz: Kopenhagen, 26. August 1910; (vorläufger telegraphischer Bericht)", Vorwärts, Berlin, 1910, Jg. 27, Nr. 200, Beil. 2, Sonnabend, 27. August, citado en Cintia Frencia y Daniel Gaido, El marxismo y la emancipación de la mujer trabajadora: De la Internacional de Mujeres Socialistas a la Revolución Rusa, Universidad de Santiago de Chile: Editorial Ariadna, 2016, p. 79.

32 "The Suffragists and Socialists Demand Votes for Women", New York Call, 1 March 1909, p. 1.
} 
en 1907 exigiendo la igualdad económica de las mujeres y el sufragio universal femenino. ${ }^{33}$

En la Conferencia de Copenhague, la delegada alemana Luise Zietz, siguiendo el ejemplo de las socialistas norteamericanas, propuso la proclamación de un "Día Internacional de la Mujer", a celebrarse anualmente. Su propuesta fue secundada por su compañera Clara Zetkin, la presidente de la Internacional de Mujeres Socialistas, y por las 100 delegadas procedentes de 17 países. La resolución adoptada sobre este punto rezaba: "De acuerdo con las organizaciones políticas y sindicales con conciencia de clase del proletariado de sus respectivos países, las mujeres socialistas de todas las nacionalidades tienen que organizar un Día de las Mujeres (Framentag) especial, el cual, ante todo, tiene que promover la propaganda del sufragio femenino. Esta demanda debe ser discutida en relación con toda la cuestión de la mujer, según la concepción socialista." 34

La "introducción del sufragio femenino" fue colocada por las mujeres socialistas en la resolución de Copenhague en el contexto de la legislación protectora de las trabajadoras, de la asistencia social para madres e hijos, de la igualdad de trato para las madres solteras, de la provisión de guarderías y jardines de infancia, de la provisión de comidas gratuitas y medios de enseñanza gratuitos en las escuelas y de la solidaridad internacional. En otras palabras, en sus orígenes el Día Internacional de la Mujer fue concebido como un día de la mujer trabajadora que tenía como objetivo inmediato el sufragio universal femenino, pero sólo como medio para un fin: el triunfo del socialismo.

El primer Día Internacional de la Mujer no fue celebrado en Alemania el 8 de marzo sino el 19 de marzo 1911. La fecha fue elegida para conmemorar la Revolución de 1848 en Berlín: el día anterior, el 18 de marzo, estaba dedicado todos los años a "los caídos de marzo". Al grito de batalla "Adelante con el sufragio femenino", más de un millón de mujeres salieron a la calle en Alemania pidiendo la igualdad social y política. "Nuestro día de marzo", rezaba el llamado publicado en la revista Die Gleichbeit: "¡Compañeras! ¡Mujeres y muchachas trabajadoras! El 19 de marzo es vuestro día. Es vuestro

33 "A.B.C. A Day of Anticipation," New York Call, 27 February 1910, Magazine, p. 13. Tanto esta cita como la anterior fueron tomadas de Kaplan 1985, pp. 165-166.

34 Cintia Frencia y Daniel Gaido, El marxismo y la emancipación de la mujer trabajadora: De la Internacional de Mujeres Socialistas a la Revolución Rusa, Universidad de Santiago de Chile: Editorial Ariadna, 2016, p. 87. 
derecho. Detrás de vuestras demandas está la Socialdemocracia, los trabajadores organizados sindicalmente. Las mujeres socialistas de todos los países se sienten solidarias con ustedes. El 19 de marzo debe ser vuestro día de gloria." El volante para participar en los actos del Día de la Mujer, encabezado con la demanda: "Adelante con el sufragio femenino", fue impreso y distribuido en una edición de dos millones y medio de copias. Ante la inminente guerra mundial, el Día Internacional de la Mujer fue puesto por las socialistas desde el principio bajo el signo de la lucha contra el militarismo imperialista y por la preservación de la paz.

En Alemania tomaron parte en los eventos y manifestaciones cerca de un millón de mujeres organizadas en el SPD y en los sindicatos, pero también muchas mujeres no organizadas. No menos importante que el carácter masivo e internacional de las manifestaciones que tuvieron lugar durante el Día Internacional de la Mujer es que este evento estuvo acompañado por la celebración de "asambleas populares políticas públicas" de trabajadoras (se contabilizaron 42 asambleas solamente en Berlín), en las cuales tenía lugar una "libre discusión" de los temas que afectaban a las trabajadoras. Además de Alemania, el Día Internacional de la Mujer se celebró en 1911 —en días diferentes- en EE.UU., Suiza, Dinamarca y Austria. Hasta la Primera Guerra Mundial se añadieron Francia, Holanda, Suecia, Rusia y Bohemia. El Segundo Día Internacional de la Mujer fue celebrado en Alemania el 12 de mayo de $1912 .{ }^{35}$

\section{El primer Día Internacional de la Mujer en Rusia (23 de febrero de 1913)}

Los años que precedieron al estallido de la Revolución de 1917 estuvieron signados por un gran crecimiento en el número de mujeres que trabajan en las fábricas rusas. Entre 1901 y 1914, la fuerza laboral industrial rusa creció en un $37 \%$. La mayoría de estos nuevos trabajadores $(64,1 \%)$ eran mujeres. Las mujeres, que constituían el $24 \%$ de los trabajadores de las fábricas en 1887, ahora representaban el 31\%, y en algunas industrias, como los textiles, más

35 Cintia Frencia and Daniel Gaido, "The Socialist Origins of International Women's Day", Jacobin Magazine: A Magazine of Culture and Polemic (Bronx, N.Y.: Jacobin Press), March 8, 2017. Disponible online. Ver también Siegfried Scholze, Der Internationale Frauentag einst und heute. Geschichtlicher Abriss und weltweite Tradition vom Entstehen bis zur Gegenwart, Berlin: Trafo, 2001. 
de la mitad — pero al mismo tiempo las mujeres constituían sólo el $6 \%$ de los miembros en los sindicatos rusos en 1912. Esta falta de organización se reflejaba en su tasa de explotación: las mujeres debían trabajar por la mitad o los dos tercios del salario de un hombre. En San Petersburgo, por ejemplo, el salario diario promedio de un hombre en la industria pesada en la víspera de la guerra era de 1 rublo 41 kopeks, mientras que para una mujer era de 72 kopeks (Elwood 1992, pp. 102-103).

La masacre de los mineros del oro a orillas del río Lena el 17 de abril de 1912 dio comienzo a una ola de huelgas de solidaridad y a nuevo período de alza del movimiento obrero, que continuó hasta el estallido de la Primera Guerra Mundial en agosto de 1914. A partir de 1912, como resultado de un aumento general del activismo laboral en Rusia, que incluyó una ola de huelgas de trabajadoras, la atención socialista a las mujeres como grupo diferenciado se hizo más pronunciada. Esto tomó un número de formas, incluida la apertura de más clubes (como el Tercer Club de Mujeres de Moscú, que llegó a agrupar a 900 miembros durante los 13 meses de su existencia, hasta que fue clausurado por la policía en noviembre de 1913), las celebraciones del Día Internacional de la Mujer en 1913 y 1914 y la publicación del periódico bolchevique Rabotnitsa (La trabajadora) en 1914.

En mayo de 1912 fue publicada una serie de artículos en Pravda que trataban extensamente sobre la explotación del trabajo de las mujeres, pero los bolcheviques entraron en una nueva etapa en su relación con las mujeres trabajadoras recién a principios de 1913. Hasta entonces, la cuestión de la mujer había sido debatida casi únicamente por miembros del Comité de San Petersburgo y no había sido objeto de ninguna forma institucional permanente. En enero de 1913 los bolcheviques, incluido Lenin, comenzaron a incluir una sección de mujeres en el periódico Pravda, en honor a la primera celebración en Rusia del Día Internacional de la Mujer, el 23 de febrero de 1913. A pesar de que aún militaba en las filas del bolchevismo, el artículo de Alexandra Kollontai "El día de la mujer" («женский хень») fue publicado en Pravda, No. 40 (244), el 17 de febrero de 1913, una semana antes de la primera celebración en Rusia del Día Internacional de la Mujer, que tuvo lugar el 23 de febrero (8 de marzo) de 1913, debido a la divergencia existente entre el calendario juliano de la iglesia ortodoxa rusa, entonces vigente en Rusia, y el calendario gregoriano.

Kollontai describía cómo los partidos socialistas habían llegado a comprender la necesidad de crear "comités especiales, 
secretarías y oficinas de mujeres" y de levantar un programa de reivindicaciones específicas para las mujeres trabajadoras, tales como "la protección y la provisión para mujeres embarazadas y madres lactantes, la regulación legislativa del trabajo femenino, campañas contra la prostitución y contra la mortalidad infantil, la demanda de derechos políticos para las mujeres, la mejora de la vivienda, la campaña contra el aumento del costo de la vida, etc.” A la objeción de que la existencia de un "Día de la Mujer' especial, de folletos especiales para mujeres trabajadoras, de asambleas y conferencias especiales de mujeres de la clase trabajadora" constituían "una concesión a las sufragistas y feministas burguesas", Kollontai respondía:

Solo aquellos que no entienden la diferencia radical entre el movimiento de las mujeres socialistas y las sufragistas burguesas pueden pensar de esta manera.

¿Cuál es el objetivo de las feministas? Conseguir los mismos privilegios, el mismo poder, los mismos derechos en la sociedad capitalista que poseen ahora sus maridos, padres y hermanos. ¿Cuál es el objetivo de las trabajadoras? Abolir todos los privilegios que deriven del nacimiento o de la riqueza. A la obrera le resulta indiferente si su patrón es hombre o mujer.

Las feministas demandan la igualdad de derechos siempre y en cualquier lugar. Las trabajadoras responden: demandamos derechos para todos los ciudadanos, hombres y mujeres, pero nosotras no sólo somos mujeres y trabajadoras, sino también madres. Y como madres, como mujeres que tendremos hijos, portadores del futuro, demandamos un cuidado especial del gobierno para nosotras y para nuestros hijos, una protección especial del estado y de la sociedad.

Las feministas se esfuerzan por adquirir derechos políticos. Sin embargo, aquí también nuestros caminos se separan.

Para las mujeres burguesas, los derechos políticos son simplemente un medio que les permite abrirse camino de manera más conveniente y segura en un mundo basado en la explotación de los trabajadores. Para las trabajadoras, los derechos políticos son un paso en el difícil y arduo camino que conduce al deseado reino del trabajo.

Los caminos seguidos por las mujeres trabajadoras y las sufragistas burguesas se han separado hace mucho tiempo. Existe una gran diferencia entre los objetivos que la vida les ha puesto. Existe una contradicción demasiado grande entre los intereses de la mujer trabajadora y la mujer propietaria, entre la sirviente y su señora... No hay ni 
puede haber ningún punto de contacto, conciliación o convergencia entre ellas. Por lo tanto, los trabajadores no deben temer a un Día de la Mujer especial, ni a las conferencias especiales de mujeres trabajadoras, ni a su prensa especial.

Cada forma especial y distinta de trabajo entre las mujeres de la clase obrera es simplemente un medio para despertar la conciencia de la trabajadora y llevarla a las filas de quienes luchan por un futuro mejor... El Día de la Mujer y el trabajo lento y meticuloso emprendido para despertar la conciencia de la mujer trabajadora están sirviendo a la causa, no de la división, sino de la unificación de la clase trabajadora.

Que la alegre sensación de servir a la clase común y de luchar simultáneamente por su propia emancipación femenina inspire a las mujeres trabajadoras a unirse a la celebración del Día de la Mujer. ${ }^{36}$

En la asamblea celebrada en el primer Día Internacional de la Mujer en San Petersbugo, el 23 de febrero de 1913, las oradoras obreras fueron Shura Alekseeva, una trabajadora textil, y Kartacheva, una oficinista. Alekseeva buscó ayuda para preparar su discurso de Anna Ulianova (la hermana de Lenin) y Konkordiia Samoilova, pero, intimidada por tener que hablar en el Gran Salón Kalashnikov y por la presencia de policías montados en la entrada y de policías en la primera fila, terminó dando un discurso improvisado sobre sus propias experiencias como trabajadora textil. A pesar de que la ley estipulaba una jornada laboral máxima de once horas, afirmó, muchas mujeres trabajaban dieciocho horas por día por salarios miserables. Como resultado, las mujeres no tenían tiempo para su propio desarrollo intelectual ni para atender las necesidades de su familia. Alekseeva también habló sobre la prostitución y acusó a las "mujeres burguesas" de considerar que las mujeres trabajadoras se sentían atraídas a la prostitución por tonterías. Por el contrario, afirmó, era la necesidad extrema la que conducía a las mujeres a ese comercio vergonzoso, no la frivolidad. Se quejó de que dentro de las fábricas los capataces oprimían a las mujeres y las obligaban a acostarse con ellas. Apeló a los sindicatos para que protegieran a las

36 А.М. Комлонтай, “Женский Аень”, Правда, № 40 (244), 17 февраля 1913 г. // Избранные статьи и речи, Москва: Издательство политической митературы, 1972, pp. 109-110. [A.M. Kollontai, "El Día de la Mujer", Pravda, No. 40 (244), 17 de febrero de 1913, en Kollontai, Artículos y discursos seleccionados, Moscú: Editorial de Literatura Política, 1972, pp. 109-110.]. 
mujeres trabajadoras y las defendieran contra los administradores. Alekseeva continuó su discurso afirmando que, si las huelgas de mujeres no habían tenido éxito hasta entonces, eso se debía a su desorganización. Llamó a todas las mujeres a unirse a la familia proletaria y a marchar juntos de la mano por un futuro mejor. Fue arrestada por su discurso esa misma noche. La bolchevique Praskovia Kudelli también habló en la misma asamblea, pero la intervención de los gendarmes le impidió analizar las consecuencias de la revolución de 1905, como tenía pensado hacer en sus discursos (Chatterjee 2002, pp. 24-26).

Sorprendentemente, en Moscú la policía no censuró ni controló el encuentro del Día Internacional de la Mujer organizado por los miembros del Tercer Club de Mujeres. Al igual que en San Petersburgo, los bolcheviques lograron con gran dificultad persuadir a una joven trabajadora nerviosa, Masha Platonova, para que hablara en público. El Día Internacional de la Mujer también se celebró en 1913 en Samara, Tiflis, Kiev y otros centros industriales de Rusia. La sede editorial de Pravda recibió saludos con motivo de la conmemoración de numerosas instituciones y organizaciones, como la fracción socialdemócrata en la Duma, grupos de presos políticos, mujeres en el exilio, trabajadores de la fábrica de Putilov, un grupo de modistas de Ekaterinoslav, y mujeres trabajadoras de Krasnoiarsk (ver los números de Pravda del 17 y 19 de febrero de 1913). Los socialistas estaban satisfechos con los resultados de la primera celebración del Día Internacional de la Mujer en Rusia. Según la activista bolchevique Anna Elizarova, desde el primer Día Internacional de la Mujer la afiliación de las mujeres a los sindicatos, clubes y organizaciones ilegales creció enormemente (Chatterjee 2002, pp. 28-29).

\section{E1 Día Internacional de la Mujer de 1914 y el periódico bolchevique Rabotnitsa}

Las trabajadoras escribían a Pravda en número cada vez mayor para quejarse sobre las condiciones laborales. Konkordiia Samoilova quedó impresionada por el tono y el volumen de esta correspondencia, pero no pudo publicar gran parte de ella. Una solución, que propuso al comité editorial, fue publicar una revista separada dirigida específicamente a las trabajadoras, que serviría de foro para estos reclamos. También discutió esta solución con Inessa Armand. Pero no fue hasta la reunión del Comité Central de septiembre de 1913 en Poronin, Galicia, que el Partido Bolchevique 
intentó sistematizar su trabajo entre las obreras. Cuando llegó a Poronin en septiembre de 1913, Armand inmediatamente buscó el respaldo de Krupskaya y de la esposa de Zinoviev, Zinaida Lilina, para el plan. Una revista de este tipo no sólo satisfaría las necesidades inmediatas de San Petersburgo, sino que podía utilizarse para desarrollar la conciencia de clase de las mujeres trabajadoras, superar su resistencia a afiliarse a sindicatos y ganarse su lealtad para el Partido Bolchevique.

El éxito de la celebración del Día Internacional de la Mujer en Rusia en 1913 dio impulso al proyecto, como lo hizo la introducción por el gobierno de un plan de seguro para los trabajadores. De acuerdo con la ley promulgada el 23 de junio de 1912, los representantes electos de los trabajadores, en consulta con la administración, debían elaborar normas de seguro precisas y administrar los fondos de enfermedad y los consejos de seguros a nivel de fábrica. El partido bolchevique era muy consciente del valor agitacional de la "campaña de seguros" y de la ventaja organizacional que se obtendría al elegir candidatos bolcheviques para estos organismos de seguros. Para tener éxito en esta empresa, sin embargo, había que buscar la manera de atraer a las trabajadoras, que tenían el mismo derecho a voto que los hombres en las elecciones.

El 12 de diciembre de 1913, seis días antes de que Armand abandonara Cracovia para trasladarse a París ${ }^{37}$, ella y Krupskaya enviaron una carta a Samoilova que decía:

Últimamente hemos estado hablando mucho aquí [en Cracovia] sobre la necesidad de comenzar a publicar un pequeño periódico especialmente para mujeres... Hemos delineado el siguiente plan aproximado para nuestro pequeño diario, que sería bueno llamar Rabotnitsa: 1) un artículo editorial sobre un tema político general; 2) el

37 “Al comienzo pensábamos que Inessa permanecería en Cracovia [pero finalmente Armand se trasladó a París]. Antes de su partida tuvimos una larga conversación sobre el trabajo de las mujeres. Ella insistió enérgicamente en la necesidad de efectuar el trabajo de propaganda entre las obreras y publicar una revista especial para las trabajadoras en San Petersburgo. Ilich escribió a Anna Ilyinishna [Ulianova] sobre la organización de una revista que se publicó un poco después. Más tarde Inessa se preocupó en gran medida por el desarrollo de la actividad entre las obreras y dedicó mucho esfuerzo a este aspecto." Nadiezhda Krupskaya, Lenin, su vida, su doctrina, Buenos Aires: Editorial Rescate, 1984, pp. 240-241. El título de este libro es Recuerdos de Lenin, Moscú: Partizdat, 1933 (Воспоминания о Аенине, Москва: Партиздат, 1933). 
movimiento obrero y la participación de la mujer trabajadora en sus diversos aspectos (lucha política, movimiento sindical, campaña de seguros, cooperativas); 3) las condiciones de trabajo de las mujeres en las fábricas, en los talleres, como vendedoras, en las industrias domésticas, las condiciones de las empleadas domésticas; 4) protección del trabajo femenino; 5) sección extranjera; 6) reseña general de eventos actuales; 7) crónica; 8) la mujer trabajadora y la familia. ${ }^{38}$

El consejo de redacción de la revista Rabotnitsa (Работничa: La trabajadora) consistiría en tres grupos de mujeres: en San Petersburgo, la hermana de Lenin, Anna Elizarova, y sus asociadas, Konkordiia Samoilova, Praskoviia Kudelli, Elena Rozmirovich y Liudmila Menshinskaya; en Cracovia, Krupskaya y "Lilina" Zinoveva; y en París, Liudmila Stal e Inessa Armand. El primer número se programó para el Día Internacional de la Mujer de 1914, y finalmente apareció como estaba previsto, a pesar de las grandes dificultades causadas por la separación de los consejos editoriales y el arresto de casi todo el personal de San Petersburgo justo antes del Día Internacional de la Mujer. La policía dio permiso para celebrar asambleas, pero en vísperas del Día Internacional de la Mujer organizó una redada del comité editorial que se había reunido en el departamento de Kudelli. Unas treinta militantes fueron detenidas y eventualmente deportadas, incluyendo a todas las integrantes del comité editorial de Rabotnitsa en San Petersburgo a excepción de Elizarova, quien había llegado tarde a la reunión y finalmente logró, trabajando en la clandestinidad, que Rabotnitsa se publicara a pesar de todos los obstáculos. Con la ayuda del diario Problemas del seguro, que

38 Citado en Ralph Carter Elwood, Inessa Armand: Revolutionary and Feminist, Cambridge and New York: Cambridge University Press, 1992, p. 118. La afirmación de que Inessa Armand era "feminista" es absurda. El 2 de enero de 1920 Armand envió una carta escrita en francés a todos los partidos de la Internacional Comunista, instándolos a que llevaran adelante un trabajo de agitación y organización entre las obreras, en la cual señaló explícitamente: "Desde hace un año estamos realizando un trabajo propagandístico bastante importante entre las mujeres obreras. Naturalmente, la finalidad de esta propaganda no es de ninguna manera feminista (Le but de cette propagande n'est naturellement aucunement féministe - subrayado por Inessa Armand). Nuestro único objetivo es atraer a la masa de las obreras a la lucha del proletariado contra el imperialismo." Citado en Cintia Frencia y Daniel Gaido, El marxismo y la emancipación de la mujer trabajadora: De la Internacional de Mujeres Socialistas a la Revolución Rusa, Universidad de Santiago de Chile: Editorial Ariadna, 2016, p. 140. 
el Partido Bolchevique pasó a controlar, Elizarova pudo imprimir doce mil copias del primer número de Rabotnitsa. Si bien esto representaba menos de una décima parte de la tirada de Die Gleichbeit y no era suficiente para que la revista circulara fuera de la capital, representó el primer intento por parte de los socialdemócratas rusos de apelar específicamente a las mujeres trabajadoras. ${ }^{39}$

El artículo editorial del primer número de Rabotnitsa, escrito por Krupskaya, distinguía claramente entre las posiciones del feminismo y las del movimiento de mujeres socialistas. Sobre la "así llamada 'cuestión de la mujer", Krupskaya escribió:

Las mujeres burguesas defienden sus "derechos de la mujer" especiales, siempre se oponen a los hombres y demandan sus derechos de los hombres. Para ellas, la sociedad contemporánea se divide en dos categorías principales, hombres y mujeres. Los hombres poseen todo, tienen todos los derechos. La cuestión es lograr la igualdad de derechos.

Para la mujer trabajadora, la cuestión de la mujer es muy diferente. Las mujeres políticamente conscientes ven que la sociedad contemporánea está dividida en clases. La burguesía es una clase, la clase trabajadora es la otra. Sus intereses son contrapuestos. La división en hombres y mujeres a sus ojos no tiene gran significado. Lo que une a la mujer trabajadora con el hombre trabajador es mucho más fuerte que lo que los divide. Están unidos por su falta común de derechos, sus necesidades comunes, su condición común, que es la explotación de su trabajo, su lucha común y sus objetivos comunes. "Todos para uno y uno para todos". Este "todos" significa todos los miembros de la clase trabajadora, hombres y mujeres por igual.

La "cuestión de la mujer", para los trabajadores y las trabajadoras, consiste en cómo involucrar a las masas atrasadas de las mujeres trabajadoras en la organización, cómo dejarles en claro sus intereses, cómo hacer que se transformen rápidamente en compañeras en la lucha común. La solidaridad entre hombres y mujeres trabajadoras, la causa común, el objetivo común y el camino común hacia esos objetivos: tal es la solución para

39 Los mencheviques también editaron en 1914 un periódico para trabajadoras, llamado Golos rabotnitsi (Voz de la trabajadora), del cual aparecieron sólo dos números (Ruthchild 2010, p. 189). En 1917 dicho periódico fue resucitado al igual que Rabotnitsa, pero también desempeñó un rol marginal (Donald 1982, p. 151). 
la "cuestión de la mujer" entre los trabajadores. Rabotnitsa repetirá incansablemente [a las trabajadoras] la necesidad de organizarse, ingresando a las organizaciones de trabajadores... En una palabra, nuestra revista se esfuerza por ayudar a las mujeres trabajadoras a volverse conscientes y organizadas. ${ }^{40}$

Desafiando la prohibición policial, las trabajadoras de San Petersbugo se reunieron en grupos dispersos por toda la ciudad para celebrar el Día Internacional de la Mujer el 23 de febrero (8 de marzo) de 1914. Dondequiera que el periódico Rabotnitsa era vendido, las multitudes se apiñaban para leerlo en voz alta en las calles. En las fábricas donde predominaban las mujeres, las trabajadoras se ausentaron y advirtieron a sus jefes de antemano que iban a tomarse el domingo libre para celebrar el Día de la Mujer. A las siete de la tarde, unas 450 trabajadoras llegaron al Salón Fedorov en Malaia Grebetskaia, el único lugar donde la policía había dado originalmente permiso a los bolcheviques para celebrar una asamblea. Pero como la mayoría de las oradoras bolcheviques estaban en la cárcel, solo habló V. P. Menzhinskaia, haciendo un llamamiento a profundizar la lucha por el derecho al sufragio, la jornada laboral de ocho horas y la protección del trabajo femenino e infantil. Panova, una empleada de comercio, habló de las condiciones de las empleadas. Como la policía no permitió que las demás oradoras hablaran, la asamblea se cerró temprano, a las nueve en punto. Pero la multitud enojada e inquieta quería escuchar más y abucheó a la policía. Varios miles de personas se dirigieron esa noche a la Avenida de la isla Kamennyi ondeando banderas rojas y cantando la Marsellesa. A diferencia del año anterior,

40 La cita proviene de Бессонова А.Ф., К истории издания журнала «Работница»: Аокументы Института Маркса-Энгельса-Аенина-Сталина при ЦК КПСС. 1913-1914 // Исторический архив. 1955 гоА, №4, С. 37-39. [A.F. Bessonova, "Sobre la historia de la publicación de la revista Rabotnitsa: Documentos del Instituto Marx-Engels-Lenin-Stalin adscritos al Comité Central del PCUS", Archivo bistórico (Moscú), 1955, n 4, pp. 37-39.] Los estalinistas editaron un volumen con motivo de la celebración del 50 aniversario de la publicación de Rabotnitsa: А^ександра Артюхина, В. Голубева, С. Аюбимова, Всегда с вами. Сборник, посвященный 50цетию журнала «Работница» (1914-1964), Москва: Правда, 1964. [Aleksandra Artiujina, V. Golubeva, S. Lyubimov, Siempre contigo: Una colección dedicada al 50 aniversario de la revista 'Rabotnitsa' (1914-1964), Moscú: Pravda, 1964. 542 pp.] Existe también una tesis de maestría canadiense: Janet Hyer, Pre-Revolutionary Rabotnitsa: A Study of Bolshevik Policy towards Working Women, unpublished M.A. thesis, Carleton University, Ottawa, 1985, 116 pp. 
cuando se trató principalmente de un asunto de mujeres, en 1914 se cumplieron las esperanzas de los bolcheviques de convertir el Día Internacional de la Mujer en una fiesta de todo el proletariado, y los hombres de la clase trabajadora acudieron en gran número para conmemorar el Día de la Mujer. Detuvieron tranvías y autobuses, y pronto llegó una gran cantidad de policías para poner fin a la manifestación. Bajo los golpes de los látigos, el grupo se dispersó y algunos trabajadores fueron arrestados. Pero más tarde esa noche, un grupo de trescientos trabajadores se dirigió al Puente Troitskii gritando "¡Viva el Día de la Mujer!" y "¡Abajo el despotismo!". La policía dispersó a los manifestantes y arrestó a un par de trabajadores.

La celebración del Día Internacional de la Mujer en Moscú en 1914 fue más moderada debido a las medidas represivas adoptadas por la policía. Hubo algunas pequeñas asambleas de mujeres en fábricas y una asamblea organizada por trabajadoras domésticas. La asamblea más grande en Moscú fue organizada por un grupo de trabajadoras textiles en los bosques en las afueras de la ciudad, protestando por la prohibición de la celebración del Día de la Mujer. Como Pravda afirmó correctamente, la discriminación de clase de la sociedad zarista era muy evidente. Aunque a las trabajadoras se les prohibió celebrar el Día de la Mujer, el gobierno e permitió a la rama de Moscú de la Liga por la Igualdad de Derechos de las Mujeres que se reuniera. Más tarde, las feministas afirmaron que fueron objeto de un hostigamiento policial; sin embargo, no se sintieron obligadas a invitar a mujeres trabajadoras, a pesar de que todas sus asambleas habían sido prohibidas. Y cuando un grupo de trabajadoras textiles se presentó en la asamblea de la Liga sin ser invitadas, no se les permitió participar en el debate.

Las celebraciones del Día Internacional de la Mujer en 1914 en otras partes del imperio fueron estrictamente supervisadas, y en consecuencia el día transcurrió sin incidentes en la mayoría de las ciudades rusas. En Samara, donde los socialdemócratas habían organizado una conferencia pública sobre el tema de las "mujeres proletarias y su participación en las cooperativas", la policía clausuró la asamblea cuando estalló una animada discusión. En Kiev, donde todas las asambleas fueron prohibidas, los socialdemócratas distribuyeron proclamas en toda la ciudad en la noche del 23 de febrero. En Rostov del Don, la policía observó un gran entusiasmo por la celebración en los círculos proletarios e intelectuales, y proclamas conmemorando el Día Internacional de la Mujer fueron distribuidas en Kronstadt (Chatterjee 2002, pp. 31-35). 


\section{Las condiciones de las trabajadoras rusas según Rabotnitsa}

Se publicaron siete números del periódico Rabotnitsa entre el 23 de febrero y el 26 de junio de 1914, con intervalos de dos semanas entre cada número, hasta que la publicación debió suspenderse poco antes del estallido de la Primera Guerra Mundial. De los siete números, dos fueron confiscados por la policía. Aun así, Rabotnitsa consiguió abordar varios de los puntos centrales del programa socialista para las trabajadoras, incluyendo el seguro de maternidad, la protección del trabajo femenino, las guarderías, información sobre las condiciones de trabajo en las fábricas, el Día Internacional de la Mujer, el sufragio universal femenino, etc.

Las mujeres eran casi invariablemente empleadas en trabajos no calificados y semicalificados. En la industria textil, alimenticia, química y del calzado, las mujeres solían desempeñar los trabajos no calificados, mientras que los hombres realizaban el trabajo especializado de mantenimiento de las máquinas y de supervisión. Incluso en las industrias más especializadas, como la metalurgia y la industria gráfica, las mujeres casi siempre realizaban tareas no calificadas. Las mujeres eran los trabajadores peor pagados: el salario promedio en el sector textil era menos de la mitad que el de la metalurgia en 1916. La tasa de alfabetización entre las trabajadoras textiles era más baja que entre los trabajadores masculinos, aunque la brecha entre la alfabetización masculina y femenina se reducía considerablemente en los grupos de edad más bajos. Por ello, las militantes de las fábricas textiles eran generalmente reclutadas entre las trabajadoras jóvenes. ${ }^{41}$

No es sorprendente entonces que Rabotnitsa reportara una tendencia a la pasividad entre las trabajadoras, una ausencia de iniciativa y perseverancia en la lucha, una indiferencia general hacia la vida pública, junto con un sentido débilmente desarrollado de la solidaridad de clase y una escasa conciencia política. Un artículo de Rabotnitsa del 16 de marzo de 1914 se preguntaba: "¿Cuántas veces hemos oído que una huelga en ésta o aquella empresa falló porque

41 El censo sindical de 1918 indicó que la tasa de alfabetización de los trabajadores de Petrogrado era del $88,9 \%$ para los hombres y del $64,9 \%$ para las mujeres, en comparación con el promedio nacional del $79,2 \%$ para los hombres y el $44,2 \%$ para las mujeres. Era más alta entre los trabajadores metalúrgicos de Petrogrado, cuya tasa de alfabetización alcanzaba el 92\% para los hombres y el 70\% para las mujeres (Hasegawa 2017, p. 81). 
'entre los trabajadores había muchas mujeres', que varias fábricas no apoyaron a sus camaradas en huelga 'porque' entre los trabajadores había muchas mujeres, que una huelga terminó prematuramente y en consecuencia se perdió 'porque' entre los trabajadores había muchas mujeres?... Las mujeres son el grupo menos consciente. Se afilian menos a los sindicatos que los hombres, van con menos frecuencia a los clubes y a las conferencias." Dado que las obreras temían "no sólo por ellas mismas, sino por sus hijos", era "más difícil organizar una huelga de trabajadoras, convencerlas de la necesidad de llevarla a su conclusión." Incluso las mujeres jóvenes a menudo temían el activismo. Cuando se celebraron elecciones legales al consejo del fondo del seguro de salud en la fábrica de cigarrillos Laferme en 1914, "las mujeres mayores dijeron: '¿Para qué necesitamos un seguro de salud? De todos modos, somos demasiado viejas para dar a luz'. Pero incluso entre las trabajadoras jóvenes, muchas estaban asustadas por las elecciones. Algunas lloraron cuando fueron elegidas, diciendo: ¿YY si nos metemos en problemas por esto? ¿Qué pasará si nos arrestan?' Una joven trabajadora incluso dijo: ‘Gracias a Dios!' cuando supo que era demasiado joven para ser electa." Una nota publicada en Rabotnitsa el 19 de abril de 1914 sobre las condiciones laborales de las trabajadoras afirmaba:

Trabajando al lado de un hombre en la fábrica durante 1112 horas, y recibiendo por su trabajo un salario significativamente más bajo, unos centavos miserables, ¿no está la mujer, cuyo organismo es más débil, también agobiada por las tareas domésticas necesarias y pesadas? ¿Es fácil para ella, después del interminable trabajo en la fábrica, cuando el hombre puede relajarse, participar en la vida pública, leer y conversar con los camaradas sobre lo que ha leído, cuando, en lugar de todo esto, ella tiene que olvidarse de sí misma y dedicar cada minuto libre al cuidado de los niños? Tienen que lavar y reparar la ropa y alimentarlos. ¿Y con qué los alimentará si los precios suben continuamente y lo salario son tan bajos?... En este tipo de consideraciones, en estos cuidados y preocupaciones sobre el hogar, pasa todo el tiempo libre de la trabajadora con una familia, y apenas tiene tiempo para descansar, para su vida personal. Exhausta, enferma por el trabajo malsano e interminable de la fábrica, sin conocer la paz en el hogar, desde la mañana hasta la noche, día tras día, mes tras mes, la madre trabajadora trabaja como una esclava y sólo conoce necesidades, sólo preocupación y dolor. Su vida transcurre en la penumbra, sin luz. Envejece rápidamente. Está rota, ha sufrido hasta 
el cansancio en los años en que una persona debería disfrutar del florecimiento completo de sus fuerzas. $\mathrm{Y}$ muere sin haber conocido la felicidad en la vida; perece como un joven árbol roto.

Las mujeres a menudo ejercían una influencia restrictiva sobre las tendencias activistas de sus maridos. Según el testimonio de Rabotnitsa del 19 de abril de 1914, una trabajadora, recordando su relación con su difunto esposo, señalaba: "En esos días, a menudo me enojaba con mi esposo cuando se iba a una asamblea o porque se sentaba a leer un periódico. ‘¿Es asunto nuestro leer los periódicos? Está bien que los caballeros se dediquen a eso, pero ¿qué podemos sacar nosotros de leerlos?"

Otro artículo de Rabotnitsa, del 4 de mayo de 1914, ofrecía el siguiente testimonio de una obrera de la fábrica textil Kenig: "Nunca nos hemos adherido a las acciones colectivas del proletariado. Y si las trabajadoras en algunos establecimientos declaran una huelga, las trabajadoras en los otros establecimientos no acuden en su ayuda. A esto, compañeras de la fábrica Kenig, es a lo que nuestro aislamiento y falta de organización nos han llevado: explotan nuestra ignorancia. $\mathrm{Y}$ así será hasta que dejemos de considerar a nuestro jefe como un benefactor y a nosotras mismas como esclavas... La mayoría de las trabajadoras, incluida nuestra fábrica, se arrastran a la cola del movimiento obrero. No existe la militancia, la energía requerida en la lucha contra el capital." 42 Todo esto cambiaría drásticamente tres años después, cuando las trabajadoras pasaron de ser la retaguardia del movimiento obrero a transformarse en su vanguardia en la Revolución de Febrero de 1917.

En términos del número de trabajadoras atraídas por el movimiento de mujeres bolchevique, los resultados del periódico Rabotnitsa no fueron significativos. Pero los bolcheviques habían tomado la idea de un periódico para las trabajadoras en Rusia y habían ideado los comienzos de una técnica. Las editoras de Rabotnitsa mantuvieron contactos con grupos de mujeres trabajadoras en la capital desde su lugar de exilio en Novgorod y el periódico reaparecería con su antiguo nombre en mayo de 1917.

42 Todos estos testimonios de Rabotnitsa están tomados del libro de David Mandel, The Petrograd Workers and the Soviet Seizure of Power: From July Days 1917 to July 1918, London: Macmillan, 1984, pp. 38-39. 


\section{La revolución del 23 de febrero (8 de marzo) de 1917}

\section{La Primera Guerra Mundial y la Conferencia de Berna}

El estallido de la Primera Guerra Mundial el 28 de julio de 1914 resultó - como resultado de la presión de la burocracia sindical y partidaria dentro del SPD, que se manifestó antes de la guerra en una creciente marginalización de la organización de mujeres y de jóvenes dentro del propio partido ${ }^{43}$ - en la traición del internacionalismo proletario por parte de la socialdemocracia alemana, que votó a favor de los créditos de guerra en el Reichstag en agosto de 1914, y en el consiguiente colapso de la Segunda Internacional (Pannekoek 1914). Debido al aumento de la represión durante los años de la guerra en Rusia, y al exilio de las organizadoras bolcheviques como Samoilova y Kudelli, no tuvieron lugar celebraciones del Día Internacional de la Mujer en 1915 y 1916.

Durante la Primera Guerra Mundial, todas las organizaciones feministas rusas - la Sociedad de Ayuda Mutua de las Mujeres de Shabanova, la Liga por los Derechos de la Mujer de Shishkina-Ravein y el Partido Progresista de la Mujer de Pokrovskaia- se volvieron defensistas y llamaron a la "movilización de las mujeres" para la guerra, como lo hizo la sufragista Christabel Pankhurst en Gran Bretaña. Las principales publicaciones feministas respondieron con un coro de arrebatos patrióticos al estallido de la guerra y se volcaron entusiastamente a actividades que ayudaron al esfuerzo militar, adoptando el argumento de que el conflicto sería bueno para la igualdad de derechos. La revista La causa de las mujeres hizo un llamado a la unidad de las mujeres, apelando al patriotismo, al nacionalismo, al sacrificio y a una posible recompensa después de la guerra en su número del 1 de agosto de 1914.

Incluso Maria Pokrovskaia, una feminista esencialista que había escrito extensamente sobre la violencia de los hombres y que podría haber considerado a la guerra como otro ejemplo de la depravación de los gobiernos dominados por hombres, se unió a la "defensa de la madre patria". Los alemanes, argumentó,

43 Sobre este tema ver Cintia Frencia y Daniel Gaido, El marxismo y la liberación de las mujeres trabajadoras: de la Internacional de Mujeres Socialistas a la Revolución Rusa, Santiago de Chile: Editorial Ariadna, 2016, "La burocracia partidaria y sindical contra el radicalismo del movimiento de mujeres socialistas", pp. 62-65. http://oapen.org/search?identifier $=619630$ 
personificaban la violencia masculina. No era sólo la nación la que enfrentaba el asalto sino específicamente sus mujeres. En las páginas de su diario, El heraldo de la mujer, los informes de atrocidades se limitaban a los presuntamente cometidos por los alemanes. Un artículo en la edición de marzo de 1915 de El heraldo de la mujer, por ejemplo, afirmaba que se alentaba a los soldados alemanes a violar a las mujeres en los países conquistados.

Anna Shabanova se sumó con entusiasmo a la campaña de apoyo a la guerra, arrastrando con ella a la Sociedad de Ayuda Mutua. Polixena Shishkina-Iavein, la líder de la Liga Panrusa por la Igualdad de Derechos de las Mujeres, en un ensayo incluido en un folleto titulado ¿Qué puede esperar Rusia de la guerra?, argumentó que en el conflicto las mujeres rusas habían demostrado que ellas, al igual que los hombres, estaban contribuyendo al esfuerzo de guerra. Todas las organizaciones de mujeres trabajaban por el "bien de la nación". Las revistas feministas resaltaban los aspectos "positivos" de las hostilidades, aplaudiendo, como lo hicieron otros defensores de la templanza, la prohibición por parte del gobierno zarista de la venta de bebidas alcohólicas el 31 de julio de 1914. Las páginas de las publicaciones feministas estaban repletas de artículos que detallaban cómo las mujeres ayudaban a la causa cosiendo vendas, visitando enfermos y heridos, trabajando como enfermeras e incluso luchando como soldados. El trabajo de las mujeres "en defensa de la patria" fue visto como una forma de probar que eran dignas de la igualdad política (Ruthchild 2010, pp. 213-216).

En contraste con las posiciones de las feministas, no sólo las mujeres más prominentes del movimiento socialista internacional, como Angelica Balabanoff, Rosa Luxemburg, Clara Zetkin, Alexandra Kollontai e Inessa Armand, se opusieron a la guerra, sino que los cinco diputados bolcheviques en la Duma debieron pasar tres años en la deportación en Siberia por oponerse a votar los créditos de guerra y por denunciar al conflicto como una carnicería imperialista. ${ }^{44}$ En línea con esta posición política, los bolcheviques tomaron parte activa en la tercera y última conferencia de la Internacional de Mujeres Socialistas celebrada en Berna en abril de 1915, la cual, aunque presidida por Clara Zetkin, de hecho se organizó a iniciativa de los bolcheviques y adoptó un manifiesto con la consigna "¡Guerra a la guerra!”. La mayoría de las delegadas a la

44 Ver las memorias del diputado bolchevique en la cuarta Duma Aleksei E. Badayev, The Bolsheviks in the Tsarist Duma, New York: International Publishers, 1932. 
Conferencia de Berna, en la que participaron Inessa Armand, Krupskaya y Lilina Zinoviev, adoptaron una posición pacifista, pero las delegadas bolcheviques suscribieron la declaración por considerarla "un paso adelante". ${ }^{45}$

El Día Internacional de la Mujer sólo pudo ser celebrado en Rusia en 1915 y 1916 mediante proclamas y asambleas rápidas, debido a las condiciones de represión imperantes. Una empleada de la Fábrica de Tuberías de Petrogrado, Melaniia Savchenko, recordaba cómo su grupo de trabajadoras y unas pocas estudiantes de medicina distribuyeron la proclama del Día Internacional de la Mujer de 1915 a sus compañeras de trabajo, pero antes del siguiente Día Internacional de la Mujer en 1916 ya todas estaban en la cárcel, donde permanecieron hasta el 27 de febrero de 1917 (Stites, p. 290). Para el Día Internacional de la Mujer de 1916, el Comité de Petersburgo del Partido Bolchevique emitió la siguiente proclama en nombre de la "Organización de Mujeres Trabajadoras del POSDR":

\begin{abstract}
¡Compañeras trabajadoras! Hoy es el día de nuestra solidaridad; el día en que la trabajadora, habiendo roto sus antiguas cadenas de obediencia, esclavitud y humillación, se une orgullosamente a las filas del proletariado internacional para luchar contra el enemigo común: el capital. ¡Trabajadoras! El gobierno ha enviado a nuestros hijos a la crucifixión en aras del capital, así que construyamos nuestras propias organizaciones, reunámonos en fábricas y talleres, en las oficinas y detrás de los mostradores, y gritemos ante el capital insaciable: ¡Basta de sangre! ¡Abajo la guerra! ¡Llevemos a la autocracia criminal ante la justicia!'46
\end{abstract}

La proclama finalizaba con un llamamiento a la unión internacional de los trabajadores y las trabajadoras.

45 Sobre la Conferencia de Berna ver Cintia Frencia y Daniel Gaido, El marxismo y la liberación de las mujeres trabajadoras: de la Internacional de Mujeres Socialistas a la Revolución Rusa, Santiago de Chile: Editorial Ariadna, 2016, pp. 92-99. Ver también los documentos en Olga Hess Gankin and H. H. Fisher, The Bolsheviks and the World War: The Origin of the Third International, Stanford University Press, 1940, pp. 286-301.

46 Александр ШАяпников, Канун семнадуатого года. Т. 2: Семнадиатый год, М.: Гос.изА-во полит.литературы, 1992, С. 173. [Alexander Shliapnikov, La víspera del decimoséptimo año. T. 2: El decimoséptimo año, Moscú: Editorial estatal de literatura política, 1992, p. 173.] 


\section{E1 libro de Kollontai sobre el Seguro estatal de maternidad (1916)}

En 1916, cuando ya había vuelto a militar en las filas de los bolcheviques, Alexandra Kollontai publicó su libro Sociedad y maternidad. I. Seguro estatal de maternidad, un trabajo masivo de 641 páginas, producto de un largo interés en el tema. En un ensayo sobre la celebración del Día Internacional de la Mujer en Rusia en 1914 publicado en Die Gleichbeit en febrero de 1914 (No. 12, p. 180), Kollontai informaba que la agenda de la celebración incluía "las siguientes demandas: el derecho al sufragio femenino, la provisión estatal de la maternidad y la cuestión del alto costo de vida." La ley de seguros aprobada en 1912 contenía un anexo que se refería a las mujeres embarazadas y con hijos, pero que la aplicación de esta ley era muy limitada. La fracción socialdemócrata en la Duma del Estado estaba preparando un proyecto de ley para la provisión efectiva de la maternidad, pero Kollontai aclaraba que "la aprobación de este proyecto dependerá de la medida en que las masas apoyen enérgicamente a sus representantes en el parlamento" mediante movilizaciones masivas. En su "Autobiografía", Kollontai señala que, en 1913, "cuando presentaron en el seudoparlamento ruso (la Duma) un proyecto de ley sobre seguridad social, la fracción socialdemócrata de la Duma (el ala menchevique) me encargó elaborar un proyecto de ley sobre protección de la maternidad. No era la primera vez que dicha fracción había utilizado mis servicios para efectuar un trabajo legislativo. Ya antes de partir a mi exilio forzoso fui consultada, en calidad de profesional, sobre el tratamiento que debía darse al problema de Finlandia en la Duma imperial" (Kollontai 1976, p. 86).

La cuestión de la protección y de la provisión para la madre y el niño constituían, según Kollontai, una parte integral del programa socialista defendido por la clase trabajadora; estaba estrechamente relacionada con los objetivos básicos de dicha clase y no se podía resolver sin alcanzar su objetivo final. La forma de provisión de la maternidad adoptada por el gobierno en Alemania y tomada como modelo por muchos otros gobiernos, que comprendía el seguro para embarazadas y madres lactantes dentro de un sistema de seguro de salud, debía, según Kollontai, servir simplemente como una etapa de transición hacia un nuevo sistema fundado en un principio diferente, en el que la provisión de la nueva generación dejara de estar a cargo de los individuos y se trasladara a la sociedad, como una de las medidas conducentes a la emancipación femenina. El seguro integral de maternidad y la provisión para los niños 
pequeños tenían que implementarse como parte de un conjunto más amplio de políticas sociales que permitieran a la mujer desempeñar su rol de madre sin abandonar su trabajo, sin perder su independencia económica y sin retirarse de la participación activa en la lucha por los ideales de su clase.

La comunidad debía garantizar a las madres durante el embarazo, el parto y el período de lactancia la asistencia material necesaria para satisfacer las necesidades tanto de la madre como del niño. Si a cada mujer trabajadora se le garantizaba una licencia por maternidad adecuada antes y después del parto; si tenía la posibilidad de dar a luz a su hijo en condiciones saludables, con el cuidado apropiado para ella y para su niño; si se le daba la posibilidad de cuidar del niño durante las primeras semanas de su vida y de alimentarlo sin correr el riesgo de perder su ingreso, esto constituiría el primer paso hacia la emancipación de la mujer trabajadora. Si, además, el Estado y la comunidad se comprometían a construir viviedas para mujeres embarazadas y lactantes; a proporcionar atención médica gratuita a la madre y al niño, y a proveerlos de los alimentos y la ropa necesaria; si además se construía una amplia red de guarderías, jardines de infantes y centros para el cuidado de los niños donde la madre trabajadora pudiera dejar a su hijo sin sentirse preocupada, este sería un segundo paso adelante. Finalmente, si la legislación social asignaba la debida importancia a la protección del trabajo femenino; si establecía una jornada laboral corta, períodos de descanso para las madres lactantes y una jornada laboral reducida para las trabajadoras jóvenes; si tomaba las medidas necesarias para reemplazar los métodos de producción nocivos con técnicas menos perjudiciales para la fisiología femenina; si prohibía un número de prácticas laborales peligrosas, etc., este sería un tercer paso adelante hacia la emancipación de la mujer trabajadora. Mientras la familia había sido fuerte, estable y viable; mientras la mujer vivía y trabajaba exclusivamente dentro de la familia, la cuestión de proteger y proporcionar los medios materiales necesarios para la maternidad no podía haber surgido. Fue sólo cuando la familia dejó de ser una unidad de producción, cuando la desaparición del campesinado y del artesanado condujeron a la generalización el trabajo asalariado bajo el capitalismo, y ante todo del trabajo de las mujeres fuera del hogar, que surgió la posibilidad de la crianza y de la educación socializada de los niños. Kollontai concluía con estas palabras:

Esa visión del seguro de maternidad, que lo ve como una medida para aligerar la carga de la maternidad para la mujer de la clase trabajadora y, al mismo tiempo, como 
una medida que alienta la transferencia de la preocupación por la nueva generación de los individuos privados [los padres] a la comunidad, es aceptable sólo si se admite que la forma presente de familia colapsará inevitablemente y se desintegrará en el curso de la futura evolución histórica de la sociedad... Hoy, cuando la familia como unidad social específica no cumple funciones de producción dentro del orden burgués, con su división generalizada del trabajo y el principio individualista de la producción, ya no hay argumentos positivos que puedan justificar dejar toda la responsabilidad por la nueva generación en manos de esta unidad privada... Lógicamente, la responsabilidad de la nueva generación debería recaer en la nueva unidad económica, en ese colectivo social que necesita de la nueva generación para su propia existencia futura. Dado que la familia ha dejado de existir como unidad económica y que ha dejado de requerir una afluencia de mano de obra nueva; dado que las personas reciben lo que necesitan para vivir, no de la familia, sino de la comunidad en general, el cuidado de los niños pequeños y de las madres que las dan a luz también deberían ser responsabilidad de esa comunidad. Tal argumento, sin embargo, es aceptable sólo para una sociedad que esté genuinamente preocupada por cuidar de sus miembros -es decir, para una sociedad socialista. ${ }^{47}$

El análisis de Kollontai en Sociedad y maternidad cerraba con este razonamiento, aceptable en términos generales para todos los marxistas. Luego de la Revolución de Octubre de 1917, Kollontai extraería de dicho análisis una serie de conclusiones sobre el carácter de las relaciones sexuales, de pareja y familiares bajo el socialismo que la acercarían a las teorías anarquistas sobre el amor libre, y que por ende dieron lugar a un debate en el seno de la cúpula bolchevique que documentamos en otro trabajo. ${ }^{48}$

47 Александра Комлонтай, Общество и материнство. I. Государственное страхование материнства. Пг.: Жизнь и Знание, 1916. [Alexandra Kollontai, Sociedad y maternidad. I. Seguro de maternidad estatal, Petrogrado: Vida y conocimiento, 1916.] La Introducción al libro fue traducida al inglés como "Preface to the Book Society and Motherhood", en Alexandra Kollontai, Selected Articles and Speeches, Moscow: Progress Publishers, 1984. Disponible online en el Marxists Internet Archive. Kollontai publicó un adelanto en alemán de su libro: Alexandra Kollontay, "Staatliche Mutterschaftsversicherung", Die neue Zeit, 33. 1914-1915, 1. Bd. (1915), H. 11/12, S. 363-371.

48 Cintia Frencia y Daniel Gaido, El marxismo y la liberación de las mujeres trabajadoras: de la Internacional de Mujeres Socialistas a la Revolución Rusa, Santiago 


\section{El Día Internacional de la Mujer de 1917 y la Revolución de Febrero}

Del 18 de julio de 1914 al 1 de octubre de 1916, 40.000 trabajadores industriales en Petrogrado fueron enrolados y enviados al ejército. Sin embargo, el número de trabajadores en la capital aumentó en 148.200 durante los tres años transcurridos entre 1914 y 1917. Esto significa que hubo una afluencia de aproximadamente 180.000 trabajadores a las filas de la clase obrera. Los campesinos constituían entre el $50 \%$ y el $75 \%$ de los trabajadores recién contratados. La segunda fuente de nuevos trabajadores fueron las mujeres y los niños. El número de mujeres aumentó en todos los sectores de la industria. Las mujeres predominaban en la industria textil antes de la guerra, constituyendo el 57\% del total de trabajadores textiles, pero la proporción de mujeres aumentó aún más durante la guerra, hasta llegar al 6\%. En la industria alimentaria, las mujeres constituían más de la mitad de la fuerza de trabajo. Incluso en la industria metalúrgica, donde en tiempo de paz sólo había habido un pequeño número de mujeres trabajadoras $(2,7 \%)$, el aumento de mujeres trabajadoras llegó a constituir más de una quinta parte durante la guerra. A principios del año 1917 había en total 129.800 mujeres trabajadoras en las fábricas de Petrogrado (Donald 1982, p. 131).

A pesar de la gran afluencia de mano de obra femenina a Petrogrado, hasta comienzos de 1917 las mujeres estuvieron empleadas predominantemente en los sectores industriales que no participaron en el movimiento huelguístico durante la guerra. Para comienzos de 1917, el descontento había llegado a las trabajadoras anteriormente desorganizadas de las fábricas textiles. El movimiento huelguístico que inició la revolución de febrero provino de estas trabajadoras.

La guerra impuso una tremenda carga a las mujeres trabajadoras, ya que el sustento de la familia a menudo caía sobre sus hombros, cuando los esposos y los padres eran enviados al frente, fallecían o eran heridos en la guerra. Trabajaban largas horas por un

de Chile: Ariadna Ediciones, 2016, pp. 129-139. Los dos ensayos en los que Kollontai desarrolló estas ideas se titulan "Tesis sobre la moral comunista en el ámbito de las relaciones conyugales” (1921) y "¡Abran paso al Eros alado! (Una carta a la juventud obrera)" (1923). Para una respuesta contemporánea ver Polina Vinodgraskaya, “El 'Eros alado' de la camarada Kollontai” (1923). Todos estos textos están disponibles online en castellano en el Marxists Internet Archive. 
salario escaso, y luego tenían que hacer las tareas domésticas cuando regresaban a casa. El cuidado de los niños era un problema gravísimo. Algunas grandes fábricas establecieron sus propias guarderías, y había una guardería cooperativa en el distrito de Vyborg. La ausencia de madres en el hogar también contribuyó a un fuerte aumento en el número de delitos cometidos por menores, que aumentó de 1.860 en 1913 a 1.987 en 1914, 2197 en 1915 y 3.301 en 1916, un aumento del 7\%. Todo esto, sumado a la carga de trabajo adicional impuesta por la introducción de horas extras en la industria, ahora abocada mayormente a la producción de guerra, así como las interminables colas en las panaderías y demás centros de abastecimiento de comestibles, transformaron a las mujeres de la retaguardia en la vanguardia de la revolución (Hasegawa 2017, pp. 7986).

El 13 de febrero de 1917, la Duma de la ciudad de Petrogrado aprobó por unanimidad la propuesta de introducir el racionamiento, que comenzaría a principios de marzo. Después de tomar esta decisión, se difundieron rumores de que el racionamiento de alimentos, que restringiría el consumo de pan per cápita, se introduciría en el futuro cercano. Esto causó pánico. Enormes colas se formaron frente a panaderías, y hubo incidentes dispersos de ataques a panaderías. No sólo desaparecieron los alimentos, sino también otros materiales esenciales: botas, chanclos, telas, jabón y medicamentos. La leña era tan costosa que muchas personas se vieron obligadas a decidir si debían calentar sus casas y sobrevivir con raciones casi de inanición o, si debían comer, pero morir congelados. Esto era particularmente difícil para los niños, que habían sido privados de leche, huevos, té y manteca, y que ahora se encontraban en la situación precaria de perder la última fuente vital de alimento: el pan. Un agente de Ojrana (la policía secreta zarista) comentó proféticamente: "El resentimiento es peor en las familias numerosas, donde los niños se mueren de hambre en el sentido más literal de la palabra, y donde no se escuchan otras palabras excepto 'paz, paz inmediata, paz a toda costa'. Y estas madres, exhaustas por estar de pie interminablemente en las colas, y por haber sufrido tanto viendo a sus niños medio muertos de hambre y enfermos, están quizás más cerca de una revolución que los Sres. Miliukov, Rodichev y Cía [líderes del Partido kadete]. Y por supuesto, son mucho más peligrosas, ya que son reservas de material inflamable, que sólo necesitan una chispa para incendiarse" (Hasegawa 2017, p. 187).

A pesar de que el Día Internacional de la Mujer había sido celebrado en Rusia en 1913 y 1914, el 23 de febrero (8 de marzo) no 
estaba tan bien integrado en la tradición del movimiento obrero ruso como el Primero de Mayo o el 9 de enero (el aniversario del "Domingo Sangriento" de 1905). Así, cuando se acercó el Día Internacional de la Mujer en 1917, no es sorprendente que ninguno de los partidos socialistas rusos lo recibiera con el entusiasmo y la determinación necesarios.

Desde finales de diciembre de 1916, los miembros la Organización Inter-Distritos de Petrogrado (межрайонцы: Mez̧braiontsy) habían intentado organizar una acción conjunta con el Comité Bolchevique de Petersburgo y el Grupo Iniciativa (Menchevique) para celebrar juntos el Día Internacional de la Mujer, pero las tres organizaciones no pudieron ponerse de acuerdo sobre las consignas y decidieron actuar de forma independiente. El Grupo Iniciativa dedicó un número de su revista, Trud (Trabajo), a la celebración del Día Internacional de la Mujer. Los Mę̧raiontsy fueron los más activos, logrando distribuir volantes entre los trabajadores, que explicaban en un lenguaje simple que los trabajadores, especialmente las mujeres, eran víctimas de la guerra, que continuaba generando enormes ganancias para los capitalistas. Enfatizando que su miseria y su hambre no serían eliminados a menos que el sistema capitalista fuera derrocado, el folleto instaba a los trabajadores a movilizarse: "Es hora de decirles en voz alta: ¡Basta! ¡Abajo con el gobierno criminal y toda su banda de ladrones y asesinos! ¡Viva la paz!". Los Mę̧braiontsy celebraron una serie de asambleas "educativas" del 20 de febrero al 23 de febrero de 1917 en la fábrica Aivaz y en la cooperativa de trabajadores Obedinenie. Varios días antes del 23 de febrero, los Mę̧raiontsy, anticipándose a una huelga general, recomendaron la elección de comités de fábrica, de distrito y de toda la ciudad.

Los bolcheviques no publicaron ningún volante ese día, ya que la imprenta del Comité de Petersburgo había sido destruida por una redada policial. La inacción bolchevique, sin embargo, fue el resultado de la política del Buró del Comité Central en Rusia, dirigida por Shliapnikov, más que de dificultades técnicas. El Buró, considerando la acumulación de fuerzas organizativas del partido como su tarea más urgente, ordenó a los órganos inferiores de los partidos que no desviaran su energía innecesariamente en esta ocasión y que restringieran sus actividades a la propaganda entre las trabajadoras. Esta política despertó resentimiento entre las militantes del Partido Bolchevique en el distrito de Vyborg, que abogaban por una acción más audaz y querían llamar a una huelga (Hasegawa 2017, pp. 201-202). 
El 22 de febrero, un trabajador bolchevique de la fábrica de Erikson y miembro del comité del distrito de Vyborg del partido bolchevique, Vasily Kaiurov, organizó una asamblea de trabajadoras, en la que explicó el significado del Día Internacional de la Mujer, la historia del movimiento de liberación de las mujeres trabajadoras y, sobre todo, el significado de la lucha contra la guerra. Kaiurov, sin embargo, instó firmemente a la audiencia a abstenerse de movilizarse y a seguir sólo las instrucciones del Partido Bolchevique. En otras palabras, incluso militantes bolcheviques fogueados como Kaiurov subestimaron la desesperación y la ira de las trabajadoras, quienes tomaron la iniciativa desobedeciendo las instrucciones expresas de los propios bolcheviques, como lo recordaba el propio Kaiurov seis años después:

La víspera del "Día de la Mujer" me habían enviado a una asamblea de obreras en Lesnaia, donde definí el sentido del "Día de la Mujer" y del movimiento femenino en general; al llegar al momento actual, insistí, sobre todo, en invitar a las obreras a evitar toda manifestación parcial y a actuar exclusivamente bajo las instrucciones del Comité del partido [...].

Entonces, cuáles no serían mi sorpresa e indignación cuando al día siguiente, el 23 de febrero, en un pasillo de la fábrica Erikson, el camarada Nikífor Ilitch vino a informarme del estallido de una huelga en varias fábricas textiles y de la llegada de una delegación de obreras que traían una resolución donde pedían el apoyo para los metalúrgicos.

Estaba indignado con la conducta de las huelguistas: en primer lugar, porque manifiestamente éstas habían hecho caso omiso de las decisiones del Comité Regional del Partido, pero, además, porque había llamado personalmente a las obreras a la contención y a la disciplina la noche anterior $\mathrm{y}$, de repente, una huelga.

Una huelga que, al parecer, no tenía más objetivo ni razón de ser que las colas, esencialmente compuestas de mujeres y niños, que se formaban delante de las panaderías para conseguir el pan. ${ }^{49}$

49 Василий Николаевич Каюров, “Шесть Аней Февральской революции” // Пролетарская револючия. 1923. No 1 (23), с. 157-170. [Vasily Nikolaevich Kayurov, "Seis días de la Revolución de Febrero", Revolución proletaria, 1923, No 1 (23), pp. 157-170. Citado en Marie 2010, p. 449.] 
Las huelgas de mujeres se extendieron rápidamente a otras fábricas en el distrito de Vyborg. En la mañana del 23 de febrero se celebraron asambleas ilegales en varias fábricas textiles en el distrito de Vyborg. Cinco de los más grandes —Nikolskaia (1.497 trabajadoras), Vyborg (755), Nevka (2.748), Sampsonievskaia (1.592) y Lebedev (998) - se concentraron a lo largo de la orilla del río Neva y de la avenida Sampsonievskii. Si bien las trabajadoras de otras fábricas textiles no habían sido arrastradas al movimiento huelguístico, las mujeres de estas fábricas habían participado activamente en el movimiento de huelga durante la guerra. Ahora abandonaron el trabajo al final de sus asambleas y marcharon a las fábricas vecinas, gritando simplemente “¡Pan!”.

La fábrica textil Nevka estaba ubicada entre dos grandes fábricas metalúrgicas, Nueva Lessner y Erikson. Las mujeres se trasladaron a estas fábricas, apelando a los trabajadores metalúrgicos a unirse a su huelga, gritando: “PPan!” y arrojando piedras a las ventanas de las fábricas. Cuando la policía arrestó a una mujer, ella le gritó al policía que la arrestaba: "No tienen mucho tiempo para divertirse, ipronto estarán colgando de sus cabezas!".

La huelga y la demostración iniciada por las trabajadoras textiles impulsaron a los militantes bolcheviques a adoptar medidas urgentes. Por un lado, sabían que el Buró Ruso del Comité Central era reacio a apoyar la acción directa en ese momento. Por otro lado, no podían ignorar y aislar a las compañeras trabajadoras que habían iniciado el movimiento huelguístico. En las asambleas celebradas en los patios de las fábricas, se pusieron al frente del movimiento que los había tomado por sorpresa. La huelga iniciada por las trabajadoras textiles que exigían pan se transformó de esa manera en una manifestación política dirigida por los elementos experimentados y conscientes de la clase trabajadora (Hasegawa 2017, pp. 206-207). ${ }^{50}$

50 "No es difícil ver que la causa directa de la huelga del 23 de febrero fue la escasez de alimentos. El eslogan 'Pan' llevó a las trabajadoras textiles del distrito de Vyborg a la calle. Unió a los trabajadores en huelga con las mujeres y los jóvenes haciendo largas colas, mientras ponía nerviosos a los soldados enviados para reprimir a los manifestantes. Pero la huelga del 23 de febrero no fue simplemente un motín de pan. La demanda de pan fue una expresión simbólica de su profunda desaprobación del sistema en sí. A pesar de la persistente afirmación de que la Revolución de Febrero fue una revolución 'espontánea', esta afirmación debe ser descartada. Tan pronto como comenzó la huelga de las trabajadoras textiles con el lema '¡Pan!', los elementos 'conscientes', los activistas experimentados de las grandes fábricas 
El segundo número del periódico bolchevique Pravda, publicado el 7 de marzo de 1917, decía lo siguiente sobre el papel del Día Internacional de la Mujer en la Revolución de Febrero, en un artículo anónimo titulado "Un Gran Día":

Mucho antes de la guerra, la Internacional proletaria designó al 23 de febrero como el Día de Internacional de la Mujer.

El 23 de febrero es el Día de la Mujer, como el $1^{\circ}$ de mayo es el día del proletariado de todo el mundo.

Hace una semana, el 23 de febrero, en Petrogrado, el antiguo gobierno impidió que las trabajadoras celebraran su día.

Y debido a esto, los primeros enfrentamientos tuvieron lugar en las manifestaciones, y la revolución comenzó en la fábrica de Putilov.

El primer día de la revolución es el Día de la Mujer, el Día de la Mujer de la Internacional de los Trabajadores.

¡Gloria a la mujer!

¡Gloria a la Internacional!

Las mujeres fueron las primeras en tomar las calles de Petrogrado en su Día de la Mujer.

En muchos casos, las mujeres de Moscú decidieron el destino de las tropas: entraron en los cuarteles, persuadieron a los soldados, y los soldados se pusieron del lado de la revolución.

¡Gloria a la mujer!

En los tristes años de la guerra, la mujer asumió sobre sus hombros una carga sin precedentes: la angustia de los seres queridos, llevados a la guerra, se alternó con el dolor de los niños hambrientos.

Y la mujer no se desesperó. Ella levantó la bandera de la revolución.

¡Gloria a la mujer trabajadora!

En los días en que las autoridades sembraban y fomentaban el chauvinismo y el odio sin sentido de algunas naciones contra otras, la trabajadora se levantó al llamado de la Internacional hace cinco años [cuando celebró por primera vez del Día Internacional de la Mujer en Rusia en 1913].

¡Gloria a la Internacional!

El Día de la Internacional de la Mujer condujo a una revolución.

metalúrgicas, se unieron a la misma y asumieron el liderazgo de la huelga y de la manifestación” (Hasegawa 2017, pp. 218). 
Y la revolución seguirá siendo fiel a este día.

La revolución liberará a la Mujer Trabajadora del dolor y

de los horrores de la guerra.

La revolución revivirá, con una fuerza sin precedentes, la

fraternidad de los trabajadores de todos los países, la

Internacional se reconstituirá.

Esta será la Tercera Internacional.

El 23 de febrero -el Día de la Mujer- es el día de la

Revolución Rusa, el primer día de la Tercera Internacional.

Un gran día para los trabajadores de todo el mundo.

¡Gloria a la mujer! ¡Gloria a la Internacional!

¡Gloria a la gran revolución rusa!

¡Proletarios de todos los países, uníos!51

El artículo "Un Gran Día" había sido también publicado como un folleto por el Comité Central del Partido Bolchevique unos cinco días antes, en las postrimerías de la Revolución de Febrero (Donald 1982, p. 132, nota 12).

\section{La organización de mujeres bolcheviques y la Revolución de Octubre}

\section{Las asambleas de trabajadoras después de la Revolución de Febrero}

Después de la Revolución de Febrero, que resultó en la abdicación del zar Nicolás II, los soviets, bajo la dirección de los mencheviques y de los socialistas revolucionarios, cedieron graciosamente el poder a un Gobierno Provisional burgués no elegido, salido del Comité Provisional de la Cuarta Duma, que continuó la guerra imperialista y que pospuso la reforma agraria hasta la elección de una Asamblea Constituyente en un futuro indefinido. Sin embargo, dado que los mismos soviets habían ordenado la elección de comités de soldados en el ejército y que les habían dado instrucciones a éstos de desobedecer las órdenes de los oficiales contrarios a los decretos del Soviet de Diputados de Trabajadores y de Soldados, el resultado final fue la inestable estructura de doble poder, signada por constantes crisis gubernamentales. La Revolución de

51 Великий день // Правда № 2 Вторник 7 марта [20 марта] 1917 г. [“Un Gran Día”, Pravda, martes 7 de marzo (20 de marzo) de 1917.] http://istmat.info/node/28027 
Febrero encontró a la mayoría de la dirección bolchevique en la deportación o en el exilio: Kamenev y Stalin retornaron a Petrogrado el 13 de marzo, Kollontai pudo retornar el 18 de marzo, Lenin, Kruspakaya y Armand el 3 de abril, Trotsky (quien se incorporó al partido bolchevique en julio) recién el 4 de mayo.

Las páginas de Pravda en el primer mes después de la Revolución de Febrero reflejan la creciente actividad política de las mujeres: casi todos los números contienen informes sobre asambleas de mujeres, que generalmente llamaban a las trabajadoras a organizarse en sindicatos, y cuyas demandas normalmente incluían puntos de especial preocupación para las mujeres trabajadoras, como la plena igualdad de derechos, el seguro para las trabajadoras y la protección de la maternidad, así como las demandas habituales de una jornada laboral de ocho horas, una república democrática y la redistribución de la tierra. Estas asambleas no fueron de ninguna manera insignificantes: los artículos a menudo informaban de una asistencia de alrededor de mil personas. ${ }^{52}$

Algunas de las notas en Pravda eran simples llamados a asambleas de trabajadoras, como este anuncio del 9 de marzo: "Las trabajadoras del distrito de Vyborg están invitadas a una asamblea de mujeres para discutir los temas planteados por el momento actual. Avenida Finlandia, $\mathrm{N}^{\circ}$ 8, Teatro de arte, el domingo 12 de marzo, a las 2 en punto de la tarde." 53 Pero otros artículos contenían informes de las resoluciones adoptadas por dichas asambleas; por ejemplo la nota "Asamblea de mujeres de la región de Moscú" informaba sobre una asamblea celebrada el 7 de marzo en la Bolsa de Trabajo, Avenida Zabalkansky, la cual adoptó la siguiente resolución:

La asamblea de mujeres de la región de Moscú, al discutir la situación del país y la situación de las mujeres en las condiciones existentes, reconoció que es necesario lograr:

52 Moira Donald, "Bolshevik Activity amongst the Working Women of Petrograd in 1917", International Review of Social History, Vol. XXVII, 1982, pp. 134-135. Donald agrega: "Para las cifras de asistencia, ver Pravda, Nos 6 (11 de marzo), 9 (15 de marzo) y 12 (18 de marzo)." (nota 22 en ibid.). Existe un estudio sobre el rol de las trabajadoras en 1917 publicado durante la era estalinista: Надежда А. Карпецкая, Работницы и Великий Октябрь, ИзАво Аенинградского университета, 1974. [Nadezhda Denisovna Karpetskaya, Las trabajadoras y la gran revolución de octubre, Editorial de la Universidad de Leningrado, 1974. 135 p.]

53 Женщины-работницы Выборгского района // Правда № 4, 9 марта [22 марта] 1917 г. [“Trabajadoras del distrito de Vyborg”, Pravda, N 4, 9 de marzo [22 de marzo] de 1917, p. 9] 
1) La República Democrática, la jornada laboral de 8 horas, la confiscación de las tierras señoriales, monásticas y de la corona para los campesinos.

2) La igualdad total de las mujeres.

3) La protección del seguro social y de la legislación laboral para las mujeres, la prohibición total de las horas extras y del trabajo nocturno para las mujeres y los niños.

Para lograr todo esto, es necesaria una lucha organizada del proletariado revolucionario y del ejército revolucionario.

¡Organícense, mujeres! 54

El 10 de marzo de 1917, en Pravda № 5, un artículo de la hermana de Lenin, Anna Elizarova-Ulianova, escribiendo bajo el seudónimo "Olga Bobyleva", describía el desarrollo de las trabajadoras rusas de 1905 a 1917, enfatizando que las trabajadoras "independientemente, por iniciativa propia, comenzaron a participar en la revolución, a aprender por su propia cuenta”. La mejor prueba estaba en que la Revolución de Febrero había sido iniciada por ellas. Como consecuencia, la mujer trabajadora podía ahora "pararse junto al obrero, acompañarlo para conquistar ese brillante ideal de igualdad socialista, que ella tiene en común con él."

Pero para esto ella necesita obtener las mismas condiciones de lucha que el hombre trabajador, y ella demostró que tiene derecho a exigirlas por sí misma. Ella necesita el mismo derecho que el hombre a participar en las elecciones, el derecho a ser elegida a la Asamblea Constituyente, a los municipios, a las organizaciones locales de los remstva y volost. Ella necesita el mismo derecho que el hombre a estudiar y a ocupar todo tipo de puestos en el estado para los cuales demuestre ser capaz, ganar lo mismo que él, tener los mismos derechos que él sobre los niños. Todo esto debe ser logrado por la mujer rusa, y ella los logrará luchando en el mismo campo que el hombre trabajador, en estrecha asociación con él. Pero para lograr esto, ella debe desplegar toda la iniciativa y la energía de la que sea capaz; debe reconstruir sus organizaciones sindicales, debe ingresar a todas las células

54 Собрания женщин Московского района // Правда № 8, 14 марта [27 марта] 1917 г. [“Asamblea de mujeres de la región de Moscú”, Pravda No. 8, 14 de marzo (27 de marzo) de 1917.] 
del partido en las fábricas y en las organizaciones del partido, debe restaurar su órgano, Rabotnitsa. ${ }^{55}$

El sufragio femenino fue demandado por asambleas de trabajadoras inmediatamente después del derrocamiento del zar, comenzando por las trabajadoras del distrito de Vyborg, una fortaleza bolchevique y el punto de partida de la principal manifestación del Día Internacional de la Mujer el 23 de febrero. Según el informe de Pravda:

El 13 de marzo, a las 2:00 pm, se realizó una asamblea de mujeres en las instalaciones de la Hermandad Cristiana. Asistieron a la misma 800 trabajadoras. Después del informe y del debate sobre el movimiento de mujeres, se adoptó la siguiente resolución:

"1) Nosotras, las mujeres proletarias, exigimos el derecho al sufragio universal, directo, igual y secreto, sin distinción de sexo y nacionalidad, para poder defender nuestros derechos nosotras mismas.

"2) Las mujeres proletarias defenderán firme y enérgicamente su derecho a participar en la Asamblea Constituyente para la implementación de un sistema democrático- republicano en Rusia.

"3) El movimiento de mujeres proletarias está en sintonía con el movimiento de toda la clase trabajadora, con la que comparte intereses comunes, y se separa del movimiento de mujeres burgués.

"4) Las mujeres proletarias luchan junto con los trabajadores masculinos no sólo por la plena libertad democrática, sino también por la destrucción del sistema capitalista en sí.

"5) Junto con el requisito de participar en la Asamblea Constituyente, las trabajadoras demandan una pronta introducción, por medios legislativos, de las siguientes reformas: a) Protección completa de la maternidad. b) Seguro para los trabajadores. c) Elección de inspectores de fábricas, con la participación directa de representantes de las mujeres." 56

55 Ольга Бобылев. Привет русской работнице // Правда № 5. 10 марта [23 марта] 1917 г. С. 8-9. [Olga Bobyleva, "Saludos a la trabajadora rusa", Pravda, No. 5, 10 de marzo (23 de marzo) de 1917, pp. 8-9.] http://istmat.info/node/28027

56 Женский митинг // Правда № 9. 15 марта [28 марта] 1917 г. С. 10. ["Asamblea de mujeres", Pravda, No. 9, 15 de marzo (28 de marzo) de 1917, p. 10.] http://istmat.info/node/ 28027 


\section{La manifestación feminista por el sufragio femenino}

Las feministas, por su parte, tampoco permanecieron pasivas. La revolución de febrero de 1917 revitalizó a la Liga Panrusa por la Igualdad de Derechos de las Mujeres y resultó en su logro más significativo. Ante el fracaso del Gobierno Provisional en apoyar la promulgación inmediata del sufragio femenino, el 19 de marzo de 1917 la Liga organizó una manifestación de aproximadamente 40.000 mujeres, dirigidas por Shishkina-Iavein y Vera Figner, una ex-heroína terrorista a quien las feministas habían ganado para su causa, montadas sobre un automóvil descapotado flanqueado por mujeres montando caballos blancos. La manifestación comenzó en la Duma de la ciudad de Petrogrado y se desplazó por la calle principal de Petrogrado, la Avenida Nevski, dirigiéndose a la sedel del Gobierno Provisional y del Soviet en el Palacio Táuride. En la manifestación se enarbolaron banderas con eslogans tales como "El lugar de la mujer es en la Asamblea Constituyente" y "Guerra hasta la victoria". ${ }^{57}$

Figner y Shishkina-Iavein buscaron el apoyo tanto del Soviet como del Gobierno Provisional, pero primero fueron a reunirse con los líderes del Soviet. Mientras aclamaba a Figner como una luchadora por la libertad, M.I. Skobelev, uno de los líderes mencheviques del Soviet, afirmó que no podía apoyar las demandas de las manifestantes sin consultarlo con los otros dirigentes. Kollontai, que acababa de regresar del exilio, se esforzó por contener su exasperación cuando Vera Figner añadió su propio discurso a las súplicas patrióticas hechas por la Dra. Shishkina-Iavein y por la kadete Ariadna Tyrkova. La multitud esperó, y finalmente exigió que Nikolai Chjeidze, el presidente del Soviet, y Mijail Rodzianko, presidente de la Duma, se reuniera con ellas. Finalmente, Chjeidze salió del Palacio Táuride y afirmó ante las mujeres congregadas que el Soviet lucharía con ellas por sus justos derechos. Ante esto, Kollontai no pudo contenerse más, y denunció a todos los que colaboraban para prolongar los horrores de la guerra. "TTodo el poder a los soviets!", gritó, y fue rápidamente arrastrada por un "patriota". Las feministas indignadas se apresuraron a atacarla y varios soldados la amenazaron con sus bayonetas, pero otras mujeres, así como algunos soldados, la apoyaron (Porter 1980, pp. 238-239). Rodzianko, aún

\footnotetext{
57 Existe una filmación de la manifestación feminista-defensista del 20 de marzo de 1917, disponible online en Davis Center for Russian and Eurasian Studies, 1917 Petrograd March for Women's Suffrage (March 19, 1917) https://youtu.be/LLOQASmngrE
} 
dubitativo, sugirió que las manifestantes apelaran directamente al Príncipe Lvov, el jefe del Gobierno Provisional. Shishkina-Iavein y Figner ingresaron al Palacio Táuride para reunirse con él. Lvov primero rechazó las demandas de las mujeres, diciendo que las reglas electorales ya habían sido anunciadas y que no podían ser revisadas, pero finalmente cedió, aceptando que el término "sufragio universal" incluyera también a las mujeres.

Dos días después, el 21 de marzo, una delegación de mujeres de Petrogrado y Moscú, que incluía una muestra representativa de líderes feministas y liberales, se reunió con Lvov. Las facciones feministas ahora estaban unificadas; la delegación incluía a Figner y Shishkina-Iavein, Shabanova, Miliukova y Tyrkova, Olga K. Nechaeva de la Unión Rusa de Organizaciones Democráticas de Mujeres, Pokrovskaia, la condesa filántropa Sofía Panina, Viceministra de Bienestar del Estado y Viceministra de Educación en el Gobierno Provisional, A.N. Rinkevich, Alexandra Kalmykova, una de los primeras patrocinadoras del "marxismo legal", y las Dras. M.I. Nikolskaia y E.V. Gorovits, representantes de las mujeres de Moscú. No hubo mujeres trabajadoras ni socialistas entre las delegadas. Figner presentó a Lvov una breve declaración sobre los derechos de las mujeres y pidió que los ministros del Gobierno Provisional expresaran formalmente su posición sobre el tema. Lvov respondió afirmando que los ministros apoyaban unánimemente el sufragio femenino y que se estaba redactando una ley que otorgaría la igualdad política a las mujeres. Las mujeres de la delegación estaban jubilosas y Pokrovskaia declaró: "¡Viva la ciudadana libre e igual!". Como resultado de la aquiescencia de los líderes del Gobierno Provisional a las demandas de las feministas, dos miembros de la Liga de Mujeres pasaron a formar parte de en la comisión electoral cuando ésta comenzó a reunirse a fines de mayo, y la ley electoral del 20 de julio ratificó el derecho de las mujeres rusas a votar y a postularse como candidatas en las próximas elecciones a la Asamblea Constituyente.

Pero el Gobierno Provisional otorgó estos derechos a las "ciudadanas libres e iguales" con el objetivo de asegurar el apoyo de las mujeres para la continuación de la guerra imperialista y de transformarlas en carne de cañón. Poco después de la "victoria del sufragio", Rodzianko se acercó a Maria Bochkareva para que creara un batallón de mujeres. ${ }^{58}$ Animadas por su nuevo "estatus de

58 Ver su autobiografía: Yashka: My Life as Peasant, Officer and Exile, by Maria Bochkareva, Commander of the Russian Women's Battalion of Death, as set 
igualdad", algunas mujeres respondieron a las apelaciones para "adoptar toda la gama de roles de ciudadanía". El reclutamiento para los Batallones de la Muerte de Mujeres (Женские батальоны смерти), de los cuales 15 fueron creados en 1917, enfatizaba los "nuevos derechos y obligaciones" de las mujeres como ciudadanas.

Habiendo obtenido la promesa de la ciudadanía plena, muchas líderes feministas vincularon la causa de la igualdad de derechos con la victoria aliada. Organizaron una serie de asambleas dedicadas tanto a obtener la "igualdad de derechos" como a organizar el esfuerzo militar. A invitación de Shabanova, las sufragistas británicas Emmeline Pankhurst y Jessie Kenney fueron enviadas por el primer ministro Lloyd George para apoyar la propaganda a favor de la guerra. Pankhurst habló al menos ante una asamblea feminista a favor de la guerra mientras estaba en Rusia. Shabanova organizó una cena en el Hotel Astoria para Pankhurst y Bochkareva, y llevó a la líder feminista británica al cuartel del Batallón de Mujeres y a varios mítines patrióticos, así como a la consagración del estandarte del Batallón en la Catedral de San Isaac de Petrogrado. Shishkina-Iavein y otros miembros de la Liga de Mujeres se les unieron para rendir homenaje al batallón y organizaron un saludo a las soldadas en la Catedral de Kazán antes de partir para el frente. Pero fuera de la concesión del sufragio femenino, y de algunas reformas muy parciales ${ }^{59}$, el Gobierno Provisional no

down by Isaac Don Levine, New York: Frederick A. Stokes Co., 1919. https://archive.org/details/yashkamylifeasp02levigoog En 1919, después de haber completado una gira por los Estados Unidos, Bochkareva regresó a Rusia y trató de unirse a los blancos. Antes de que pudiera llegar al ejército de Kolchak, los bolcheviques la detuvieron. Fue juzgada, declarada culpable de traición y ejecutada en mayo de 1920.

59 A las mujeres se les permitió ser miembros del jurado y se las admitió a la práctica legal. En agosto, el Gobierno Provisional les concedió a las mujeres igualdad de oportunidades, remuneración, beneficios y títulos en el servicio civil (ver los documentos en Kerensky 1961, "The Question of Women Jurors", p. 225, "The Admission of Women to the Bar", p. 238, "The Extension of the Rights Granted to Women to Enter the Civil Service", p. 239). Esta concesión fue particularmente significativa para las maestras de escuela, el mayor grupo de empleadas estatales, que por primera vez se encontraron en condiciones de igualdad con los hombres-lo que probablemente explique las prolongadas huelgas que llevaron adelante contra el gobierno bolchevique después de la revolución de octubre. La rama de Moscú del VUS (Sindicato Panruso de Maestros), que poseía unos 4.000 miembros, se unió casi unánimemente a la huelga de los empleados municipales de Moscú y se mantuvo en huelga hasta el 11 de marzo de 1918. 
promovió un código que estipulara la igualdad de derechos de las mujeres: la inferioridad jurídica de la mujer continuó, como lo hicieron las leyes sobre el matrimonio y la familia, hasta la revolución bolchevique (Ruthchild 2010, pp. 227-232).

El 21 de marzo de 1917, el mismo número de Pravda que contenía la primera "Carta desde lejos" de Lenin publicó "Las Trabajadoras y la Asamblea Constituyente", el primer artículo de Kollontai en Rusia, motivado por la manifestación de las feministas. Denunciando las ilusiones de "las señoras burguesas de la Liga por la Igualdad de Derechos" en la "'promesa' del Sr. Rodzianko de admitir a las mujeres a la Asamblea Constituyente", Kollontai afirmó que "la Asamblea Constituyente no es un club cuyas llaves están en el bolsillo del Sr. Rodzianko, y al cual no solo él, sino también todo el Gobierno Provisional, puede dejar o no entrar a ésta o aquella parte de la población." Kollontai advertía que "el Sr. Rodzianko y sus colegas cerrarán las puertas de la Asamblea Constituyente en las caras de esas mismas trabajadoras gracias a cuya lucha heroica se encuentran en el poder." No sólo los hipócritas del Gobierno Provisional, sino también aquellos que llevaban brazaletes rojos en el Soviet, pensaban en establecerse más cómodamente en el poder abriendo la puerta a las mujeres de la clase media y excluyendo a las trabajadoras, que amenazaban con acabar con el estado de cosas existente. "¡Pero la cuestión es precisamente los derechos políticos de todas las mujeres, de los muchos millones de mujeres trabajadoras!"

Kollontai subrayaba que la lucha por el sufragio universal femenino pasaba por continuar la revolución y por elegir un nuevo parlamento soberano que representara al pueblo. "Pero, al levantar la campaña por la representación y participación de las trabajadoras en la Asamblea Constituyente, debemos involucrarnos inmediatamente en un amplio trabajo entre las trabajadoras, debemos hacer un llamamiento a ellas para que se unan, se organicen en torno a nuestro estandarte socialista, en el cual la sangre de los proletarios dice: ‘iLibertad, pan y paz!'. Sólo se asegurará la participación de las mujeres trabajadoras en la Asamblea Constituyente si de inmediato asumen la tarea de ganar estos derechos por sus propias manos, si lideran esta lucha bajo la bandera de la socialdemocracia

En Petrogrado, la huelga de maestros se prolongó hasta el 6 de enero de 1918 (Fitzpatrick 1977, p. 55). Por el contrario, el Gobierno Provisional no hizo casi nada por las trabajadoras fabriles. Sólo en agosto de 1917 prohibió el trabajo nocturno en las fábricas tanto de las mujeres como de los niños, pero esta prohibición no afectó a miles de costureras que trabajaban en el hogar (Koenker 1981, p. 68). 
revolucionaria."60 Cinco días después, Pravda publicaba una resolución adoptada por la asamblea de trabajadoras de la fábrica textil Baranov exigiendo el derecho a voto en las elecciones a la Asamblea Constituyente. Dicha resolución, muy similar a la adoptada pocos días antes por las trabajadoras del distrito de Vyborg, decía lo siguiente:

En la asamblea de la fábrica Baranov, un gran número de personas estuvieron presentes, y dichas personas, en su mayoría mujeres, adoptaron la siguiente resolución.

"1) Damos la bienvenida a los Socialistas Revolucionarios y a los Socialdemócratas, y exigimos la organización inmediata de la convocatoria a la Asamblea Constituyente sobre la base del sufragio universal, igual, directo y secreto. "2) Las mujeres proletarias defenderán firme y enérgicamente sus derechos en la Asamblea Constituyente para la implementación de un sistema democrático en Rusia.

"3) Las mujeres proletarias luchan junto con los trabajadores no sólo por la plena libertad democrática, sino también por la destrucción del sistema capitalista en sí.

"4) Junto con la demanda de participación en la Asamblea Constituyente, las mujeres proletarias demandan la pronta introducción de la siguiente legislación: a) seguro de maternidad completo, b) seguro de trabajo, c) elección de inspectoras de fábrica con la participación directa de las trabajadoras." 61

\section{Los esfuerzos de los bolcheviques por organizar las luchas de las trabajadoras}

Un ejemplo de los artículos publicados en Pravda contra el separatismo organizativo preconizado por las feministas es la nota publicada el 7 de abril de 1917 con el título "La mujer en el movimiento obrero", que transcribimos a continuación:

60 А. Колонтай. Работницы и Учредительное Собрание. // Правда № 14. 21 марта [3 апреля] 1917 г. C. 2-4. [A. Kollontai, "Las trabajadoras y la Asamblea Constituyente", Pravda, No. 14, 21 de marzo [3 de abril] de 1917, pp. 2-4.] http://istmat.info/node/28027

61 Резолюции // Правда № 18. 26 марта [8 апреля] 1917 г. С. 9. ["Resoluciones", Pravda, No. 18. 26 de marzo [8 de abril] de 1917, p. 9.] http://istmat.info/node/28027 
En los últimos años, la mujer proletaria ha ocupado una posición cada vez más prominente en la economía contemporánea del país.

Reemplazar el trabajo de los hombres con el de las mujeres, incluso en aquellas ramas de la producción donde el trabajo de las mujeres era casi inexistente, se ha convertido en un fenómeno normal. Así, en la industria metalúrgica en 1913, el trabajo de las mujeres fluctuaba entre el 3.3\% y el 4.3\%, mientras que para fines de 1916 pasó a constituir del 20\% al 25\%. En general, en la región de Petrogrado, a comienzos de 1916 se incorporaron más de 50.000 trabajadoras.

Pasando del hogar familiar a la máquina de la fábrica, la mujer se convirtió en una camarada del trabajador masculino. Su conciencia ya no está determinada por la economía cerrada de la familia, sino por la fábrica y el colectivo de trabajo. Allí soportó todas las pruebas de la vida en la fábrica: bajos salarios y trabajo nocturno de 12 horas, la ausencia de protección como madres, etc., etc.

Pero, al mismo tiempo, la mujer proletaria absorbió la voluntad del colectivo consciente; junto con el trabajador de sexo masculino, se convirtió en miembro de las filas del partido, de los sindicatos y de otras organizaciones y, junto con él, trabajó para resolver en común las tareas proletarias generales.

La revolución se estaba precipitando, y la mujer fue, sin temor a nada, a abrirse camino hacia un nuevo orden libre. Y ahora, cuando la revolución todavía no se ha completado, cuando el proletariado requiere de todo el esfuerzo y de toda la energía disponibles, la mujer proletaria debe desplegar sus fuerzas para estar activa en todos los frentes: en el partido, en los sindicatos, en los clubes, en los municipios y en las elecciones a la Asamblea Constituyente.

Pero, recordando que sólo quien no está solo, quien forma parte del colectivo, es fuerte, la mujer proletaria debe organizarse y ser miembro del partido de la clase obrera.

Las mujeres de las clases burguesas crean sus propias organizaciones puramente femeninas, donde las mujeres se oponen a los hombres y sólo demandan igualdad.

A la mujer proletaria se le plantean otras tareas, más complejas. Como representante de la clase obrera, no se distingue de toda la familia proletaria y lucha por los objetivos comunes. Por lo tanto, desde el punto de vista organizativo, una trabajadora no debe distinguirse de toda la masa de trabajadores. Junto con el trabajador construyen distintas formas de organización e ingresan en ellas como 
representantes de la clase obrera, independientemente de su sexo.

Es inútil y dañino crear organizaciones puramente femeninas, pero en las organizaciones generales es útil realizar propaganda y agitación entre las mujeres: organizar asambleas de mujeres, conferencias sobre los temas que son más relevantes para las trabajadoras, etc.

Ahora, cuando comienza una nueva construcción organizacional abierta, cuando se requiere la mayor coordinación de fuerzas, es necesario no dispersarse, sino marchar y vencer juntos. ${ }^{62}$

El 10 de marzo, una reunión del Comité Ejecutivo del Comité de Petrogrado había puesto a Vera Slutskaya, ahora secretaria del comité bolchevique de la isla Vasilev, a cargo de la agitación entre las trabajadoras, y tres días después, en una sesión ampliada del Comité Ejecutivo, Slutskaya recomendó que el comité de Petrogrado incluyera una secretaría de la mujer, a la que cada distrito elegiría a una representante. Una reunión del Comité de Petrogrado del 15 de marzo resolvió establecer una secretaría para realizar el trabajo de agitación entre las mujeres y tomar medidas para reiniciar la publicación de Rabotnitsa. En el n. 34 del 16 de abril, Pravda anunció que la primera reunión de la secretaría de mujeres, que se había establecido de conformidad con las propuestas de Slutskaya, había tenido lugar, y que sólo dos días después de esta reunión la secretaría organizó una asamblea pública sobre las celebraciones del $1^{\circ}$ de mayo, la guerra y la Internacional, a la que asistieron unas 2.000 personas. Pero la secretaría de la mujer pronto fue suplantada por un centro organizativo más efectivo, el Consejo Editorial del Rabotnitsa, cuando la revista fue relanzada el 10 de mayo de 1917 (Donald 1982, pp. 133-134, 137-138).

A Kollontai le preocupaba que las soldatki (las esposas de los soldados) aún no hubieran sido alcanzadas por la propaganda del Partido. Al salir de las oficinas de Pravda una noche con Lenin, Nadezhda Krupskaya y un grupo de camaradas del partido, Kollontai se quejó de esta indiferencia. Lenin le propuso que discutiera la idea con otras militantes y que presentara sugerencias al respecto en la conferencia del Partido que se celebraría a fines de abril. Sin esperar a la celebración de la conferencia, Kollontai se puso en contacto con

${ }^{62}$ Н. ГАебов, Женщина в рабочем движении // Правда № 26. 7 апреля [20 апреля] 1917 г., C. 1-2 [N. Glebov, "La mujer en el movimiento obrero", Pravda, No. 26. $7^{20}$ (20) de abril de 1917, pp. 1-2.] http://istmat.info/node/28027 
varias soldatki y el 11 de abril de 1917 organizó una marcha de esposas de soldados hacia el Palacio Táuride, para rivalizar con la demostración feminista del mes anterior y para presentar ante el Soviet la demanda de que su miserable pensión mensual de siete rublos fuera aumentada a veinte rublos. Unas 15.000 mujeres se congregaron en el lugar y fueron recibidas por el menchevique Fyodor Dan como representante del Comité Ejecutivo del Soviet, quien se presentó ante ellas con un uniforme de médico del ejército, habló de la "caja vacía" y les aconsejó luchar "no por un aumento de la ración, sino por la paz". Kollontai se dirigió a las mujeres congregadas pidiéndoles que eligieran a sus propias delegadas al Soviet y que tomaran en sus manos la distribución de sus raciones y pensiones. Kollontai concluyó afirmando: "Estas mujeres odian profundamente la guerra: no pueden ser engañadas por las mentiras de las frases defensistas [...] un instinto infalible les dice que esta guerra, iniciada por una banda de ladrones, de grandes potencias, es una guerra ajena a los intereses del pueblo." Finalmente, a mediados de abril 35 esposas de soldados lograron formar un comité de soldatki en Petrogrado, a partir del cual se desarrolló una red de organizaciones similares en Rusia y Ucrania. ${ }^{63}$

El comité de soldatki decidió tomar en sus manos el bienestar de las familias de los soldados y renovar la demanda de una asignación de veinte rublos. A fines de mayo, una Conferencia de Mujeres Trabajadoras del distrito de Vyborg organizada por los bolcheviques aprobó una resolución de las representantes de las esposas de soldados de Vyborg exigiendo un subsidio de veinte rublos, que las esposas de los oficiales recibieran el mismo subsidio que las soldatki comunes, que "nuestros esposos, agotados por tres años de guerra, sean reemplazados [en el frente] por miembros de la burguesía y otros que se esconden de la guerra", y que "esta guerra de ladrones que sólo trae ganancias a los capitalistas se termine

63 Kollontai, Alexandra 1937, "Die Frauen im Jahre 1917", Rabotnitsa, Nr. 31, November 1937, S. 12-13, in Kollontai, "Ich habe viele Leben gelebt": Autobiographische Aufzeichnungen, Berlin: Dietz Verlag, 1980, S. 348-353. [Kollontai, Alexandra 1921, "Las mujeres en el año 1917", La trabajadora, N ${ }^{\circ}$ 3 Nr. 31, November 1937, pp. 12-13, en Kollontai, "He vivido muchas vidas": Apuntes autobiográficos, Berlin: Dietz Verlag, 1980, pp. 348-353.] El artículo de Kollontai sobre la manifestación de las esposas de los soldados apareció en Pravda como А. Колонтай, Аемонстрация солАаток // Правда № 30 Среда 12 апреля [25 апр.] 1917 г. С. 5-6 [A. Kollontai, "Manifestación de mujeres de soldados", Pravda, № 30, miércoles 12 de abril [25 de abril] de 1917, pp. 5-6.] http://istmat.info/node/28027 
inmediatamente". La resolución concluía con la demanda "Todo el poder a los Soviets". En junio, el comité de soldatki formó una "Unión de esposas de soldados" para realizar un trabajo de agitación sistemático (Donald 1982, pp. 142).

Esta iniciativa se dio en el marco de una ola de militancia obrera en la que las trabajadoras jugaron un rol destacado. Las empleadas domésticas de Petrogrado, por ejemplo, se habían estado reuniendo en número cada vez en mayor desde finales de marzo. "Camaradas empleadas domésticas", escribió una de ellas en Pravda, después de que una asamblea se desbordó en la calle: "iNecesitamos una sala más grande!". Los trabajadores de los restaurantes también formaron su propio sindicato, el cual lanzó una campaña de afiliación entre "todas las camaradas que trabajan en los salones de té de Petrogrado". Las mujeres de la fábrica de chocolate Mignon hicieron un llamamiento al Soviet para protestar contra las condiciones de trabajo intolerables; las trabajadoras de las fábricas de tabaco exigían protección para las obreras embarazadas; y en la fábrica textil Frolic los trabajadores exigieron aumentos salariales del 100\% para los hombres y del 125\% para las mujeres (Porter 1980, pp. 252).

Los bolcheviques obtuvieron un triunfo comparable al obtenido entre las mujeres de los soldados con la organización de la huelga de las lavanderas de la capital. Las siete u ocho mil lavanderas de Petrogrado trabajaban hasta catorce horas diarias en las condiciones más insalubres. Habían comenzado a organizarse después de la Revolución de Febrero, anunciando sus asambleas en Pravda, y para principios de mayo habían logrado que unas 3.000 lavanderas de la capital se afiliaran al sindicato de lavanderas recién formado. Las lavanderas decidieron declararse en huelga después de que sus demandas de una jornada laboral de ocho horas y de un salario mínimo de cuatro rublos por día fueran rechazadas por los propietarios de las lavanderías. La huelga comenzó el $1^{\circ}$ de mayo y se extendió rápidamente, por lo que al día siguiente tres cuartas partes de las lavanderas de la ciudad estaban en huelga.

Los esfuerzos de mujeres bolcheviques como Goncharskaya, que encabezó el sindicato de lavanderas, NovikKondratieva y Sajarova, que dirigió el comité de huelga, y por supuesto Kollontai, quien publicitó la causa de las lavanderas en el Soviet, en Pravda y en Rabotnitsa, impulsaron al Partido Bolchevique a dar un apoyo total y activo a las lavanderas. Kollontai lanzó la campaña con dos artículos en ediciones consecutivas de Pravda titulados "En la primera línea de fuego", en los que describió las condiciones de trabajo en la industria, explicó las demandas de las 
lavanderas y pidió a los trabajadores que respondieran a la amenaza de cierre de los propietarios con la demanda de municipalización de las lavanderías. Describió los esfuerzos de los empleadores por romper la huelga formando su propio sindicato de rompehuelgas y utilizando métodos aún más violentos. Kollontai enfatizó que las lavanderas estaban luchando no sólo por ellas mismas sino por los intereses de toda la clase trabajadora, y que su victoria sería una nueva victoria para todo el proletariado. Instó a que se diese tanto apoyo moral como material a las lavanderas, y a que el Soviet declarara su solidaridad con ellas, ya que estaban luchando para obligar a los empleadores a acceder a las demandas que habían sido aprobadas por el Soviet.

Las apelaciones de Kollontai fueron exitosas. El 8 de mayo, en respuesta a su informe sobre la difícil situación de las lavanderas, el Comité Ejecutivo del Soviet acordó conceder a las mujeres huelguistas 5.000 rublos. Pravda dedicó diariamente espacio a lo largo de un mes a informes sobre la huelga, apelaciones a aportar al fondo de huelga y mensajes de apoyo de los trabajadores en otras industrias. ${ }^{64}$ Las donaciones de los sindicatos, soviets de distrito, comités de fábrica y comités de marineros fluyeron al fondo de huelga de las lavanderas. Los mensajes de solidaridad que se difundieron en Pravda instaban a las lavanderas a perseverar en su lucha contra los empleadores y los rompehuelgas, y reiteraban el llamado de Kollontai "Vuestra victoria es nuestra victoria".

Finalmente, el 31 de mayo, Pravda anunció que la huelga había terminado con éxito y que los empleadores habían aceptado las demandas de las mujeres. Pero la victoria fue sólo parcial, porque cuando las lavanderas volvieron al trabajo, los empleadores frecuentemente incumplieron sus promesas. Las trabajadoras que tomaron parte activa en la huelga no fueron readmitidas y muchas lavanderías fueron cerradas. No fue sino hasta después de la Revolución de Octubre que las demandas de las lavanderas se implementaron por completo. Sin embargo, la huelga de las lavanderas fue una importante victoria para los bolcheviques y para

64 Por ejemplo: Работницы и рабочие прачечных заведений // Правда № 6. 11 марта [24 марта] 1917 г. С. 5 [“Trabajadoras y trabajadores de lavanderías", Pravda No. 6, 11 (24) de marzo de 1917, p. 5.]. Собрание рабочих и работниц прачечных заведений // Правда № 17. 25 марта [7 апре я] 1917 г. С. 9. ["Asamblea de trabajadoras y trabajadores de lavanderías”, Pravda No. 17, 25 de marzo (7 de abril) de 1917, p. 9.] 
sus esfuerzos por organizar las luchas de las trabajadoras (Donald 1982, pp. 143-144). ${ }^{65}$

\section{El relanzamiento de la revista Rabotnitsa}

La publicación de Rabotnitsa se reanudó del 10 de mayo de 1917 como un semanario del Comité Central del Partido Bolchevique. Hasta el 26 de enero (8 de febrero de 1918), cuando su publicación fue suspendida por falta de papel, se publicaron 13 números, con una circulación promedio de entre 30 y 43 mil copias. El periódico era editado por la trabajadora A. Vasileva, asistida por Kollontai y por las veteranas de la Rabotnitsa de 1914: Lyudmila Stal, Praskovia Kudelli, Elena Rozmirovich y Konkordiia Samoilova. Esta última había sido arrestada como una de las editoras originales de Rabotnitsa y había sido liberada por la Revolución de Febrero después de tres años de prisión, luego de lo cual había sido nombrada secretaria de Pravda, donde había iniciado la página de mujeres.

El primer ejemplar de la nueva Rabotnitsa, un número doble, se publicó el 10 de mayo. Las contribuciones fueron principalmente de miembros del comité editorial, aunque Zinaida Lilina y B. Breslav también proporcionaron material. Los artículos discutían asuntos de interés para las mujeres trabajadoras, tales como la historia de la revista Rabotnitsa, el papel de la mujer trabajadora rusa en el movimiento obrero, los logros de la Revolución Rusa para las mujeres y las tareas que se avecinaban, y la lucha por la paz. También se analizaban cuestiones tales como la jornada laboral de ocho horas, la licencia por maternidad, el trabajo infantil y las condiciones de trabajo. El primer número de Rabotnitsa contenía avisos de asambleas

${ }^{65}$ Cabe mencionar en este contexto el accionar de los comités de fábrica, en los cuales los bolcheviques fueron la fuerza dominante en 1917 desde el comienzo, a diferencia de los soviets y de los sindicatos. Según el testimonio del historiador anarquista Paul Avrich, la acusación de "comportamiento grosero" fue empleada contra el personal directivo para describir una variedad de delitos, incluyendo el abuso de las trabajadoras. El capataz Avram Lebedev de la fábrica textil Ivan Garelin en Ivanovo-Voznesensk incurrió en un "comportamiento grosero" cuando recorrió la fábrica en estado de embriaguez, maldiciendo, interfiriendo con la producción, impidiendo la reparación de maquinaria y abusando de las obreras; en otra fábrica de la misma ciudad (un centro de la industria textil con una gran concentración obrera femenina), el subdirector Tuzhilov "intentó seducir a las mujeres en la empresa". Todos estos abusadores fueron expulsados sin ceremonia por los comités de fábrica (Avrich 1963, p. 172). 
de mujeres, anuncios de otras publicaciones bolcheviques, en particular un folleto elaborado por el comité editorial de Rabotnitsa titulado "La inflación y la guerra", solicitudes de contribuciones financieras y de artículos para los siguientes números, y una declaración que llamaba a las trabajadoras a colaborar con la distribución de la revista. "¡No te mantengas a un lado!", escribió Kollontai en su artículo "Nuestras tareas", publicado en el primer número de Rabotnitsa: ";Organizadas, somos una fuerza poderosa que nadie puede destruir!" Dicho número incluía también un artículo de Konkordia Samoilova sobre Bebel y un llamamiento a las mujeres para organizar grupos de trabajadoras lo suficientemente masivos como para elegir delegadas al soviet (Porter 1980, pp. 255-256).

La publicación de Rabotnitsa fue parte integral de una campaña de agitación mucho más amplia que cobró impulso durante mayo y junio, con la organización de asambleas públicas por el consejo editorial y con la formación de una escuela de agitadoras adjunta a la revista. Las editoras acordaron organizar la escuela y elaborar un programa para ella en una reunión el 4 de mayo. Las conferencias tendrían lugar semanalmente, comenzando con una conferencia sobre las elecciones a las dumas regionales. Los miembros de la escuela formaron grupos en las fábricas que ayudaban a distribuir Rabotnitsa y a organizar asambleas y conferencias. Más tarde, los miembros de estos grupos se convirtieron en agitadoras entre las trabajadoras, y finalmente en corresponsales de Rabotnitsa.

Desde mediados de mayo en adelante, el grupo Rabotnitsa desarrolló un programa intensivo de asambleas públicas. El 11 de junio tuvo lugar en el circo Cinizelli la primera de una serie de grandes asambleas públicas sobre el tema "La guerra y la inflación". Asistieron alrededor de 10.000 personas, y la multitud se desbordó en las calles, donde se realizó una segunda asamblea al aire libre. Se aprobó una resolución de protesta contra "los precios monstruosamente altos, la pesada carga que recae sobre los pobres, y su verdadera causa, la guerra mundial de los imperialistas" (Donald 1982, pp. 145-147).

Rabotnitsa se transformó así en el centro de una red de agitación entre las obreras. Con el fin de mantener sus artículos actualizados, Konkordiia Samoilova, Klavdia Nikolaeva y Lyudmila Stal, después de escribir para el periódico por la mañana, viajaban a las fábricas y tiendas para hablar personalmente con las trabajadoras. Lyudmila Stal describió el trabajo de Rabotnitsa a los marineros en Kronstadt, Nadezhda Krupskaya y Zhenya Egorova oraron ante 
grandes asambleas mixtas en el distrito de Vyborg, Anna Itkina hizo otro tanto con las mujeres en el distrito de Narva, y Vera Slutskaya organizó asambleas masivas de mujeres en la isla de Vasilev. Un punto culminante en la campaña de los bolcheviques para ganarse la lealtad de las mujeres trabajadoras se alcanzó con la aceptación del documento de Kollontai sobre la protección del trabajo femenino, la igualdad salarial y la necesidad de atraer a más mujeres al movimiento sindical en el Primer Congreso Panruso de Sindicatos celebrado a fines de junio de 1917.

Pero el crecimiento constante de la influencia bolchevique entre las trabajadoras de febrero a junio se detuvo abruptamente después de las Jornadas de Julio. ${ }^{66}$ Durante las semanas de reacción que siguieron, el apoyo a los bolcheviques se redujo considerablemente. Todos los aspectos del trabajo político se volvieron más difíciles, y el trabajo entre las mujeres sufrió particularmente, pero de ninguna manera fue abandonado. Las mujeres del consejo de redacción de Rabotnitsa menos Kollontai, que había sido arrestada, lograron mantener la publicación de la revista, y durante un tiempo fue de hecho el único órgano legal del Partido Bolchevique. La primera edición de Rabotnitsa después de la crisis de julio incluyó el artículo de Lenin "Tres crisis". 67 El Gobierno Provisional intentó confiscar dicho número, pero las trabajadoras burlaron a los Junkers (alumnos de las academias militares) que irrumpieron en las instalaciones, y el número de Rabotnitsa fue editado y distribuido con éxito.

Pasó un mes sin que se celebrara una asamblea de Rabotnitsa, y cuando finalmente se consiguió organizar una para el 30 de julio, atrajo a 700 personas. Para fines de julio, lo peor había pasado. Con el fracaso de la ofensiva de junio, comenzaron las deserciones masivas en el frente. La situación económica era cada vez más desesperada, y las trabajadoras sufrían especialmente por el aumento del desempleo y la caída de los salarios reales durante este período. Los bolcheviques se beneficiaron de esta situación y el resurgimiento general del apoyo a ellos se reflejó en una mayor concurrencia a las asambleas de mujeres trabajadoras. El 1 de agosto, la revista de la Organización Militar bolchevique Rabochii $i$ Soldat (Trabajador y soldado) publicó un informe de una asamblea de

66 Ver Daniel Gaido, "Las Jornadas de Julio”, Jacobin Magazine, 27 de Julio del 2017. Disponible online.

67 V.I. Lenin, “Tres crisis", escrito el 7 (20) de julio de 1917, publicado en la revista Rabotnitsa, No. 7, el 19 de julio de 1917, en Lenin, Obras completas, Madrid: Akal, Tomo 26, 1976, pp. 246-250. 
empleadas domésticas en el Circo Moderno, a la que asistieron mil trabajadoras domésticas que protestaron contra los ataques difamatorios contra los bolcheviques y el encarcelamiento de sus líderes. En particular, exigieron la liberación inmediata de Kollontai, quien, declararon, "había promovido el desarrollo de nuestro sindicato". El 22 de agosto se celebró una gran asamblea en el Circo Moderno para protestar por la continuación del encarcelamiento de Kollontai, cuya salud se había deteriorado seriamente. Una semana después, otra asamblea de Rabotnitsa, a la que asistieron 5.000 personas, exigió la inmediata liberación de todos los bolcheviques bajo arresto y el regreso libre a Rusia de Lenin y Zinoviev, entonces en exiliados en la clandestinidad en Finlandia. En otra asamblea en el Circo Moderno, celebrada el 25 de septiembre, Kollontai, quien recientemente había sido liberada del arresto domiciliario, fue llevada en andas ante el fuerte aplauso de la multitud (Donald 1982, pp. 148150).

El Partido Bolchevique creó a principios de octubre el Grupo de Iniciativa de Mujeres Trabajadoras, cuya tarea principal era preparar una Conferencia de Mujeres Trabajadoras de Petrogrado que se celebraría en octubre, como parte de la campaña bolchevique para las elecciones a la Asamblea Constituyente. La primera reunión del Grupo de Iniciativa, que consistió en 19 mujeres de varias fábricas, organizaciones del partido y del consejo editorial de Rabotnitsa, tuvo lugar en octubre. A principios de octubre, el trabajo entre las mujeres alcanzó un nivel de actividad que recordaba al pico anterior en junio. El 1 de octubre, Kollontai, Kudelli y Samoilova oraron en una asamblea celebrada en el Circo Moderno sobre la Asamblea Constituyente. Kollontai también publicó al menos dos folletos sobre el tema, y ella y Samoilova escribieron artículos sobre la Asamblea Constituyente para Rabochii Put' y Rabotnitsa.

El 10 de octubre, la Tercera Conferencia de Petrogrado del Partido Bolchevique llamó a convocar lo antes posible la Conferencia de Mujeres Trabajadoras, y acordó realizar elecciones de delegadas de las fábricas y de los distritos del partido, y formar comités de agitación. El 14 de octubre tuvo lugar la segunda reunión del Grupo de Iniciativa. Se propuso que la conferencia se celebrara entre el 27 de octubre y el 1 de noviembre. La agenda sería la siguiente: una exposición de las tareas de la conferencia; informes de las delegadas; discursos sobre la Asamblea Constituyente y la mujer trabajadora; discursos sobre la protección laboral y el seguro para las trabajadoras; la Asamblea Constituyente y los partidos feministas burgueses; el socialismo y la mujer trabajadora; y, finalmente, cuestiones 
organizativas. Las oradoras propuestas fueron Nikolaeva, Prokhorova, E. Solin, Samoilova, Kudelli, Lilina y Kollontai.

El 22 de octubre, el comité editorial de Rabotnitsa, junto con el sindicato de lavanderas, celebró otra asamblea en el Circo Moderno sobre la Asamblea Constituyente. En total, durante el período previo a la Conferencia de Mujeres Trabajadoras, el Grupo de Iniciativa organizó setenta asambleas y publicó numerosos folletos tanto sobre la Asamblea Constituyente como sobre la conferencia que se avecinaba. Los preparativos para la apertura de la conferencia transcurrían sin tropiezos cuando fueron repentinamente interrumpidos por la insurrección armada de los bolcheviques en la noche del 25 al 26 de octubre (Donald 1982, pp. 150-152).

\section{Inessa Armand y la organización de las trabajadoras de Moscú}

En Moscú, Inessa Armand y Varvara Yakovleva se pusieron al frente del trabajo del Partido Bolchevique para la organización de las trabajadoras. El 7 de abril de 1917, la Liga Panrusa por la Igualdad de Derechos de las Mujeres organizó la primera asamblea feminista después de la revolución de febrero, un Congreso de Mujeres de toda Rusia celebrado en Moscú que contó con la presencia de Vera Figner, de las socialistas revolucionarias Breshko-Breshkovskaia y Maria Spiridonova y de la ex-integrante del grupo "Emancipación del Trabajo" Vera Zasulich. En dicho congreso, la dirigente de la Liga, Polixena Shishkina-Iavein había encabezado la formación de un nuevo grupo de coalición, la "Unión Republicana Panrusa de Organizaciones de Mujeres Democráticas” (Всероссийский Республиканский Союз Аемократических женских организаций). Con un programa de apoyo a la guerra y de obtener el respaldo de las mujeres en las próximas elecciones a la Asamblea Constituyente, la Unión Republicana reflejaba las prioridades de los líderes del Gobierno Provisional y del Soviet, es decir de los kadetes, los socialistas revolucionarios y de los mencheviques. ${ }^{68}$

68 Existe una versión en inglés de un folleto de Olga Zakuta de mediados de 1917, titulado ¿Cómo en la era revolucionaria la Liga Panrusa para la Igualdad de Derechos de las Mujeres ganó el sufragio para las mujeres rusas?, en el que la autora exalta el rol de la manifestación del 19 de marzo y concluye afirmando que la Liga “organiza la Unión Republicana Panrusa de Organizaciones de Mujeres Democráticas para hacer campaña entre las mujeres a fin de prepararlas para las elecciones" a la Asamblea Constituyente (Zakuta 1917). 
Inessa Armand, que había regresado a Rusia junto con Lenin, se trasladó a Moscú a comienzos de mayo de 1917 y comenzó a editar, junto con Yakovleva, la revista La vida de las trabajadoras (Жизнь работнищьъ). En un artículo sobre el Congreso de Mujeres, Armand escribió con el pseudónimo de "Blonina":

La burguesía siempre intenta usar la ignorancia de éstas o aquellas capas proletarias para contraponerlas a la vanguardia obrera $y$, de esa forma, desunir a los trabajadores. Ahora, las damas burguesas de la Unión por la Igualdad de Derechos («Союза Равноправия») desean fervientemente someter a las trabajadoras a su influencia y se empeñan de todas las formas posibles en sacarlas de las luchas del proletariado, contando con la inexperiencia política de ellas. Por ejemplo, unas semanas atrás, estas "defensoras de la igualdad de derechos" (равноправки) у representantes de otras organizaciones de mujeres burguesas organizaron el Congreso de Mujeres de Toda Rusia. Representantes de organizaciones burguesas y proletarias fueron invitadas a asistir a la asamblea preliminar sobre la organización de este congreso. El debate en esta asamblea mostró claramente los objetivos de todo este intento: por un lado, separar a las trabajadoras de los trabajadores y de su movimiento y, por el otro, usarlas en las elecciones a la Asamblea Constituyente.

Las organizaciones burguesas por la igualdad de derechos (буржуазные равноправки) proclamaron abiertamente las "tareas comunes" en relación con la campaña electoral para la Asamblea Constituyente, la necesidad de que haya un gran número de representantes de mujeres en esta asamblea, etc. Hablaron sobre los discursos de los trabajadores contra las trabajadoras, afirmando que los trabajadores nunca lucharon por la emancipación de las mujeres, y así sucesivamente.

Siete representantes de los sindicatos y del Comité de Moscú abandonaron la asamblea, declarando que las mujeres burguesas y proletarias no tienen tareas comunes y que creían que las proletarias no deberían celebrar un congreso conjunto con representantes de la burguesía.

Una representante de los mencheviques, fiel a su papel de auxiliar de la burguesía, defendió la necesidad de participar en este congreso con espuma en la boca, y logró, desafortunadamente, confundir a varias representantes de los sindicatos, quienes no se retiraron de la asamblea. El plan de las "defensoras de la igualdad de derechos" (равноправок) finalmente fracasó, pero no se desaniman y 
continúan con la agitación para el congreso. Probablemente, estarán agitando para él en las provincias.

En todas partes, las trabajadoras deben ofrecer la más tenaz resistencia a esos intentos de las mujeres burguesas de llevar a las trabajadoras con ellas. Las mujeres burguesas son tan explotadoras, tan enemigas del movimiento obrero y de la revolución obrera como los hombres burgueses. No hay ninguna diferencia entre ellos. En la campaña electoral, no importa si es a la Asamblea Constituyente, a las Dumas de la ciudad, etc., no sólo no podemos estar de acuerdo con las mujeres burguesas, sino que debemos luchar contra ellas de la manera más enérgica. Sus intereses y nuestros intereses están completamente en desacuerdo. Ellas, junto con todos los burgueses, quieren una representación burguesa que garantice los intereses de los propietarios, los intereses de los capitalistas, y nosotras no queremos una representación burguesa sino de los trabajadores, que garantice los intereses de los trabajadores.

Dentro de la Asamblea Constituyente o de las Dumas de las ciudades, las mujeres burguesas buscarán implementar ordenanzas, leyes, sistemas de gobierno necesarios para los burgueses, y se opondrán firmemente a la legislación laboral, al sistema estatal necesario para los trabajadores, a las luchas obreras.

No hay intereses comunes entre las mujeres, no puede haber una representación general de mujeres o una lucha general de mujeres. La trabajadora se une a las filas de los trabajadores contra toda la clase de los capitalistas, sin distinción de sexo. Ella lucha por la eliminación de la explotación, del poder y de la fuerza de los capitalistas, por el socialismo. La mujer burguesa está de acuerdo con el hombre burgués contra toda la clase trabajadora, por el mantenimiento de la explotación y del poder burgués, contra el socialismo.

En otros países, las trabajadoras lo entendieron hace tiempo y ya declararon que no hay nada en común entre ellas y las mujeres burguesas, y que no van con éstas a ningún congreso común. Lo mismo deben decir las trabajadoras rusas, tanto más ahora que se acentúa la lucha contra la burguesía en el umbral de la gran revolución proletaria mundial. ${ }^{69}$

69 АрманА, Инесса Федоровна, "Работница и Всероссийский Женский СъезА”, Жизнь работниць, 1917, N. 1, С. 5-6 // Статьи, речи, письма - М.: Политиздат, 1975 - С. 36-38. [Inessa Armand, "La trabajadora en el Congreso de Mujeres de Toda Rusia", La vida de las trabajadoras, abril de 1917, 
Aunque estaba programado que La vida de las trabajadoras saliera cada dos semanas, las editoras lograron publicar sólo dos números, una de ocho páginas el 20 de junio y otro de dieciséis páginas el 15 de julio de 1917. Su circulación nunca llegó a más de 15.000 ejemplares, un tercio de la tirada de Rabotnitsa en Petrogrado. Esto reflejaba el menor grado de conciencia y de diferenciación política en Moscú, donde la revolución bolchevique triunfó sólo después de una semana de combates y con un saldo de 400 muertos -mayormente bolchevique ejecutados después de rendirse por los alumnos de las escalas militares (Junkers), en lo que Victor Serge llamó "los comienzos del terror blanco" (Serge 1930, pp. 73-76).

Moscú fue también el escenario de un evento significativo en la lucha por la emancipación de las mujeres en el imperio ruso: la reunión de representantes de la "nación musulmana" de Rusia, que se celebró en Moscú del 1 al 11 de mayo de 1917. Fueron las personas más moderadas, los diputados musulmanes de la Duma, quienes propusieron la idea, pero la radicalización política fue tan rápida que los creadores del movimiento -Maksudov, Kalikov, Safarovquedaron atrás, al igual que los representantes de Alash-Orda, vinculados a los cadetes. En un mes, se llevaron a cabo unas diez convenciones preliminares. Al congreso asistieron más de novecientos delegados, que representaban proporcionalmente a todas las poblaciones musulmanas, así como a sociedades culturales, militares, de profesores, etc. El Presidio incluyó a doce personas, de las cuales seis eran tártaros (tres de Kazan-Orenburg y dos de Bakú), uno bashkir, un oseta, un turco de Crimea, un sart y un kirghiz. Una mujer, Selima Jakubova, presidió la convención.

Fue la situación de la mujer la que causó las primeras escaramuzas entre progresistas y conservadores. Los primeros ganaron gracias a las delegadas mujeres, a quienes los clérigos trataron en vano de excluir de la sala de reuniones. La resolución que se adoptó encarnaba las esperanzas de las mujeres en la Rusia islámica: igualdad absoluta entre los sexos, incluyendo la igualdad de derechos políticos, "porque así está escrito en las Escrituras"; la prohibición de enclaustrar a las mujeres, porque "no se encuentra en el Corán"; la obligación del consentimiento de las jóvenes para el matrimonio y la fijación de la edad mínima de 16 años para el casamiento; prohibición de la poligamia; derecho al divorcio; abolición de los prostíbulos y de las leyes existentes sobre la

N. 1, pp. 5-6, en Articulos, discursos, cartas, Moscú: Politizdat, 1975, pp. 36-38.] http://books.e-heritage.ru/book/10089772 
prostitución, etc. Más de doscientos clérigos musulmanes protestaron ruidosamente en nombre de la moralidad ante la adopción de dicho programa, pero fueron derrotados. Rusia se convirtió así en el país que dio los pasos más audaces hacia la liberación de la mujer musulmana. ${ }^{70}$

\section{La revolución bolchevique y la campaña electoral para la Asamblea Constituyente}

El 24 de octubre de 1917 los bolcheviques derrocaron al Gobierno Provisional y proclamaron un gobierno obrero-campesino, al que poco después se sumarían los socialistas revolucionarios de izquierda. Aunque la revolución en Petrogrado, a diferencia de Moscú, fue relativamente incruenta, poco después de la insurrección de octubre la organización de mujeres bolcheviques en la capital sufrió un duro golpe con la muerte de Vera Slutskaya, quien murió el 12 de noviembre de 1917 en manos de los cosacos cuando la unidad de Guardias Rojos a la que pertenecía fue enviada a sofocar la revuelta de Kerensky-Krasnov.

Las elecciones a la Asamblea Constituyente se celebraron el 25 de noviembre de 1917, y todos los partidos desarrollaron una intensa campaña en torno a las mismas con un alto grado de libertad (Radkey 1990). La Liga Panrusa por la Igualdad de Derechos de las Mujeres presentó una lista feminista, que incluía a Shishkina-Iavein, Maria Chejova, Ekaterina Kuskova, Ekaterina Shchepkina, Liubov Gurevich, las historiadoras populistas Alexandra Efimenko y Alexandra Kalmykova, y la instructora del Instituto Médico de Mujeres L.M. Gorolits-Vlasova, una médica de Kiev.

Por su parte, los bolcheviques hicieron un esfuerzo para movilizar a las obreras en apoyo de la lista electoral del Partido Bolchevique para las elecciones a la Asamblea Constituyente. La Conferencia de Mujeres Trabajadoras finalmente comenzó el 5 de noviembre, con una conferencia preliminar a la que asistieron 500 delegadas, representando a 80.000 mujeres trabajadoras no sólo de Petrogrado, sino de Moscú, Ivanovo y Tula. Se habían previsto alimentos y alojamiento para unas ochenta mujeres, pero pronto se hizo evidente que los bolcheviques habían subestimado enormemente las cifras. Esta respuesta fue una amplia justificación para los meses de trabajo que las mujeres bolcheviques habían

${ }^{70}$ Ferro 1972, pp. 150-151, ver la resolución conteniendo las aspiraciones de las mujeres musulmanas en el apéndice documental, pp. 356-357. 
realizado entre las mujeres trabajadoras de Petrogrado. La Primera Conferencia de Mujeres Trabajadoras de Petrogrado fue convocada oficialmente una semana después, el 12 de noviembre. El tema principal de discusión en el primer día de la conferencia fueron las elecciones a la Asamblea Constituyente. Konkordiia Samoilova dio el discurso de bienvenida.

Klavdia Nikolaeva, una obrera gráfica, la presidente de la conferencia y una de las editoras de Rabotnitsa a pesar de poseer sólo cuatro años de educación formal, habló primero. Nikolaeva explicó que, de las diecinueve listas electorales, sólo una, la de los bolcheviques, se había comprometido a representar a los trabajadores y se esforzaría por consolidar las conquistas revolucionarias obtenidas con tanto esfuerzo (para entonces el gobierno bolchevique ya había promulgado los decretos soviéticos sobre la paz, la tierra y la jornada de trabajo de ocho horas, y al día siguiente del discurso de Nikolaeva se promulgó el decreto sobre el control obrero de la industria). Nikolaeva advirtió a sus oyentes que no se dejasen engañar para votar por la lista no. 7, la lista de la Liga por la Igualdad de Derechos de la Mujer, compuesta principalmente por kadetes. Haciendo campaña en las fábricas, las portavoces de la Liga se comprometían a defender los intereses de las mujeres trabajadoras, explicó. En realidad, si eran elegidas para la Asamblea Constituyente, las delegadas de la Liga representarían a las mujeres privilegiadas. "Nosotras, las mujeres con conciencia de clase, sabemos que no tenemos ningún interés únicamente femenino, que no deberían existir organizaciones de mujeres separadas," declaró Nikolaeva. "Sólo somos fuertes cuando estamos unidos en una familia proletaria fraternal con todos los trabajadores que luchan por el socialismo." 71

Antes de que esta sesión de la conferencia terminase, la Dra. Doroshevskaia, pidió la palabra. Explicó que ella era uno de los candidatos a la Asamblea Constituyente y que quería hablar en nombre de la Liga por la Igualdad de las Mujeres. Una andanada de silbidos acogió sus palabras, pero, ante la insistencia de Kollontai, se le dio la oportunidad de hablar. La Dra. Doroshevskaia inmediatamente les aseguró que no era un parásito social, diciendo: "Yo misma soy una mujer trabajadora, una médica, mi esposo me abandonó, así que debo alimentar a mis hijos con mi propio trabajo". "En todas partes las mujeres están sometidas", prosiguió. "En todas partes todavía luchan por sus derechos. Las mujeres que nos visitan de América e Inglaterra se solidarizan con nosotras y nos desean lo

${ }^{71}$ Rabotnitsa, 8 de diciembre de 1917, pp. 10-11. 
mejor en nuestra lucha. Los hombres no pueden defender nuestros intereses, porque no nos entienden."

Ninguna de las obreras fabriles presentes expresó simpatía por Doroshevskaia. Más bien estaban claramente de acuerdo con la delegada Fyodorova, la esposa de un soldado, que se burló de la idea de que todas las mujeres tenían intereses comunes y sugirió que le preguntaran a las "compañeras empleadas domésticas" que trabajaban para gente como Doroshevskaia si esto era cierto. Las obreras fabriles estaban, obviamente, también de acuerdo con una segunda delegada, que se preguntó en voz alta dónde estaba la Liga por la Igualdad de Derechos de la Mujer cuando la jornada laboral de las obreras fabriles era de catorce horas, y cuando las trabajadoras embarazadas perdían a sus bebés en sus bancos de trabajo. ${ }^{72}$

Al día siguiente, dos obreras gráficas llamados Prokhorova y Vasileva y una trabajadora de una fábrica óptica, llamada Fomichev, leyeron informes sobre las condiciones de trabajo de las mujeres, y Anna Itkina habló de su trabajo con las mujeres del distrito de Narva. Kollontai aconsejó a las trabajadoras que estuvieran atentas a sus propios intereses y que eligieran a sus propios representantes a la Asamblea Constituyente, quienes plantearían la cuestión de la igualdad salarial, de la licencia por maternidad remunerada, y de la prohibición de las horas extras, del trabajo nocturno y de todo trabajo perjudicial para la salud de la mujer. Dada la pobreza y el aislamiento del nuevo gobierno, argumentó Kollontai, no se podía esperar que hiciera más al principio que proporcionarles a las mujeres la igualdad jurídica, introduciendo el matrimonio civil, legitimando por igual a todos los niños nacidos dentro y fuera del matrimonio, y otorgando el derecho al divorcio. Las mujeres todavía tendrían que luchar por conseguir su plena igualdad en el estado de los trabajadores, y esto, subrayó, solo podría hacerse si las trabajadoras formaban sus propios grupos dentro de los sindicatos, de los comités de fábrica, de los soviets y de las organizaciones del Partido (Porter, pp. 280-281).

Más de cuarenta millones de votos fueron emitidos en las elecciones a la Asamblea Constituyente. La tasa de participación electoral ha sido estimada por el historiador Oliver Radkey en aproximadamente un 5\%. La participación femenina en las ciudades, un 54 por ciento, superó a la de los hombres, un $47 \%$. A pesar de

\footnotetext{
72 Rabotnitsa, 8 de diciembre de 1917, pp. 11-12. Las citas de Rabotnitsa están tomadas del libro de Alexander Rabinowitch, The Bolsheviks in Power: The First Year of Soviet Rule in Petrograd, Bloomington: Indiana University Press, 2007, pp. 64-65.
} 
todos los obstáculos a su voto, el porcentaje de mujeres votantes alcanzó el 70\% en las zonas rurales; el total de hombres fue del 77\%. Entre las nacionalidades no rusas la participación fue alta. En áreas urbanas como Bakú, el número de mujeres musulmanas que votaron ascendió al 77\%. En total, 10 de los 767 diputados electos fueron mujeres; entre ellas se encontraban las bolcheviques Evgenia Bosh, Elena Rozmirovich, Alexandra Kollontai y Varvara Iakovleva y las socialistas revolucionarias Maria Breshko-Breshkovakaia, Vera Figner, Maria Spiridonova, M.D. Perveeva, O.A. Matveevskaia. Una feminista se presentó en la lista del partido kadete: Ariadna Tyrkova, en la lista de los kadetes en Nóvgorod, quien fue derrotada por una lista bolchevique que incluía a Trotsky.

Radkey da un total de 7.676 votos para la lista feminista: 5.310 votos en Petrogrado y 2.366 en el distrito electoral de Pskov un resultado insignificante para un total de más de 40 millones de votos (Radkey 1990, pp. 154, 157). La última evidencia de la actividad de la Liga Panrusa por la Igualdad de Derechos de las Mujeres es un folleto de 1918 titulado "Llamamiento de la Liga por la Igualdad de Derechos de las Mujeres a todos los rusos", exhortando a las mujeres a defender su patria de los invasores extranjeros y de los bolcheviques (Ruthchild 2001, p. 40).

En sus reminiscencias de la Primera Conferencia de Trabajadoras de Petrogrado, Kollontai no subrayó la victoria sobre las feministas sino el hecho de que en dicha conferencia se dieron "los primeros pasos para la protección de la maternidad", debido a las Tesis sobre Protección de la Maternidad adoptadas en la misma, las cuales fueron luego enviadas al Comisariado del Pueblo para la Asistencia Pública y al Comisariado del Pueblo del Trabajo, que incluía el Departamento de Bienestar Social, como "una guía". ${ }^{73}$

La Primera Conferencia de Trabajadoras de Petrogrado fue además importante por otro motivo, de carácter político más general. A principios de abril de 1917, Lenin asombró tanto a sus amigos como a sus enemigos cuando, después de llegar a la estación Finlandia, leyó su tesis defendiendo la transición de la Revolución Rusa de su primera etapa burguesa a una segunda etapa durante la cual el poder pasaría a manos del proletariado. Esta nueva política iba

\footnotetext{
73 Alexandra Kollontai "Die ersten Schritte zum Mutterschutz" (Manuskript 1927), in Kollontai, „Ich habe viele Leben gelebt": Autobiographische Aufzeichnungen, Berlin: Dietz Verlag, 1980, S. 348-353. [Alexandra Kollontai, "Los primeros pasos para la protección de la maternidad" (manuscrito de 1927), en Kollontai, "He vivido muchas vidas": Apuntes autobiográficos, Berlin: Dietz Verlag, 1980, pp. 348-353.]
} 
en contra de la perspectiva política de lo que Lenin llamó el "viejo bolchevismo" (la cual, a pesar de rechazar un frente común con la burguesía y abogar por una alianza del proletariado y el campesinado, limitaba la revolución a la consecución de metas democrático-burguesas) y señaló su acercamiento a la perspectiva de la revolución permanente bosquejada por primera vez por Trotsky y otros teóricos marxistas durante la revolución de 1905. Este rearme del Partido Bolchevique dio lugar a furiosas polémicas en sus filas en abril de 1917 y a un giro brusco en sus políticas, que documentamos en un artículo anterior. ${ }^{74}$ Las polémicas que tuvieron lugar en el seno del Partido Bolchevique entre el ala izquierda dirigida por Lenin y Trotsky y el ala derecha dirigida por Kamenev, Rykov, Zinoviev, Nogin y Vladimir Miliutin, entre otros, continuaron entre mayo y noviembre de 1917. Como lo demostró Alexander Rabinowitch, la revolución rusa no fue llevada a cabo por un partido "monolítico" sino en el marco de una lucha de tendencias, que reflejó tanto las tradiciones del "viejo bolchevismo" como las presiones a las que los dirigentes estuvieron sujetos por parte de otras tendencias políticas. La tendencia conciliacionista fue también muy fuerte en los primeros días posteriores a la toma del poder, ante la amenaza de una huelga general por parte del Comité Ejecutivo del Sindicato Panruso de Ferroviarios (Vikzhel) a menos que se estableciera un gobierno de coalición con los mencheviques y los socialistas revolucionarios, y no fue derrotada sino el 6 de noviembre de 1917, entre otras cosas gracias a la intervención de la Primera Conferencia de Trabajadoras de Petrogrado. ${ }^{75}$

Las aproximadamente quinientas mujeres presentes en la primera sesión de la Conferencia se inclinaron originalmente a apoyar la posición de los moderados bolcheviques sobre la construcción de un gobierno de coalición con los mencheviques y los socialistas revolucionarios, hasta que Liudmilla Stal, una ardiente oradora, una de los editoras de Rabotnitsa y una firme leninista, las persuadió de la crucial importancia de retener el gobierno existente, exclusivamente

\footnotetext{
${ }^{74}$ Daniel Gaido y Kevin Murphy, "De la dictadura democrática a la dictadura del proletariado: El debate en el Partido Bolchevique sobre las Tesis de Abril de Lenin", Hic Rhodus. Dossier: A cien años de la revolución rusa, nro. 12, agosto de 2017, pp. 1-30.

http://www.sinpermiso.info/textos/de-la-dictadura-democratica-a-ladictadura-del-proletariado-el-debate-en-el-partido-bolchevique

75 Alexander Rabinowitch, The Bolsheviks in Power: The First Year of Soviet Rule in Petrograd, Bloomington: Indiana University Press, 2007, p. 43, citando a Izvestiia, 7 de noviembre de 1918, p. 7.
} 
bolchevique, y de poner fin a las disputas intrapartidarias. En la noche del 5 de noviembre de 1917, una delegación de mujeres elegidas en la sesión se dirigió a Smolny, la sede del nuevo gobierno revolucionario, para transmitir estos sentimientos a los líderes bolcheviques. La delegación de trabajadoras, encabezada por Klavdiia Nikolaeva, se encontró en Smolny con Grigorii Zinoviev y Lev Kamenev, a quienes reprendieron por haber dividido al Partido y al gobierno bolchevique en un momento tan difícil. Según Stal, Zinoviev, a pesar de su elocuencia característica, no pudo hacer frente a lo que ella caracterizó como el "instinto de clase saludable" de las trabajadoras, las cuales "se aferraron" a su opinión de que el gobierno debía organizarse sobre la base del Partido Bolchevique solamente. En otra descripción del encuentro, Roza Kovnator, una destacada activista de Moscú, corroboró esta historia y señaló: "La delegación tuvo una conversación particularmente larga con el compañero Zinoviev, y tal vez algún día nos diga qué influencia tuvieron sobre él estas demandas de las trabajadoras de Petrogrado."76

\title{
Cierre: el gobierno bolchevique y la liberación de la mujer
}

\begin{abstract}
"Elijan más obreras al Soviet, tanto comunistas como apartidistas. Con tal que sean obreras honradas, capaces de realizar su trabajo de manera inteligente y honesta, aunque no sean miembros del partido, jelíjanlas al Soviet de Moscú!

“¡Más obreras en el Soviet de Moscú! ¡Que el proletariado de Moscú demuestre que está dispuesto a hacer y hace todo lo necesario para la lucha hasta la victoria, para la lucha contra la vieja desigualdad, contra la vieja humillación burguesa de la mujer!

"El proletariado no puede lograr la victoria completa sin conquistar la plena libertad para la mujer.

"N. Lenin (21 de febrero de 1920)."
\end{abstract}

A pesar de la hostilidad de las organizaciones feministas hacia la revolución bolchevique, la mujeres obtuvieron gracias a ella

76 Elizabeth A. Wood, The Baba and the Camarada: Gender and Politics in Revolutionary Russia, Bloomington: Indiana University Press, 1997, p. 70, citando a Roza [Kovnator], "Pervaia konferentsiia Petrogradskikh rabotnits," Kommunistka, No. 5, octubre de 1920, pp. 23-24. 
todos los derechos por los que las feministas habían estado luchando, no sólo en Rusia sino a nivel internacional, incluyendo los Decretos sobre el matrimonio civil y el divorcio del 16 y del 18 de diciembre de 191777, el Código de Leyes sobre el estado civil y las relaciones domésticas, el matrimonio, la familia y la tutela, del 16 de septiembre de $1918^{78}$, y el Decreto sobre la legalización del aborto promulgado el 10 de noviembre de $1920 .{ }^{79}$ El Decreto del Consejo de Comisarios del Pueblo de la RSFSR del 29 de octubre de 1917 sobre la jornada laboral de ocho horas, adoptado el 29 de octubre de 1917 (cinco días después de que los bolcheviques tomaran el poder), cumplió con lo estipulado en el programa bolchevique acerca de la protección de las mujeres trabajadoras, reduciendo drásticamente la jornada laboral.

77 Аекрет ВЦИК и СНК о расторжении брака. 16 Аекабря 1917 г. [Decreto del Comité Ejecutivo Central de toda Rusia y del Consejo de Comisarios del Pueblo sobre el divorcio (16 de diciembre de 1917)] http://www.hist.msu.ru/ER/Etext/DEKRET/17-12-16.htm Аекрет о гражданском браке, о детях и о ведении книг актов состояния. 18 Аекабря 1917 года. [Decreto soviético sobre el matrimonio civil, los niños y el registro civil (18 de diciembre de 1917)] http://istmat.info/node/28231

78 Всероссийский центральный исполнительный комитет (ВЦИК): Кодекс законов об актах гражАанского состояния, Брачном, Семейном и Опекунском праве. (22 октября 1918 года.) [Comité Ejecutivo Central Panruso (VTsIK): Código de leyes sobre actos de estado civil, matrimonio, familia y derecho custodio. (22 de octubre de 1918).] http://istmat.info/node/31624 El Código de Familia de 1918 ha sido traducido al inglés como The Marriage Laws of Soviet Russia: Complete Text of First Code of Laws of the Russian Socialist Federal Soviet Republic dealing with Civil Status and Domestic Relations, Marriage, the Family and Guardianship. New York: Russian Soviet Government Bureau, 1921. Disponible online en https://archive.org/details/marriagelawsofso00sovi

79 Una versión española del Decreto soviético sobre el aborto, promulgado por el Comisariado del Pueblo de Salud el 18 de noviembre de 1920 con el título "Sobre la protección de la salud de las mujeres", aparece en El marxismo y la liberación de las mujeres trabajadoras: de la Internacional de Mujeres Socialistas a la Revolución Rusa, Santiago de Chile: Editorial Ariadna, 2016, pp. 110-111. Lenin y los bolcheviques venían defendiendo el derecho al aborto ya antes de la revolución de octubre: "Exigir la abolición absoluta de todas las leyes contra el aborto o contra la difusión de literatura médica sobre medidas anticonceptivas. Semejantes leyes no muestran sino la hipocresía de las clases dominantes... Libertad para la propaganda médica y la protección de los derechos democráticos elementales de los ciudadanos, hombres y mujeres" (Lenin, "La clase obrera y el neomalthusianismo", Pravda, No. 102, 5 de mayo de 1913, en Lenin, Obras completas, Madrid: Akal, 1971, tomo 19, p. 480.) 
Además, las siguientes tres secciones hacían referencia al trabajo femenino:

6. Se prohíbe el trabajo nocturno de mujeres y varones menores de 16 años. [...]

15. Se prohíbe el trabajo subterráneo de mujeres y de adolescentes de ambos sexos menores de 18 años. [...]

18. Se prohíbe que trabajen horas extras todas las mujeres y varones menores de 18 años. ${ }^{80}$

Además, el Código de Trabajo adoptado por la República Socialista Federativa Soviética de Rusia en diciembre de 1918 estipulaba, en el artículo I, inciso 3(b), que las trabajadoras tenían derecho a una licencia por maternidad de 112 días, 8 semanas antes y 8 semanas después del parto, percibiendo íntegramente su salario, y, en el artículo VII, inciso 89, que a toda trabajadora madre de un hijo lactante se le debía otorgar cada tres horas un descanso de media hora para amamantar a su hijo. Además de esto, a cada trabajadora se le otorgaba un subsidio adicional durante el período de lactancia (alrededor de 600 rublos por mes en Moscú), e inmediatamente después de haber dado a luz se le concedía una subvención especial equivalente al salario de una quincena (720 rublos en Moscú) para la ropa del bebé y gastos similares. ${ }^{81}$ En 1923, la República Soviética Rusa incluso adoptó un estatuto pionero contra el acoso sexual de mujeres. ${ }^{82}$

80 Аекрет Совета Народных Комиссаров: О восьмичасовом рабочем Ане) [29 октября 1917 г.] [Decreto del Consejo de Comisarios del Pueblo: Sobre la jornada laboral de ocho horas (29 de octubre de 1917)] http://constitution.garant.ru/history/act1600-1918/5306/

81 Кодекс законов о труде 1918 года

http://www.hist.msu.ru/Labour/Law/kodex_18.htm Versión inglesa: The Labor Laws of Soviet Russia. With a supplement on The Protection of Labor in Soviet Russia, by S. Kaplun, of the Commissariat of Labor. $4^{\text {th }}$ ed. New York: Russian Soviet Government Bureau, 1921, pp. 15, 27, 56.

82 Cuando en 1926 se publicó un código penal revisado de la RSFSR, que reemplazó al código penal ruso de 1922, una enmienda de 1923 al artículo 169, que prohibía el acoso sexual a las mujeres, se transformó en el artículo 154. La edición de 1926 del artículo del código penal ruso declaraba lo siguiente: "La compulsión de una mujer a entablar relaciones sexuales o a satisfacer el deseo sexual en otra forma por parte de una persona de la cual la mujer era material o profesionalmente dependiente, [conlleva una pena de] encarcelamiento por hasta cinco años." ("154. Понуждение женщины к вступлению в половую связь или к удовлетворению половой страсти в иной форме Аицом, в отношении коего женщина явцялась материально 
Estos avances dramáticos se debieron a la política revolucionaria consecuente de los bolcheviques -que a diferencia de los partidos burgueses y pequeñoburgueses no buscaron llegar a un compromiso con el clericalismo, sino que llevaron a cabo una separación tajante entre la iglesia y el estado- pero también al gigantesco impulso que la militancia de las trabajadoras rusas había dado a la revolución. Pero a pesar de su carácter revolucionario (y en el caso del aborto, inédito) estas medidas democráticas eran vistas por los bolcheviques sólo como un primer paso hacia la abolición de la esclavitud doméstica mediante la socialización del trabajo doméstico y de la educación de los niños, lo cual crearía las bases materiales para la emancipación de la mujer y para el surgimiento de una nueva forma de familia. Dichos proyectos chocaron con los límites brutales impuestos por la herencia del atraso ruso, la destrucción causada por la Primera Guerra Mundial, la guerra civil y la intervención extranjera, y el aislamiento de la revolución, por lo que debieron ser parcialmente revertidos con la adopción de la Nueva Política Económica (NEP) en marzo de 1921, para finalmente ser liquidados con el ascenso de Stalin a partir de 1923. La emancipación de la mujer trabajadora representa, por ende, una tarea pendiente del movimiento obrero y socialista, lo que vuelve al rescate de la experiencia bolchevique al respecto una labor de importancia no solamente académica sino también política.

или по службе зависимой, - Аишение свободы на срок до пяти мет." Уголовный Кодекс РСФСР редакции 1926 [El Código Penal de la República Socialista Federativa Soviética de Rusia de 1926, artículo 154] https://coollib.com/b/124310/read (Healey 2001, pp. 160, 111, 305, 319) 


\section{Apéndice: \\ Los bolcheviques y los soviets de lucha contra la prostitución}

\section{August Bebel y Friedrich Engels sobre la prostitución}

La primera edición del libro de Bebel La mujer y el socialismo, que Kollontai llamaría la "Biblia" de las mujeres, apareció en 1879 con el título La mujer en el pasado, presente y futuro (McDermid and Hillyar 1999, p. 38 citando el prefacio de Kollontai a la edición rusa de A. Bebel, Zhenshchina i sotsializm, Petrograd, 1918, p. iv). Según Bebel, la penetración del nexo del dinero en todos los aspectos de las relaciones sociales, había convertido al matrimonio burgués en algo sin amor y al matrimonio proletario en algo miserable, llevando a un crecimiento gigantesco de la prostitución, con todas sus temidas consecuencias para las mujeres y jóvenes de la clase obrera, que de modo creciente se veían obligadas a dedicarse a ella para poder vivir, sobre todo en épocas de crisis y desocupación. Bebel consideraba a la prostitución "una institución social necesaria de la sociedad burguesa, al igual que la policía, el ejército permanente, la iglesia y la clase capitalista" (Bebel 1891, p. 141).

A fines del siglo XIX la mayoría de los estados europeos habían comenzado a legalizar y regular la prostitución, lo que significaba que los prostíbulos eran autorizados por el gobierno y se requería de las prostitutas registrarse y someterse a exámenes médicos periódicos. La reglamentación de la prostitución era vista como una reforma social destinada a mejorar la salud pública y reducir las enfermedades venéreas. Bebel se oponía al reconocimiento legal y a la supervisión estatal de la prostitución, y criticaba a quienes consideraban que la vigilancia policial de la prostitución era justificable y que el Estado debía proporcionar a los hombres prostitutas libres de sífilis. Además, el control de las prostitutas no incluía a los clientes, lo que volvía una farsa a la vigilancia médica como medida de profilaxis. La experiencia había enseñado que ni la introducción de burdeles públicos bajo supervisión policial ni el examen médico regular impedían la propagación de enfermedades venéreas (en particular la sífilis y la gonorrea), por no hablar del estigma social que imponían a las prostitutas que debían someterse a tales exámenes. Sujetas a la arbitrariedad policial, a la detención arbitraria y a la prisión, las mujeres que habían caído bajo el control policial eran degradadas a 
meros objetos. Bebel creía que la regulación estatal de la prostitución hacía "extremadamente difícil, incluso imposible, para la prostituta volver a encontrar alguna vez un trabajo decente. Una mujer que ha caído bajo el control de la policía está perdida para la sociedad, y por lo general se hunde en la miseria en unos pocos años" (Bebel 1891, p. 146). Finalmente, la prostitución daba lugar a la trata de mujeres a escala internacional, "esclavas blancas" a las que se mantenía atrapadas en los burdeles mediante un sistema de esclavitud por deudas (Bebel 1891, pp. 149-151).

Cinco años después de la publicación del libro de Bebel apareció el famoso libro de Engels El origen de la familia, la propiedad privada y el Estado. Siguiendo la tesis del antropólogo estadounidense Lewis H. Morgan, Engels sostenía que la primera institución doméstica en la historia humana no había sido la familia sino el clan matrilineal, y afirmaba que el derrocamiento del derecho materno por los griegos y los romanos fue "la gran derrota histórica del sexo femenino en todo el mundo."

Ya "en la época floreciente de Atenas" Engels atestiguaba la existencia de "una prostitución muy extensa y protegida por el Estado". La proliferación de hetairas era la contrapartida de la degradación de la mujer destinada a procrear descendientes legítimos: "En Eurípides se designa a la mujer como un oikurema, como algo destinado a cuidar del hogar doméstico (la palabra es neutra), y, fuera de la procreación de los hijos, no era para el ateniense sino la criada principal" (Engels 1884, pp. 78-79). En Roma, la palabra familia no se aplicaba a la pareja conyugal y a sus hijos, sino tan sólo a los esclavos. Famulus quería decir esclavo doméstico, y familia era el conjunto de los esclavos pertenecientes a un mismo hombre. En tiempos de Gaius la "familia, id es patrimonium" (es decir, herencia), se transmitía aun por testamento. Esta expresión designaba un nuevo organismo social, cuyo jefe tenía bajo su poder a la mujer, a los hijos y a cierto número de esclavos, con la patria potestad romana y el derecho de vida y muerte sobre todos ellos. El fin de la nueva institución familiar era procrear hijos cuya paternidad fuera indiscutida; esto era indispensable porque los hijos serían los herederos de las propiedades del padre (Engels 1884, pp. 70-71).

La aparición de una clase social desprovista de medios de producción y de bienes que puedan ser transmitidos en herencia por primera vez sentó las bases para la desaparición de la monogamia y para el surgimiento de nuevas formas de relaciones entre los sexos, desprovistas de consideraciones materiales. "Así, pues, la familia del proletario ya no es monogámica en el sentido estricto de la palabra" y 
señala la transición hacia una nueva forma de familia y de sociedad (Engels 1884, p. 88). Engels se preguntaba qué sucedería con la prostitución en este nuevo orden social, y contestaba: "con la transformación de los medios de producción en propiedad social desaparecen el trabajo asalariado, el proletariado, y, por consiguiente, la necesidad de que se prostituyan cierto número de mujeres que la estadística puede calcular. Desaparece la prostitución, y en vez de decaer, la monogamia llega por fin a ser una realidad, hasta para los hombres" (Engels 1884, p. 92). La familia individual dejaría de ser la unidad económica de la sociedad y la economía doméstica se convertirá en un asunto social; el cuidado y la educación de los hijos, también. La sociedad cuidaría por igual de todos los niños, dando lugar al desarrollo de relaciones sexuales más libres y, al mismo tiempo, a la desaparición de la prostitución junto con la monogamia, ya que "en el mundo moderno la prostitución y la monogamia, aunque antagónicas, son inseparables, como polos de un mismo orden social" (Engels 1884, p. 93).

\section{La prostitución en Rusia antes de la Revolución de Octubre de 1917}

En la Rusia zarista, la prostitución estaba generalizada. Un sistema de registro de las prostitutas estaba en uso, y poco antes de la Primera Guerra Mundial, 40.000 mujeres se habían registrado en San Petersburgo y 20.000 en Moscú. Muchas más mujeres practicaban la prostitución sin registrarse (Quigley 1991, p. 1204).

Los móviles que, antes de la Revolución de Octubre, empujaban a las mujeres rusas a seguir el camino de la prostitución eran, en primer lugar, causas comunes al conjunto de los países capitalistas, tales como los salarios insuficientes (menos de la mitad de los pobres salarios de los trabajadores), las largas horas el trabajo, la falta de protección laboral y de inspección de las condiciones higiénicas, el desempleo, etc. En segundo lugar, existían una serie de causas derivadas del carácter inconcluso de la revolución democrático-burguesa en Rusia: la restricción extrema de los derechos civiles y políticos de las mujeres, su imposibilidad absoluta de acceder a las carreras de Estado, las oportunidades limitadas de obtener una calificación mediante la instrucción, la prohibición de obtener trabajo en toda una serie de profesiones, la servidumbre en el ámbito de los derechos de propiedad y de herencia.

La inferioridad y subordinación de la mujer en la familia estaban sancionadas por la legislación. El artículo 107 del tomo X del 
"Código Civil" de la Rusia zarista, publicado en 1832 bajo el título de "Cuerpo de leyes del Imperio de Rusia", decía: "La mujer está obligada a obedecer a su marido como cabeza de familia; a amarlo y respetarlo y manifestarle una obediencia ilimitada ( $v$ neogranichennom poslushanii); a testimoniar su satisfacción y apego a él como cabeza de familia" (Lamarche Marrese 2006, p. 337). Los cónyuges estaban obligados a vivir juntos y, por tanto, en caso de mudanza, de entrada, en funciones, o de cualquier otro cambio de residencia permanente del marido, la mujer estaba obligada a seguirle. Por las mismas causas existía una ausencia de responsabilidad del padre hacia los niños nacidos fuera del matrimonio.

El mayor número de prostitutas era reclutado entre las sirvientas que generalmente venían del campo. La tierra fragmentada al extremo, las granjas campesinas que no poseían un caballo, el hambre y la miseria del pueblo forzaban a cientos de miles de campesinas jóvenes a dejar el campo para buscar trabajo en la ciudad. De acuerdo con el censo de la población rusa en 1897, el número de empleadas domésticas era 1.300.000. En la mayoría de los casos, las empleadas domésticas enfrentaban condiciones de trabajo extremadamente duras y serviles. Cuando perdían su trabajo, y al mismo tiempo su salario y su hogar, las empleadas domésticas quedaban desamparadas, y a menudo, encontrándose en la calle, tomaban el camino de la prostitución:

Según el censo de 1889 de Dubrovskii, 8.151 prostitutas (46 por ciento) enumeraban el servicio doméstico como su antiguo trabajo. Otros estudios también demostraban que la mayoría de las prostitutas afirmaba haber trabajado como ama de llaves, cocinera y niñera antes de dedicarse a la prostitución. Por ejemplo, 1.753 (41 por ciento) de las mujeres estudiadas por Oboznenko en 1891-93 habían sido sirvientas. Entre las mujeres que se registraron [como prostitutas] en 1909, el 48 por ciento había estado en el servicio doméstico. A modo de comparación, las sirvientas en general comprendían solamente un tercio de las trabajadoras en San Petersburgo (1890) y el 28 por ciento de las mujeres en Moscú (1902) (Bernstein 1995, pp. 107108).

Un número significativo de prostitutas eran ex-trabajadoras textiles que vivían de un salario miserable, sujetas a la buena voluntad de sus jefes, que a menudo eran procuradores y transformaban sus talleres en centros de reclutamiento para prostíbulos. 
La situación económica de las trabajadoras fabriles, cuyo salario promedio era de 9 a 10 rublos al mes, es decir de dos a dos veces y media menor que el de los hombres, no era envidiable tampoco. Sin embargo, a pesar de este salario de hambre las trabajadoras resistían tenazmente las tentaciones de la prostitución, ya que eran sostenidas, en la fábrica, por una creciente conciencia de clase de la cual estaban desprovistas las empleadas domésticas. Vimos más arriba el testimonio de Nadezhda Krupskaya, en su folleto "La mujer trabajadora" (1899), sobre cómo los empleadores instaban a las obreras a prostituirse para complementar sus magros salarios y cómo los trabajadores respondieron incendiando los burdeles.

\section{La regulación de la prostitución en la Rusia zarista}

En Rusia antes de la Revolución de Octubre, como en muchos otros países de la época, existía una regulación de la prostitución, estrechamente relacionada con una vigilancia médicopolicial. Esta vigilancia médico-policial incluía no sólo la revisión obligatoria de las mujeres sometidas a examen y su confinamiento forzoso en caso de enfermedad, sino también una serie de medidas que exacerbaban la posición inferior de las mujeres y empeoraban su situación económica.

Estas medidas incluían ante todo el registro de prostitutas, es decir, el registro oficial de sus nombres en la lista de prostitutas. Les retenían el pasaporte (en la Rusia prerrevolucionaria cada persona tenía necesariamente un pasaporte expedido por la policía o, en el campo, por las autoridades locales), que sustituían por una tarjeta especial. La libertad de movimiento de una prostituta bajo vigilancia era limitada. Experimentaba tales dificultades en la elección de su casa, que casi todas las prostitutas se reunían en un local especial - los burdeles.

La tarjeta médica expedida a mujeres inscritas en las listas de la prostitución era llamada, en la Rusia zarista, la "tarjeta amarilla". Cada vez que estaba obligada a presentar un documento de identidad, la prostituta no podía ocultar su condición, por lo que su tarjeta amarilla le impedía, en la mayoría de los casos, el retorno a la vida laboral. Cuando, empujadas por el desempleo, la temporada baja, o salarios extremadamente reducidos, las mujeres recurrían a la prostitución como un medio temporal de sustento, eran registradas con facilidad y recibían la tarjeta amarilla, que luego volvía casi imposible para ellas recomenzar una vida de trabajo. 
En muchas ciudades, el estado de servidumbre impuesto por la tarjeta amarilla era reforzado con medidas adicionales. Por ejemplo, en Varsovia, de conformidad con una decisión del comité médico-policial, las mujeres inscritas en las listas de las prostitutas debían, en el momento del censo, ser designadas como "prostitutas"; en las listas de los inquilinos que se mostraban en la entrada de cada casa, había que dejar un espacio en blanco en la rúbrica "profesión" antes del apellido de la prostituta, que debía ser subrayado, pero en la práctica en lugar del nombre subrayado simplemente se escribía "prostituta". Las prostituidas registradas tenían en principio derecho a elegir una vivienda; pero en realidad encontraban enormes obstáculos para ejercerlo. Por ejemplo, el municipio de Minsk había decretado: "se prohíbe la vivienda en alquiler para las prostitutas sin el permiso del Comité de Salud". En varias otras ciudades se decidió que las prostitutas que no vivían en los burdeles podrían ocupar viviendas particulares, pero en algunas calles y de forma individual.

Eran especialmente los burdeles los que alojaban a las prostitutas y las retenían en dicha condición. Si las condiciones de control y las regulaciones a las que estaba sujeta la mujer que vivía en viviendas privadas, obligada para poder vivir a ejercer parcialmente la prostitución, la privaban de la posibilidad de ganarse la vida mediante un trabajo o un oficio cualquiera, las condiciones de vida en un burdel destruían en ella el hábito del trabajo.

La supervisión médico-policial de las prostitutas tenía un carácter de clase muy marcado, lo cual afectaba particularmente a las mujeres pertenecientes a los estratos más pobres de la población. De acuerdo con la normativa aplicable en Riga, por ejemplo, sólo podían ser objeto de supervisión "las personas pertenecientes a los estratos más bajos de la población." En Kronstadt, el reglamento indicaba que la supervisión debía extenderse sólo a las mujeres "del pueblo" y no a las personas de las clases "distinguidas". Según el reglamento de San Petersburgo, la policía debía someter a la consulta médica sólo a "mujeres de clase baja." De acuerdo con el reglamento de Jarkov, era necesario, en las búsquedas de prostitutas clandestinas, "limitarse a detener a las mujeres proletarias" (Bronner 1936, pp. 10-11).

En virtud de la ley, si una prostituta se negaba a someterse a la supervisión y contagiaba a un cliente de una enfermedad venérea, era castigada con la detención o con una multa de 500 rublos. La supervisión de la prostitución clandestina se hacía generalmente mediante redadas, mediante detenciones en las calles, en los cabarets y en los refugios nocturnos de mujeres sospechosas de ejercer la 
prostitución clandestina, donde se detenía a menudo también a mujeres inocentes. "San Petersburgo exigía que todas las mujeres vagabundas se sometieran a exámenes médicos, y los agentes del comité de hecho incluían a mujeres en las listas de prostitutas contra su voluntad" (Bernstein 1995, p. 37). Una vez en las garras de la regulación, era casi imposible para la mujer escapar de dicha condición.

Por otro lado, la supervisión de la prostitución en la Rusia zarista no daba ningún resultado desde el punto de vista sanitario: las consultas médicas en todas las ciudades del Imperio Ruso estaban mal organizadas; se examinaba a las mujeres en locales donde las prostitutas no podían siquiera desvestirse; la inspección se realizaba a toda prisa, en un cuarto oscuro, a menudo por un enfermero o enfermera; el resultado de esta visita médica sólo beneficiaba al fisco. Según el testimonio ofrecido en 1897 por el doctor Konstantin Stürmer, director del departamento médico:

las prostitutas en la ciudad de Bakú eran examinadas en la comisaría de policía en un salón deshilachado o en una mesa prestada de otra oficina. Las prostitutas aguardaban su turno para encontrarse con el "público abigarrado" habitual y, según los funcionarios de Bakú, a menudo estaban demasiado "avergonzadas" para llegar sobrias. Por los funcionarios de Saratov, Stürmer se enteró de que las prostitutas en burdeles eran examinadas en simples tablas. Se desnudaban, montaban la mesa y, como no había espéculo disponible, extendían sus propios labios vaginales (ocultando a veces las úlceras venéreas con los dedos). En Orel, las prostitutas eran examinadas en una habitación pequeña, húmeda y mal iluminada en la comisaría local. En Nikolaevsk y Tula, los policías llevaban a las prostitutas a las celdas de la prisión para sus exámenes. En Astrajan, las mujeres eran examinadas en una silla de madera por médicos que carecían de instrumentos médicos. Los médicos de la ciudad báltica de Revel (ahora Tallin) tampoco contaban con equipo médico especial para exámenes internos, y examinaban a las prostitutas en una habitación pequeña y sin calefacción. El comité médicopolicial de Varsovia realizaba los exámenes de prostitutas en un sótano oscuro ante la humillante presencia de varios policías. Stürmer se refirió a las condiciones de Zamost como "indignantes". En el informe del médico del distrito, descubrió que los exámenes se realizaban en una habitación de la planta baja cuya ventana daba a la calle. Cuando las prostitutas venían para sus exámenes 
semanales, una multitud de espectadores se reunía en la calle para echar un vistazo por la ventana abierta y burlarse (Bernstein 1995, pp. 107-108).

No estaba mejor organizado el tratamiento médico de las prostitutas. Era insuficiente incluso en las grandes ciudades. En Nizhny Novgorod, Saratov, Kiev, Tomsk no se hospitalizaba, por falta de espacio, a todas las prostitutas que tuvieran enfermedades venéreas contagiosas. En muchas ciudades, las prostitutas se veían obligadas a pagar el tratamiento médico, que costaba a menudo grandes sumas. Es evidente que los resultados de dicha supervisión médico-policial eran muy insatisfactorios.

En 1889, A. Dubrovskii, editor de un censo de la prostitución rusa en el imperio, estimó que el 58 por ciento de todas las prostitutas registradas sufría de una enfermedad venérea. En la muestra de Oboznenko, alrededor de la mitad de las prostitutas habían contraído sífilis o gonorrea durante el primer año después del registro... También existían tasas extremadamente altas de enfermedades venéreas entre las mujeres recién registradas como prostitutas, lo que a menudo eran una indicación de que habían tenido relaciones sexuales comerciales. Entre los inscritos por primera vez en San Petersburgo en 1908, 213 (28 por ciento) de 756 mujeres sufrían de enfermedades venéreas. En 1909, el porcentaje subió a 37 por ciento, o 199 de las 545 mujeres que se registraron. (Bernstein 1995, pp. 74, 48)

No es de extrañar que en estas circunstancias también en Rusia naciera un movimiento a favor de la abolición de la supervisión médico-policial. El gobierno se limitó a permitir en el año 1910 la convocatoria a un congreso de lucha contra el tráfico de mujeres y sus organizaciones. En la Segunda Conferencia Internacional de Mujeres Socialistas celebrada en Copenhague, Dinamarca, en agosto de 1910, Alexandra Kollontai presentó un informe sobre el movimiento de trabajadoras rusas en el que señalaba que, al igual que el movimiento obrero y la izquierda en su conjunto, el movimiento de mujeres proletarias también había sufrido los golpes de la reacción que siguió a la revolución de 1905, "pero el Congreso para la lucha contra la prostitución que tuvo lugar en abril de 1910 en San Petersburgo reavivó la actividad de los círculos de trabajadoras en Petersburgo y Moscú. Asambleas públicas y secretas tuvieron lugar, e incluso fue enviada como delegada al congreso una representante de 
las trabajadoras de Moscú" (Kollontai 1910, p. 75). Su actitud, al igual que la de sus camaradas, era una de oposición frontal a la prostitución. El congreso decidió por unanimidad apoyar la demanda de exigir al gobierno el cierre inmediato de los burdeles. Esta decisión, sin embargo, no se implementó.

\section{La revolución bolchevique y la liberación de la mujer}

La revolución bolchevique tuvo un carácter combinado: fue producto de la combinación de una revolución obrera socialista en las ciudades con una revolución democrático-burguesa respaldada por una gran revuelta campesina en las zonas rurales, en las cuales residía la aplastante mayoría de la población -el 84\% en 1926, según Moshe Lewin (Lewin 2005, p. 61). Esto se reflejaba en muy bajos niveles de alfabetización: en 1920, sobre 1.000 mujeres había apenas 225 que sabían leer y escribir, lo que arrojaba una tasa de analfabetismo femenino del $78 \%$ (Bronner 1936, p. 23). La legislación soviética temprana también tuvo, en consecuencia, un carácter combinado, que reflejaba este proceso de revolución permanente -es decir, de combinación de las tareas democráticas y socialistas en la revolución.

Entre las medidas de carácter democrático adoptadas por el gobierno bolchevique a fin de impulsar la liberación de la mujer se cuentan los Decretos sobre el matrimonio civil y el divorcio del 18-19 de diciembre de 1917;83 el Código de Leyes sobre el estado civil y las relaciones domésticas, el matrimonio, la familia y la tutela del 16 de septiembre de 1918; ${ }^{84}$ y el Decreto sobre la legalización del aborto promulgado el 10 de noviembre de 1920, el cual convirtió a Rusia en el primer estado del mundo en legalizar la interrupción voluntaria del embarazo. ${ }^{85}$

La legislación soviética colocó a la mujer jurídica y políticamente en pie de igualdad con el hombre. Sin embargo, esto de por sí no eliminó la prostitución. En un escrito de julio de 1920 titulado "La obrera en la Rusia soviética", Inessa Armand, la dirigente del de Zhenotdel, el Departamento de Mujeres de la Secretaría del

\footnotetext{
83 Ver la version inglesa en Decrees and Constitution of Soviet Russia, reprinted from The Nation, New York, December 28, 1919, pp. 56-60.

84 Ver la version inglesa en The Marriage Laws of Soviet Russia 1921, con un prólogo fascinante del editor en jefe del Colegio de Leyes, A. G. Hoichbarg. 85 Ver la versión española del decreto en Cintia Frencia y Daniel Gaido, El marxismo y la liberación de las mujeres trabajadoras: de la Internacional de Mujeres Socialistas a la Revolución Rusa, Santiago de Chile: Editorial Ariadna, 2016, pp. 109-111. http://oapen.org/search?identifier=619630
} 
Comité Central del Partido Comunista de Rusia, señalaba que objetivo de la erradicación de la prostitución (a la cual describía como "el fenómeno más repugnante, el más odioso de la esclavitud asalariada del proletariado") había sido afirmado en el Primer Congreso de Toda Rusia de Trabajadoras y Campesinas, celebrado en Moscú del 16 al 21 de noviembre de 1918, al que asistieron 1.147 delegadas en representación de más de un millón de mujeres. ${ }^{86} \mathrm{La}$ resolución al respecto rezaba:

Constatando que las raíces de la prostitución están profundamente arraigadas en la sociedad capitalista, la primera conferencia de toda Rusia de obreras y campesinas pobres invita a luchar contra la prostitución no sólo mediante el cierre de los prostíbulos, no sólo mediante el castigo a los proxenetas... sino mediante la erradicación de todo el legado del régimen capitalista a través de la aplicación del seguro de maternidad, de la educación universal de los niños y de la substitución de la familia burguesa por el matrimonio libre (Armand 1921, p. 13).

El congreso declaró que la mujer rusa, como ciudadana libre e igual, ya no debía estar sujeta a la prostitución, y aprobó una resolución que afirmaba que "la ciudadana de la Rusia soviética nunca debe ser objeto de compra y venta" (Wood 1997, p. 112).

\section{La prostitución bajo el comunismo de guerra (1918-21)}

El 28 de junio de 1918 el gobierno soviético se vio obligado a dar inicio a la política económica conocida como "comunismo de guerra", basada en la requisa forzosa de grano debida al bloqueo y al consecuente colapso de la producción industrial. Dicha política, que los campesinos soportaron porque detrás de los ejércitos blancos se encontraban los antiguos terratenientes que hubieran revertido la reforma agraria adoptada por el nuevo régimen, permitió al gobierno bolchevique poner en pie un Ejército Rojo de cinco millones de personas y derrotar a los blancos, pero entró en crisis con la finalización de la guerra civil y de la guerra ruso-polaca, lo que

86 Первый Всероссийский съезА работниц и крестьянок, Москве 16-21 ноября 1918 года. Ver la nota de Kollontai sobre el congreso en Колмонтай 1923 y las resoluciones del congreso en Первый Всероссийский съезА работниц 16-21 ноября 1918 года и его резолюции, Харьков, 1920 (El Primer Congreso de Mujeres Trabajadoras de Rusia del 16 al 21 de noviembre de 1918 y sus resoluciones, Kharkov, 1920. 23 pp.) 
condujo a masivos levantamientos campesinos como la revuelta de Tambov (Antonovshchina) y finalmente a la revuelta de Kronstadt en marzo de 1921, que forzó al Décimo Congreso del Partido Bolchevique a abandonar el "comunismo de guerra" y a adoptar la Nueva Política Económica (NEP).

Durante los duros años del "comunismo de guerra" el problema de la prostitución perdió su filo. En un momento en que para toda la población la falta de mercancías era general, y en el que el dinero había perdido todo valor y era reemplazado por la cartilla de racionamiento, la clientela de la prostitución en general se redujo drásticamente. Al mismo tiempo, el poder soviético estableció la obligación general de trabajar. La primera Constitución soviética, adoptada el 10 de julio de 1918, afirmaba explícitamente: "La República Socialista Federativa de los Consejos (Soviets) de Rusia considera el trabajo como deber de todos los ciudadanos de la República y proclama esta divisa: 'el que no trabaja no tiene derecho a comer'.” (p. 101) La obligación universal del trabajo vigente bajo el comunismo de guerra, presuponiendo la inexistencia del desempleo, se refleja claramente en el siguiente poster contemporáneo:

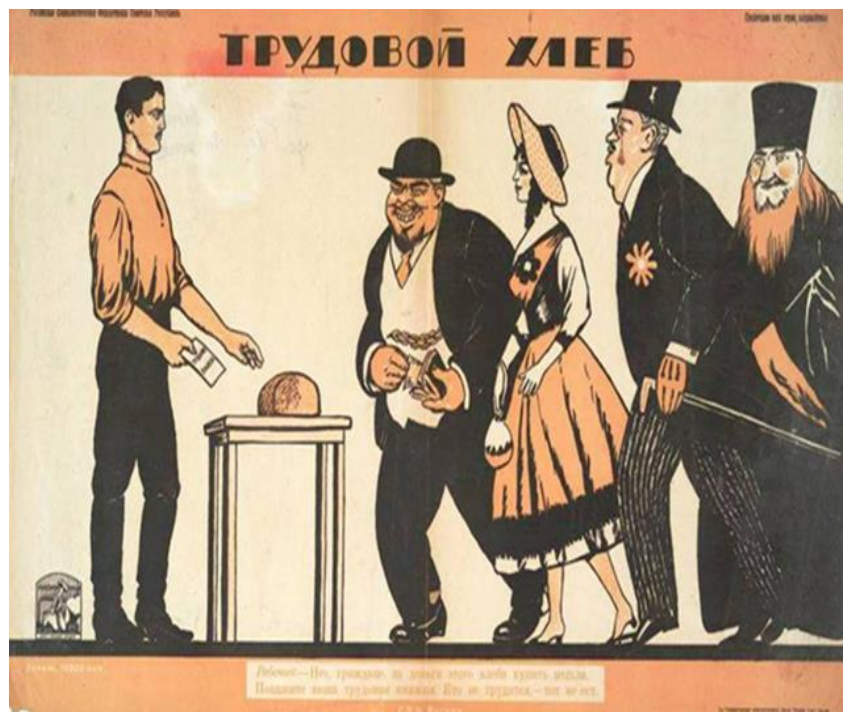

Трудовой хлеб. «Нет, гражАане, за деньги этого хлеба купить нельзя. Покажите ваши трудовые книжки. Кто не трудится, - тот не ест». (1920) Pan ganado con el trabajo. "No, ciudadanos, no se puede comprar este pan con dinero. Muestren sus registros de empleo. Quien no trabaja - no come". (1920) 
Es en este contexto que fue pronunciado el discurso de Alexandra Kollontai, entonces Comisaria del Pueblo para la Asistencia Pública, en 1921, en ocasión de la tercera conferencia de dirigentes de los Departamentos Regionales de la Mujer de toda Rusia. Titulado "La prostitución y las formas de combatirla", dicho discurso afirmaba que, en el marco de la política del comunismo de guerra, las prostitutas debían ser consideradas como "desertoras del trabajo" y ser objeto de la obligación universal del trabajo como todos los otros ciudadanos soviéticos (Kollontai 1921b).

En una serie de catorce lecciones pronunciadas en la Universidad Sverdlov de Leningrado en la primavera de 1921, Kollontai resumió como sus argumentos de la siguiente manera:

Como es natural tampoco existe en nuestra nueva sociedad sitio para los parásitos femeninos -por ejemplo, para las queridas bien alimentadas que viven a cuenta de sus maridos o amantes o para las prostitutas profesionales-, pues entre nosotros campea el lema: «la que no trabaja, que no coma». Pero no solamente ha cambiado nuestra relación respecto al matrimonio y a la familia, sino también nuestro criterio frente a la prostitución. Las distintas formas del fenómeno de la prostitución que existen en la sociedad burguesa, y van en aumento, retroceden cada vez más en nuestra república de trabajadores. Esa prostitución es consecuencia de la situación social insegura de la mujer y de su dependencia del hombre. Desde que nos preocupamos de que la implantación del trabajo general obligatorio se extienda a todo trabajo, naturalmente ha retrocedido también la prostitución profesional. En los lugares donde sigue existiendo esa prostitución en nuestra república de trabajadores es combatida por las autoridades. Pero la combatimos no porque la consideremos un delito contra las buenas costumbres, sino porque se trata de una forma del fenómeno de «deserción de la producción», ya que una prostituta profesional no aumenta con su trabajo la riqueza de la sociedad, sino que en realidad vive de la ración de otros. Por eso condenamos la prostitución y la combatimos como una forma de negarse a trabajar. Las prostitutas no son ante nuestros ojos una categoría de seres especialmente reprobables, y en definitiva en nuestra república de trabajadores no juega ningún papel si ahora una mujer vende su cuerpo a muchos hombres o solamente a uno; por consiguiente, si se mantiene a costa de un marido o como prostituta profesional a costa de muchos hombres. Pues en ambos casos las mujeres no se 
alimentan con su propio trabajo productivo. Por eso todas las mujeres que no acuden al trabajo general obligatorio, $y$ no tienen en su familia niños pequeños a quienes atender, son obligadas a trabajar exactamente como las prostitutas (Kollontai 1921c).

Pero la realidad soviética, signada por la herencia del atraso ruso y por la devastación causada por la primera guerra mundial, la guerra civil y la guerra rusa-polaca, con sus secuelas de millones de muertos, distaba mucho de la visión idealizada de Kollontai sobre el comunismo de guerra. En 1920, Krupskaya describía en la revista Komunistka ( $\mathrm{La}$ comunista) cómo mujeres abandonadas, viudas campesinas, madres de hijos pequeños, todas desesperadas, se entregaban a la prostitución: "La pobreza obliga a las mujeres a venderse", escribía Krupskaia. "No son prostitutas que hacen un negocio con esto, sino madres de familia". La pobreza empujaba a las mujeres al "sexo por un trozo de pan"; era "la tumba de las relaciones humanas" (Крупской 1920, p. 18). Para el año 1922, luego de la terrible hambruna de 1921, había en Rusia al menos 7 millones de niños sin hogar (besprizorniki), reducidos al vagabundeo, la limosna, la delincuencia y la prostitución (Ball 1994, p. 1).

\section{La nueva definición legal de la prostitución}

Las medidas adoptadas por el gobierno bolchevique con el fin de liberar a las mujeres fueron acompañadas por una política de erradicación de la prostitución. Dentro del Partido Comunista, se estableció en agosto de 1919 un Departamento de Mujeres de la Secretaría del Comité Central (Zhenotdel) que consideraba a la eliminación de la prostitución como uno de sus objetivos principales. En 1919, el Comisariado del Pueblo de Salud formó por primera vez una comisión contra la prostitución, la cual fue reorganizada en 1923 bajo el Comisariado del Pueblo de Salud como el Consejo Central de Lucha contra la Prostitución.

En consonancia con la actitud de Bebel, el gobierno soviético abolió la política regulatoria zarista hacia la prostitución y se opuso tanto a la regulación como a la criminalización. Por lo tanto, la prostitución no fue considerada un delito, pero se prohibió el proxenetismo o regentear un prostíbulo. En 1921, un tribunal ruso condenó a varias mujeres por dedicarse a la prostitución. En el mismo caso, el tribunal condenó a otras personas por proxenetismo y por permitir la prostitución en su departamento. El Comisariado del Pueblo de Justicia, en ejercicio de su poder de "control judicial 
supremo", revocó las condenas por ejercicio de la prostitución, mientras que mantuvo las convicciones de las demás personas. El Comisariado explicó de la siguiente manera los motivos de su decisión:

\begin{abstract}
$\mathrm{Si}$ bien es indiscutible que el proxenetismo y el mantenimiento de un centro de corrupción son delitos penales, el acto de ejercicio de la prostitución como tal no puede de por sí ser considerado punible; la lucha contra este mal social, que es el resultado, principalmente, de la pobreza de las masas y de la condición inferior de la mujer, una herencia inevitable del orden burgués-capitalista, debe llevarse a cabo a través de medidas dirigidas a la eliminación de las causas que lo generan (Comisariado del Pueblo de Justicia, Decisión en la causa penal No. 2828 de 1921, citado en Quigley 1991, p. 1211).
\end{abstract}

Por lo tanto, el ejercicio la prostitución no estaba tipificada como delito. El primer Código Penal de la Rusia Soviética fue promulgado en 1922. No penalizaba ejercer la prostitución o la compra de los servicios de una prostituta. Pero en línea con la decisión del Comisariado del Pueblo de Justicia de 1921, el artículo 171 prohibía el proxenetismo y el artículo 172 penalizaba regentear un prostíbulo. Los tribunales imponían penas severas, por lo general de tres años o más, a las personas condenadas en virtud de estos artículos (Quigley 1991, p. 1211).

\title{
Las Directrices para el Movimiento Comunista Femenino y la prostitución (1920)
}

La Internacional Comunista, fundada en marzo de 1919, creó en una rama femenina autónoma en abril de 1920, la cual organizó la primera de una serie de cuatro Conferencias Internacionales de Mujeres Comunistas en Moscú entre el 30 de julio y el 2 de agosto de 1920, durante el Segundo Congreso de la Internacional Comunista. Las "Directrices para el Movimiento Comunista Femenino" fueron redactadas por Clara Zetkin y, previa consulta con el Comité Ejecutivo de la Internacional Comunista, editadas por ella para su presentación al Segundo Congreso de la Internacional Comunista.

El Congreso, por falta de tiempo, no pudo tratar la cuestión de las mujeres según lo previsto inicialmente, pero de todas maneras las Directrices de Zetkin fueron publicadas en el órgano oficial de la 
Tercera Internacional, Die Kommunistische Internationale, y son indicativas de la política de los bolcheviques hacia la prostitución (Zetkin 1920).

Las Directrices instaban a los Partidos Comunistas en los países en los cuales el proletariado había conquistado el poder estatal y edificado su dominio en el sistema de los soviets, como en Rusia, a adoptar "previsiones económicas y educativas que permitan la recuperación de las prostitutas, esa herencia del orden burgués, rescatándolas del lumpenproletariado y reincorporándolas a la comunidad de los trabajadores" (Zetkin 1920, p. 545).

En todos los países en los cuales el proletariado seguía luchando por la conquista del poder político, las Directrices instaban a los Partidos Comunistas a la "Adopción de disposiciones económicas y sociales adecuadas para combatir la prostitución; medidas higiénicas contra la difusión de las enfermedades venéreas; eliminación del ostracismo social hacia las mujeres prostituidas; superación de la doble moral sexual, distinta para los dos sexos" (Zetkin 1920, p. 548).

Luego del fallecimiento de Inessa Armand a causa del cólera el 24 de septiembre de 1920, fue Kollontai quien presentó el informe introductorio de la Segunda Conferencia Internacional de Mujeres Comunistas que se reunió en junio de 1921 bajo la presidencia de Clara Zetkin, en vísperas del Tercer Congreso de la Internacional Comunista. En dicha Conferencia, Kollontai propuso tres líneas de intervención: "El Día Internacional de la Mujer del 8 de marzo, la lucha contra la prostitución y la batalla por la despenalización del aborto" (Marie 2010, p. 455).

\section{La Nueva Política Económica (NEP) y el resurgimiento de la prostitución}

La Nueva Política Económica -adoptada, como dijimos, bajo la presión de las rebeliones campesinas y de la revuelta de Kronstadt- fue básicamente una política de concesiones al campesinado, comenzando por la abolición de la requisa de granos, reemplazada por un impuesto en especie sobre un porcentaje de la cosecha, y por la restauración del comercio privado entre la ciudad y el campo mediante la abolición de los destacamentos camineros y de la estabilización del valor de la moneda.

Como consecuencia, aumentó la producción agrícola y la superficie cultivada, y la población urbana que había escapado al 
campo pudo volver a las ciudades. Surgió un estrato de campesinos ricos, conocidos como kulaks, en una sociedad abrumadoramente rural, y reaparecieron las diferencias sociales abolidas durante el comunismo de guerra.

Se llevó a cabo una descentralización de las industrias estatales, que fueron agrupadas en trusts regulados por los principios de la contabilidad comercial y la generación de ganancias, dando lugar a una especie de capitalismo de estado erigido sobre una economía atrasada, caracterizada por la exportación de productos primarios y la importación de maquinarias y manufacturas. Esto implicó una ola de despidos y un renacimiento del desempleo, que hizo que resurgiera la prostitución.

Cuando se introdujo la NEP en marzo de 1921, las condiciones de la prostitución cambiaron. El desempleo afectó en primer lugar a las trabajadoras menos calificadas. Dos tercios de los desempleados eran mujeres. Las oportunidades para el desarrollo de la prostitución se recrearon y empezaron a crecer. El Consejo Central de Lucha contra la Prostitución, establecido por el gobierno para coordinar los esfuerzos contra la prostitución, explicaba: "no podemos aceptar la opinión de que [dedicarse a la prostitución] debe ser castigado, mientras persista el desempleo y no podamos acabar con él" (Halle 1934, p. 229).

En enero de 1923, el primer Comisario del Pueblo de Salud, Nikolái Semashko, afirmaba: "La Nueva Política Económica dio a luz una vez más un aumento de la prostitución, que había desaparecido. Está llegando información de varias partes de la república acerca del resurgimiento de todo tipo de prostitución profesional, de burdeles secretos y de proxenetismo."

Semashko afirmaba que "los viejos métodos de control utilizados en la Rusia pre-revolucionaria, que en lugar de proteger a las mujeres las oprimían, deben ser absolutamente repudiados. Esto incluye las razzias, la investigación de las prostitutas y los exámenes médicos forzados." Ante todo, debían atenderse las necesidades materiales de las prostitutas mismas, ya que la falta de atención sobre este asunto, afirmaba Semashko, "inevitablemente empuja a los sectores más vulnerables a la prostitución" (Circular del Comisario del Pueblo de Salud, No. 21, "Acerca de las medidas para la lucha contra la Prostitución", Semanario judicial soviético, 26 de enero de 1923, citado en Quigley 1991, pp. 1206, 1215).

Las afirmaciones de Semashko se basaban en datos empíricos, ya que "numerosos estudios contemporáneos destacaban la conexión entre la prostitución y el desempleo durante la NEP". 
Incluso las mujeres empleadas se veían forzadas ocasionalmente a prostituirse, dada su concentración en empleos de bajos salarios y sin calificación. "Un estudio de 1923 reveló que muchas trabajadoras fabriles recurrían a la prostitución para complementar sus salarios." Los dos grupos más grandes de prostitutas urbanas eran las besprizorniki, niñas, adolescentes y mujeres sin hogar que rápidamente descubrían que la prostitución era más lucrativa que la mendicidad, y las mujeres desocupadas que no lograban hallar un trabajo estable (Goldman 2011, pp. 126-128).

Durante la década de 1920, el gobierno y los académicos soviéticos analizaron las condiciones de vida de las mujeres que ejercían la prostitución, como base para su eliminación. Descubrieron que las mujeres que ejercían la prostitución con frecuencia desarrollaban problemas de alcoholismo. También encontraron que las prostitutas eran frecuentemente detenidas por robo o por alteración del orden público. Por otra parte, las mujeres que ejercían la prostitución vivían en viviendas deficientes o eran personas sin hogar. Muchas eran analfabetas o no habían completado la educación primaria, y pocas tenían calificaciones que les permitieran conseguir un trabajo. Estos hechos indicaban que las mujeres habían sido arrastradas a la prostitución provenían de las clases más humildes (Quigley 1991, pp. 1206-1207).

\section{El decreto sobre las medidas de lucha contra la prostitución (26 de diciembre de 1922)}

En Izvestia, el diario del Comité Ejecutivo Central de la URSS, en la edición del 26 de diciembre de 1922, fue publicado un decreto sobre las medidas de lucha contra la prostitución, proveniente del Comisariado del Pueblo para Asuntos Internos, el Comisariado del Pueblo para la Salud Pública y el Consejo Central de toda Rusia de los Sindicatos. El editorial en este número de Izvestia informaba que

La ausencia de instrucciones claras dadas por el centro a las localidades en lo que respecta a la cuestión de la lucha contra la prostitución ha dado lugar a hechos extremadamente lamentables. En presencia de un aumento de la prostitución, los órganos de administración local se han visto obligados a elegir por sí mismos los medios para luchar contra la prostitución, y a menudo han cometido negligencias graves. En muchas ciudades surgió una 
regulación encubierta de las mujeres prostituidas, que son acosadas, procesadas y llevadas por la fuerza a realizarse exámenes médicos. Tal situación, obviamente, debe ser considerada inadmisible. El centro debe examinar esta cuestión con absoluta claridad e indicar a los órganos de poder local que la lucha contra la prostitución no puede ser sustituida en modo alguno por una lucha contra las mujeres prostituidas. Esto resulta con nitidez del decreto sobre este tema publicado en este número.

El decreto "Sobre las medidas contra la prostitución" indicaba en sus partes principales:

La ola de prostitución, que descompone la vida social, se levanta y, con ella, están aumentando sus compañeros inevitables: las enfermedades venéreas. Dirigimos la atención de todos los órganos de poder local a la urgencia de la lucha más enérgica contra el mal antes mencionado y les pedimos que empiecen a tomar las siguientes medidas:

a) Sigan las instrucciones dadas a las localidades por el Comisariado del Pueblo y muestren especial prudencia antes de despedir mujeres como resultado de la reducción de personal, en particular a las mujeres más vulnerables desde el punto de vista material (mujeres solteras, mujeres jóvenes sin hogar, mujeres embarazadas, mujeres con hijos menores de edad). Las secciones de defensa y los sindicatos deben defender en primer lugar los intereses de estos grupos de mujeres, recordando que las medidas imprudentes empujan a las mujeres más vulnerables a las filas de la prostitución.

Podemos ver los esfuerzos en este sentido realizados por los sindicatos en el cartel de la página siguiente.

El decreto "Sobre las medidas contra la prostitución" continuaba afirmando que se debían tomar las siguientes medidas adicionales:

b) Organizar talleres conjuntos, de tipo industrial y agrícola, que sean capaces de incluir ciertos grupos de mujeres desempleadas con cualificaciones insuficientes. Estas comunas deben organizarse con una amplia participación de los entes locales y disfrutarán de las condiciones más favorables desde el punto de vista de la disponibilidad de edificios, gastos de alquiler, impuestos, así como de provisión de crédito y de equipos esenciales. 


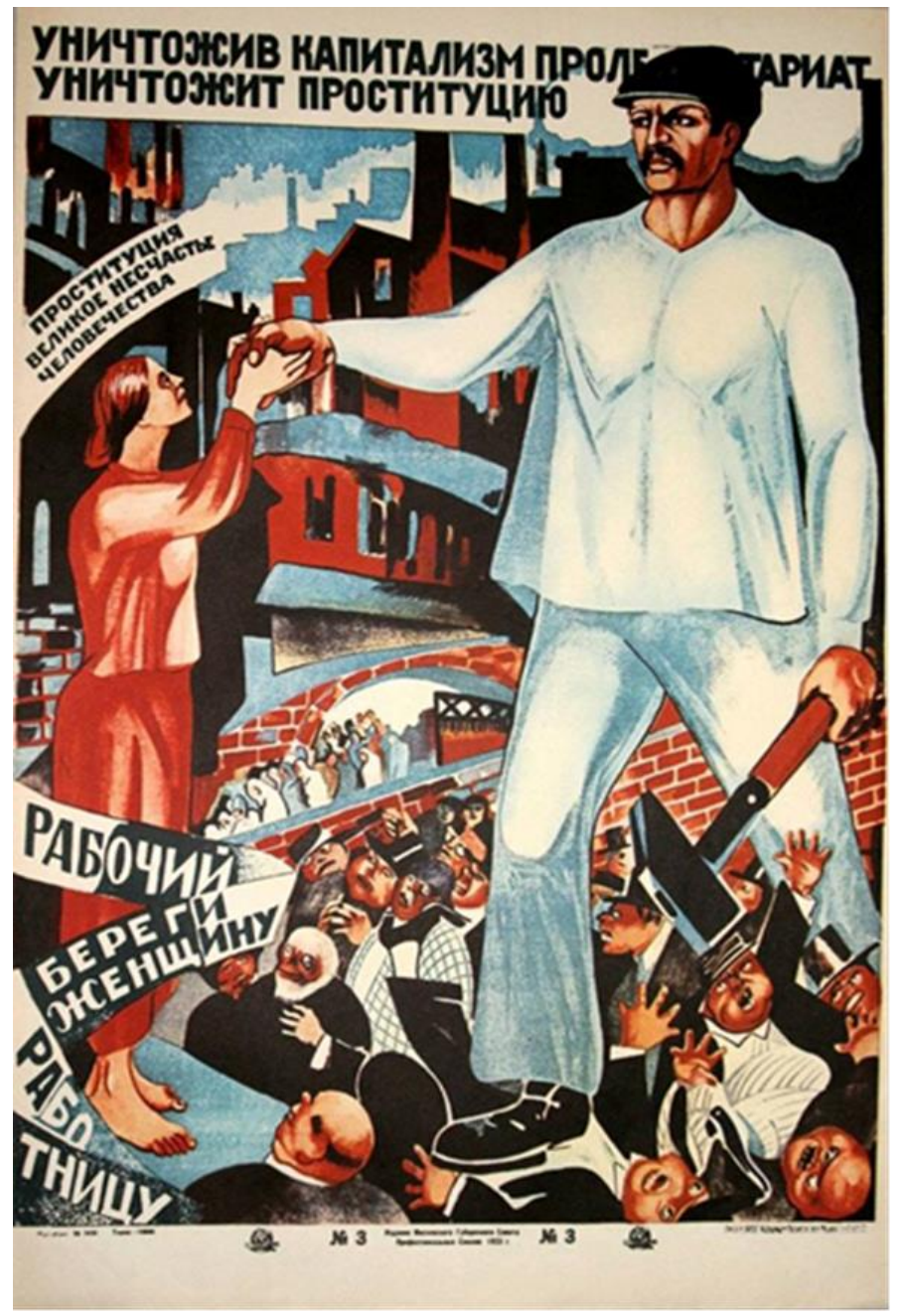

Уничтожив капитализм, пролетариат уничтожит проституцию. Проституция великое несчастье человечества. Рабочий, береги женщину-работницу! "Destruyendo al capitalismo, el proletariado destruye a la prostitución. La prostitución es una gran desgracia para la humanidad. ¡Trabajador, cuida a la trabajadora!" (Soviet Provincial de Sindicatos de Moscú, 1923)

c) Promover la cualificación profesional de las mujeres garantizando un número de plazas en las escuelas de educación profesional y técnica. 
d) Luchar contra el hecho de que todavía existan mujeres sin hogar, organizando casas conjuntas para las mujeres desempleadas y casas de estancia temporal para las mujeres y las jóvenes que recién llegan a las ciudades.

e) Reforzar las medidas de protección para con las niñas sin hogar.

f) Intensificar la labor de propaganda y educación entre la población trabajadora - entre los adultos y adolescentes, así como en las organizaciones profesionales, sindicatos, clubes de jóvenes, el Ejército Rojo, y en las escuelas. Este trabajo, que tiene como objetivo informar a los trabajadores acerca de la naturaleza de la prostitución, la inadmisibilidad y la indignidad de su existencia en la república de los trabajadores y los peligros que la acompañan, debe hacerse a través de los esfuerzos combinados de los sindicatos, las organizaciones del Partido y el Ejército Rojo.

Todas estas medidas son preventivas. Fortaleciendo la resistencia de las masas trabajadoras, ayudan a mitigar el aumento de la prostitución.

Junto a las medidas mencionadas anteriormente, también es necesario tomar medidas radicales para luchar contra la prostitución que ya existe y en contra de las consecuencias que de ella resultan. Entre estas medidas, debemos indicar las siguientes:

1. Reforzar la supervisión administrativa allí donde la población trabajadora pueda ser incitada a la corrupción y las mujeres a la prostitución. Este control debe ser llevado a cabo por las secciones de administración de los soviets locales. Cabe señalar que los antiguos métodos de supervisión practicados en la Rusia zarista, que de hecho no conducían a la protección sino a la opresión de las mujeres, deben ser rechazados totalmente. Estos métodos repudiables incluyen los allanamientos, la persecución de las mujeres prostituidas, las inspecciones médicas forzosas, etc. La lucha contra la prostitución no puede de ninguna manera ser sustituida por la lucha contra las mujeres prostituidas.

2 Llevar a cabo una lucha radical contra los proxenetas, los procuradores, los dueños de prostíbulos bajo no importa qué rótulo, aplicando todos los medios de represión administrativa y judicial.

3. Organizar un tratamiento médico gratuito y accesible a las masas para tratar las enfermedades venéreas, 
preferentemente mediante la organización de clínicas. (Bronner 1936, pp. 27-30)

\section{Los Soviets de lucha contra la prostitución y la revisión del Código Penal}

Para coordinar las medidas tomadas en la lucha contra la prostitución con las requeridas para la solución de los problemas que tenían su origen en las condiciones locales, se crearon, además de las secciones para proteger la salud pública, Consejos para combatir la prostitución o Soviets de lucha contra la prostitución (советов по борьбе с проституцией). ${ }^{87}$

Según el testimonio de Alexandra Kollontai, la Comisaria del Pueblo para la Asistencia Pública los Consejos (soviets) de lucha contra la prostitución, igual que la legislación sobre el aborto, fueron adoptados por el gobierno bolchevique a iniciativa de las obreras:

Por iniciativa del grupo de mujeres comunistas en Moscú y con el pleno apoyo del Comité Central del Partido Comunista fue organizada en noviembre de 1918 en Moscú, el Primer Congreso panruso de obreras y campesinas [был I Всероссийский съезА работниц и крестьянок]. Asistieron más de un millar de delegadas elegidas en asambleas de obreras y campesinas. Esta conferencia sólo tuvo una importancia crítica como propaganda, sino que sentó las bases de la organización en el Partido Comunista de un aparato especial en el Comité Central para la dirección del trabajo entre las mujeres en toda Rusia [Zhenotded. La formación de un aparato especial dentro del partido, con miras a la participación de las masas femeninas en la construcción de la República del trabajo y en la lucha por el comunismo fue así oficialmente reconocida por el partido.

En un primer momento, fueron las Comisiones para la agitación y la propaganda entre las trabajadoras [«Комиссии по агитации и пропаганде среди работниц»], organizadas en torno a los comités del partido, las que llevaron a cabo este trabajo. El lema de estas comisiones es: agitación, no sólo de palabra, sino por la acción, lo que significaba la formación de comunistas conscientes y activas mediante la participación de las campesinas y de las trabajadoras en el trabajo vivo y activo de los soviets. Con este fin, las

87 Sobre la operación de los Soviets para combatir la prostitución en los Urales ver Мирошниченко 2011 у 2013. 
Comisiones de trabajadoras [Комиссии работниц] crearon un dispositivo especial que conecta el partido con las amplias masas atrasadas de las trabajadoras, a saber, la asamblea de delegadas. Cada fábrica, cada taller con cincuenta trabajadoras elige su representante para la asamblea de delegadas de las trabajadoras. Las delegadas son elegidas por tres meses. Ellas están obligadas a asistir a las reuniones semanales donde las delegadas se ponen al corriente de los acontecimientos políticos actuales, trabajan en diferentes áreas de la construcción del Estado soviético, en particular las relativas a la educación social, la alimentación social, la protección de la maternidad y otras áreas de la tarea soviética que contribuyen directamente a la emancipación económica de las trabajadoras. Las delegadas no sólo asisten a reuniones, sino que se distribuyen sus fuerzas para la realización de una serie de trabajos prácticos, tanto en las empresas (como miembros de las comisiones de trabajo llevado a cabo para la mejora de las condiciones materiales, para la protección de la maternidad, etc.) como en la inspección de las instituciones soviéticas, para el estudio de los métodos y sistemas de trabajo en las diferentes áreas del aparato soviético, así como para participar en la diversas campañas llevadas a cabo por el partido o por los órganos soviéticos. A medida que el trabajo del partido entre las mujeres aumentaba, surgió la necesidad de ordenar el trabajo, de profundizarlo y armonizarlo. En el otoño de 1919, el partido reorganizó sus comisiones de trabajadoras en el Departamento para el trabajo entre la Mujer (Zhetnoded) [ОтАем по Работе Среди Женщин (ЖенотАел)]. Este Departamento tiene representación hoy en día en cada comité local del partido, empezando por el Comité Central y terminando en los comités de pueblo, de barrio y de distrito.

Los Departamentos de trabajadoras [Отделы работниц] по sólo involucran a las obreras y campesinas en el partido y en los órganos de la construcción soviética, formando así comunistas activas, sino que toman la iniciativa en la construcción del sistema soviético, planteando ante el partido y ante los órganos soviéticos los problemas relativos a la cuestión de la emancipación total y práctica de la mujer. De este modo, por iniciativa de los Departamentos de trabajadoras se adoptó la ley sobre la legalización del aborto; el octavo Congreso de los Soviets decidió la participación activa de las trabajadoras en la reconstrucción de la economía del país, en la organización de la producción mediante su participación en el trabajo de todos los 
órganos de gobierno de la economía popular; por iniciativa de los Departamentos de trabajadoras se formó la Comisión para combatir la prostitución [комиссия по борьбе с проституцией] у se crearon comisiones destinadas a ayudar a los órganos de protección de la maternidad y la infancia; también fueron aceptados, durante la redacción de la ley sobre el trabajo obligatorio (abril de 1920), una serie de puntos relativos a la protección de la fuerza, la salud y los intereses de la mujer-madre. Finalmente, en abril de este año [1921], a propuesta de las secciones de mujeres, a través del Consejo de Comisarios del Pueblo, se promulgó una ley sobre las pasantías, es decir, una ley que decreta la participación de las trabajadoras y campesinas en el trabajo de las distintas secciones de los comités ejecutivos de los soviets y sus instituciones durante dos meses, con el fin de dar más vida al aparato soviético, liberarlo de sus elementos burocráticos y transformar mediante la práctica a estas obreras en buenas trabajadores soviéticas (Kollontai 1921d, pp. 8-10, énfasis nuestro).

En 1921 el Comisariado del Pueblo de la Seguridad Social de la RSFSR creó la Comisión Interdepartamental para combatir la prostitución [образована Межведомственная комиссия по борьбе с проституцией], y un año después en el Comisariado del Pueblo de Salud de la RSFSR comenzó a funcionar el Consejo Central para combatir la prostitución [Центральный совет по борьбе с проституцией: Tsentral'nyy sovet po bor'be $s$ prostitutsiyey], con Semashko, el Comisario del Pueblo para la Salud Pública, a la cabeza. La incorporación de los Consejos para combatir la prostitución a los servicios de salud pública fue causada por el hecho de que estos servicios debían luchar contra las enfermedades venéreas.

Las actividades del Consejo Central de Lucha contra la Prostitución se iniciaron con la revisión de los artículos vigentes en el Código Penal relativos a la lucha contra la prostitución. En febrero de 1923, el Consejo planteó esta cuestión ante el Comisariado del Pueblo de Justicia. Por lo tanto, el Comisariado del Pueblo de Justicia precisó los artículos en cuestión y les dio la siguiente forma:

\section{Artículo 170}

Cualquier tipo de coacción, ejercida por codicia o con otros fines personales, que conduzca a la prostitución, por medio de la influencia física o moral, será castigada con prisión por un período mínimo de tres años. 
Artículo 171

Los proxenetas, los traficantes que reclutan mujeres para la prostitución y los operadores de prostíbulos serán sancionados con prisión por un período mínimo de tres años, con confiscación parcial o total de la propiedad personal. Si las personas inducidas a la prostitución estaban bajo la tutela o la autoridad de los acusados, y si no habían alcanzado la mayoría de edad, la pena se agravará y conllevará a un período mínimo de prisión de cinco años. (Bronner 1936, p. 35)

Mijail Strogovich, un especialista en derecho penal, explicó la opinión del gobierno soviético de que la prostituta era la víctima de la prostitución afirmando que los artículos 171 y 172 del Código Penal sólo castigaban al móvil de ganancia material del proxeneta. Dichos artículos se incluían en un capítulo del Código Penal titulado Crimenes contra la vida, la salud, la libertad y la dignidad del individuo: "Esto significa que los crímenes previstos por los dos artículos indicados se practican en contra de la personalidad de las mujeres que ejercen la prostitución [....] en los casos de los delitos previstos en los artículos 170 y 171 del Código Penal, una mujer dedicada a la prostitución es la víctima" (Mijail Strogovich, "La lucha contra la prostitución a través de la represión penal", Semanario judicial soviético, no. 37, 1925, citado en Quigley 1991, p. 1210, 1211, 1213).

\section{La milicia para combatir la prostitución}

Sin embargo, en muchos lugares la lucha contra la prostitución había tomado la forma de una lucha contra las propias mujeres prostituidas. Los servicios locales de la milicia habían adoptado con frecuencia los métodos de control practicados por la policía zarista: organizaban redadas contra las prostitutas, que eran detenidas y forzadas a realizar revisaciones médicas; se les prohibía a aparecer en los cafés, en establecimientos de recreación, etc. El Consejo Central de Lucha contra la Prostitución llamó la atención del Comisariado del Pueblo para Asuntos Internos sobre la inadmisibilidad de tales casos y, de acuerdo con él, elaboró una "Instrucciones a los órganos de la Milicia para combatir la Prostitución", publicadas por orden del Comisariado del Pueblo para 
Asuntos Internos el 25 de enero de 1924. ${ }^{88}$. Los pasajes clave dichas Instrucciones rezaban:

1. Las tareas principales de la milicia para la lucha contra la prostitución son las siguientes:

a) Descubrir los lugares de corrupción que ayudan al desarrollo de la prostitución y crean formas horribles de explotación, manejadas por elementos criminales, para las mujeres que caen en la prostitución debido a las condiciones económicas u otras.

b) Descubrir y evitar que las personas que realizan el trabajo de proxenetas y reclutadores de mujeres para la prostitución (comercio de mercancía humana), vivan a expensas de las mujeres prostituidas.

c) Tomar medidas para impedir el uso de lugares públicos y de entretenimiento a los fines de la prostitución.

2. Todas las personas que pertenecen a la categoría de ciudadanos que figuran en el apartado "b" del artículo 1 de la presente Instrucción, descubiertos durante una ronda de la milicia, serán detenidos o sometidos a una investigación criminal, y los prostíbulos serán cerrados inmediatamente.

3. La aplicación práctica de las medidas anteriores se llevará a cabo por la milicia de la siguiente manera:

a) Visitas periódicas a establecimientos de carácter público como cafeterías, bares, restaurantes, etc. Debe notarse que en el cumplimiento de este deber los miembros de la milicia tienen el derecho de visitar sin excepción todas las habitaciones y cuartos privados de estas instituciones.

b) La vigilancia continua de los baños públicos y, durante la temporada de verano, de bulevares, jardines y plazas.

c) Visita de edificios residenciales en los que se supone que se practica la prostitución.

4. Llevando a cabo esta misión con energía y severidad, la milicia no puede, sin embargo, aplicar métodos de

88 "Инструкция органам милиции по борьбе с проституцией". Приказ ЦАУ НКВА (25 января 1924 г.), еп История поличии и миличии России. Хрестоматия / Сост.: Гребенкин М.Ю., Кофман Б.И., Миронов С.Н.; Под ред.: Сафиулиин Н.Х. - Казань: ИзА-во ЮриА. ин-та МВА России, 2005, pp. 144-145. ["Instrucciones a los órganos de la Milicia para combatir la Prostitución", Orden de la Admiración Central de la NKVD (25 de enero de 1924), en Historia de la policía y de la milicia de Rusia, compilado por M.J. Grebenkine, B.I. Kaufman y S.N. Mironov; editado por N.H. Safiullin, Kazan: Editorial Jurídica del Instituto del Ministerio del Interior de Rusia, 2005, pp. 144-145.] 
represión contra las mujeres prostitutas y sus clientes; si es necesario, se los puede citar el tribunal como testigos.

Nota: Las prostitutas que no hayan alcanzado la edad de 16 años serán derivadas a las organizaciones respectivas de Comisariado del Pueblo para la Educación.

5. Teniendo en cuenta que la mujer que vive en la prostitución ha sido empujada a situación por las condiciones materiales y los avatares de una vida fallida, todos los miembros de la milicia deben observar para con ellas las reglas de cortesía y no utilizar bajo ninguna circunstancia métodos rudos. (Bronner 1936, pp. 31-32)

Los Consejos de Lucha contra la Prostitución organizaron el trabajo de erradicación en el ámbito local, con diferentes grados de éxito. Proporcionaban viviendas temporarias a mujeres desempleadas y a campesinas que migraban a las ciudades. Ambos grupos de mujeres eran vistos como poblaciones vulnerables que podrían recurrir a la prostitución. El gobierno soviético también estableció clínicas para el tratamiento de enfermedades venéreas en forma gratuita (Quigley 1991, p. 1215).

Los Consejos de Lucha contra la Prostitución instaban a que los nombres de los clientes fueran colocados en las pizarras de anuncios de las fábricas en las que trabajaban (Halle 1934, p. 231). La policía informaba a los empleadores de los clientes, cuyos nombres se publicaban en los periódicos locales. El Partido Comunista incluso expulsaba a miembros que hubieran frecuentado una prostituta (Quigley 2007, p. 44).

\section{La respuesta a la "Carta de la prostituta Tania" (1925)}

El Consejo Central de la Lucha contra la Prostitución recibió en 1925 una carta firmada por la "prostituta Tania." En esta carta, dicha prostituta, "en nombre de muchas otras", criticaba al Consejo por "la lucha contra los lugares de libertinaje", alegando que este método era en realidad especialmente perjudicial para las prostitutas, porque todo se hacía para reducir su ganancia al mínimo, quitándole sus medios de existencia. "Las ganancias," dijo en su carta, "caen día a día, dada la dificultad de encontrar un lugar, y si finalmente se lo encuentra el pago es tan caro, que elimina toda la ganancia."

El presidente del Consejo Central del Comisariado del Pueblo para la Salud Pública, N. Semashko, publicó en el diario 
Rabóchaia Moskva, con su propia firma, una "Respuesta a la prostituta Tania". En la misma se afirmaba:

En nombre de varias otras se ha dirigido Ud. al Consejo Central de Lucha contra la Prostitución, quejándose de que con su creación la situación ha empeorado para las prostitutas. Pide Ud. que las prostitutas sean dejadas en paz, afirmando que no roban ni cometen delitos. No piensa Ud. que la prostitución sea un caldo de cultivo de enfermedades venéreas, uno de los peores flagelos, cuya existencia requiere de la lucha contra la prostitución. Ud. se queja de que, como resultado de esta lucha, resulta difícil encontrar un lugar para las prostitutas y sus clientes, y afirma que, debido al Consejo, las ganancias de la prostituta han caído en picada, y que esto demuestra que las medidas tomadas son incorrectas. Pide Ud. al Consejo de Lucha contra la Prostitución que no entregue a las mujeres prostituidas el control de la milicia.

En realidad, no existe un control de las mujeres prostituidas, no debería haber control alguno. La tarea a realizar por la milicia es identificar los diferentes lugares de corrupción, para poner en manos de la justicia a los proxenetas y procuradores - y esta difícil tarea, la milicia la cumple con dedicación. Por otro lado, la milicia no tiene derecho a utilizar contra las mujeres prostituidas medidas represivas. En este sentido la sección de la milicia, que pertenece al Comisariado del Pueblo para Asuntos Internos, ha dado a los servicios locales directrices muy claras. No negamos la posibilidad de que un miembro particular de la milicia, inferior a su tarea, haya fracasado en el cumplimiento de su deber. Tal ofensa no quedará impune. Cualquier mujer prostituida cuyos derechos civiles hayan sido infringidos por un miliciano tiene derecho a demandarlo ante la corte, después de haber establecido su identidad, poniéndose en contacto con el Consejo local para la Lucha contra la Prostitución, o directamente con las autoridades judiciales.

La prostitución es un mal doloroso de nuestra organización social. Lo hemos heredado del sistema capitalista, junto con otras enfermedades sociales. Y esta enfermedad, así como las demás y probablemente más rápido que ellas, vamos a liquidarla mediante el fortalecimiento de nuestra vida económica. Sabemos que no es, en la mayoría de los casos, por sed de lujo que las mujeres se ven obligadas a vender su bien más valioso, su propio cuerpo, sino por una necesidad desesperada. También sabemos que la lucha contra la 
prostitución afecta a la mujer prostituida por la disminución de sus ingresos, pero aun así llevaremos adelante esta lucha, porque el interés de la comunidad, al cual subordinamos los intereses de los individuos y grupos aislados, así lo exige. (Bronner 1936, pp. 33-35)

\section{Conclusión}

Los marxistas históricamente consideraron a la prostitución, no como un "trabajo sexual", sino como la forma más extrema de explotación y de degradación de la mujer en la sociedad de clases, es decir, como un producto de las desigualdades sociales destinado a desaparecer con ellas. Al mismo tiempo, se opusieron a transformar la lucha contra la prostitución en una lucha contra las prostitutas, a las que consideraban víctimas de la sociedad capitalista, así como a la regulación y normativización de la prostitución por el Estado, y sostuvieron que la erradicación de la prostitución era una utopía irrealizable si no se abolía al mismo tiempo la explotación del hombre por el hombre. En el marco de este trabajo analizamos las políticas adoptadas por el gobierno bolchevique para erradicar la prostitución. Corresponde cerrarlo haciendo un balance crítico de la experiencia soviética a la luz de las propias premisas marxistas y con una referencia al abandono de las políticas bolcheviques por el estalinismo.

En un ensayo sobre la prostitución en la Rusia posrevolucionaria, la historiadora Elizabeth Walters señaló que "hubo sin duda una ruptura entre el tratamiento de la prostitución por los bolcheviques y su tratamiento por los estalinistas" (Walters 1992, p. 161). En el marco de la expropiación política de las masas trabajadoras soviéticas por la burocracia, se adoptaron medidas crecientemente opresivas hacia la mujer, las cuales, entre otras cosas, dificultaron mucho el divorcio, prohibieron el aborto, y reemplazaron los debates abiertos sobre la prostitución por la negación oficial de su existencia. En su análisis de la degeneración estalinista de la revolución bolchevique, escrito en 1936, Trotsky constataba que "la prostitución, última degradación de la mujer en provecho del hombre capaz de pagar, existe en la URSS", y que el retorno de la prostitución era un producto directo del aumento de las desigualdades sociales fomentado por la burocracia estalinista. Reafirmando el ideal marxista de liberación de la mujer, Trotsky concluía afirmando que "es imperdonable hablar del triunfo del socialismo mientras subsista la prostitución" (Trotsky 1936, p. 144). 


\section{Referencias}

Armand, Inès 1920, "L'ouvrière en Russie soviétiste", Bulletin communiste, première année, numéro 17 (8 juillet 1920) sous le pseudonyme Hélène Blonina, pp. 12-15.

Avrich, Paul 1963, "Russian Factory Committees in 1917," Jahrbücher für Gescbichte Osteuropas, Neue Folge, Bd. 11, H. 2 Juni 1963), pp. 161-182.

Ball, Alan M. 1994, And Now My Soul Is Hardened: Abandoned Children in Soviet Russia, 1918-1930, Berkeley: University of California Press.

Badayev, Aleksei E. 1932, The Bolsheviks in the Tsarist Duma, New York: International Publishers.

Bebel, August 1891, Die Fran und der Sorialismus (Die Fran in der Vergangenheit, Gegenwart und Zukunft), neunten Auflage, Stuttgart: J. H. W. Dietz, 1891.

Bernstein, Laurie 1995, Sonia's Daughters: Prostitutes and Their Regulation in Imperial Russia, Berkeley: University of California Press.

Bochkareva, Maria 1919, Yashka: My Life as Peasant, Officer and Exile, by Maria Bochkareva, Commander of the Russian Women's Battalion of Death, as set down by Isaac Don Levine, New York: Frederick A. Stokes Co., 1919.

Bernstein, Laurie 1995, Sonia's Daughters: Prostitutes and Their Regulation in Imperial Russia, Berkeley: University of California Press.

Blanc, Eric 2015, "Finlandia 1906: Las raíces revolucionarias del sufragio femenino", Sin Permiso, 08/03/2015. old.sinpermiso.info/articulos/ficheros/femhis.pdf

Bronner, V. M. 1936, La lutte contre la prostitution en URSS, Moscou: Société pour les relations culturelles entre l'U.R.S.S. et l'étranger. [Броннер, Вульф Моисеевич, Проституиия и пути еe миквидачии. А.: ГМИ, 1931.]

Chatterjee, Choi 2002, Celebrating Women: Gender, Festival Culture, and Bolshevik. Ideology, 1910-1939, University of Pittsburgh Press.

Clements, Barbara Evans 1979, Bolshevik. Feminist: The Life of Aleksandra Kollontai, Bloomington: Indiana University Press.

Clements, Barbara Evans 1997, Bolshevik. Women, Cambridge University Press.

Constitución de la República Socialista Federativa de los Consejos (Soviets) de Rusia, 1918. Apéndice del libro de Quintiliano Saldaña, La Revolución Rusa: La Constitución rusa de 10 de julio de 1918, Madrid. Editorial Reus, 1919, pp. 95-116. 
Davis Center for Russian and Eurasian Studies, 1917 Petrograd March for Women's Suffrage (March 19, 1917) https://youtu.be/LLOQASmngrE

Decrees and Constitution of Soviet Russia, reprinted from The Nation (New York, December 28, 1919).

Donald, Moira 1982, "Bolshevik Activity amongst the Working Women of Petrograd in 1917”, International Review of Social History, XXVII, pp. 129-60.

Edmondson, Linda 1976, "Russian Feminists and the First All-Russian Congress of Women", Russian History, Vol. 3, No. 2 (1976), pp. 123-149.

Edmondson, Linda 1984, Feminism in Russia: 1900-1917, Stanford, Calif.: Stanford University Press.

Edmondson, Linda 1992, “Women's Rights, Civil Rights and the Debate over Citizenship in the 1905 Revolution", in Edmondson (ed.), Women and Society in Russia and the Soviet Union, Cambridge University Press, pp. 77-100.

Elwood, Ralph Carter 1992, Inessa Armand: Revolutionary and Feminist, Cambridge and New York: Cambridge University Press.

Engels, Friedrich 1884, El origen de la familia, la propiedad privada y el estado, Santiago de Chile: Editorial Quimantú, 1972.

Erste Internationale Konferenz Sozialistischer Frauen, Stuttgart 1907, Internationaler Sozialisten-Kongress, 18.-24. August 1907, Offizielles Kongressprotokoll: Anhang: Erste Internationale Konferenz Sozialistischer Frauen, Berlin, 1907, pp. 124-145.

Ferro, Marc 1972, The Russian Revolution of February 1917, Englewood Cliffs, NY: Prentice-Hall.

Fieseler, Beate 1989, "The Making of Russian Female Social Democrats, 1890-1917”, International Review of Social History, vol. 34, no. 2 (1989), pp. 193-226.

Fitzpatrick, Sheila 1977, Lunacharski y la organización soviética de la educación y de las artes, 1917-1921, Madrid: Siglo XXI.

Frencia, Cintia, y Daniel Gaido 2016, El marxismo y la liberación de las mujeres trabajadoras: de la Internacional de Mujeres Socialistas a la Revolución Rusa, Santiago de Chile: Ariadna Ediciones, 2016. http://oapen.org/search?identifier=619630

Frencia, Cintia, y Daniel Gaido 2017, "The Socialist Origins of International Women's Day", Jacobin Magazine: A Magazine of Culture and Polemic (Bronx, N.Y.: Jacobin Press), March 8, 2017.

Frencia, Cintia, and Daniel Gaido 2018, "'A Clean Break': Clara Zetkin, the International Socialist Women's Movement and Feminism", International Critical Thought, Official publication of the 
Chinese Academy of Social Sciences (CASS), Vol. 8, No. 2, June, 2018, pp. 1-27.

Gaido, Daniel y Kevin Murphy 2017, "De la dictadura democrática a la dictadura del proletariado: El debate en el Partido Bolchevique sobre las Tesis de Abril de Lenin”, en Daniel Duarte y Diego Bruno (Compiladores), El impacto de la revolución rusa en la teoría marxista, Ciudad Autónoma de Buenos Aires: Teseo Press, 2017, pp. 33-88. ISBN 978-987-42-6487-9 (Publicado como artículo en la revista Hic Rhodus. Dossier: A cien años de la revolución rusa, nro. 12, agosto de 2017, pp. 1-30.)

Gankin, Olga Hess, and H. H. Fisher 1940, The Bolsheviks and the World War: The Origin of the Third International, Stanford University Press.

Goldman, Wendy Z. 2011, La mujer, el estado y la revolución: Política familiar y vida social soviética 1917-36, Buenos Aires: Instituto del Pensamiento Socialista.

Halle, Fannina W. 1934, Woman in Soviet Russia [Die Frau in Sonjet-Russland], translated from the German original of 1932 by Margaret M. Green, London: Routledge.

Hasegawa, Tsuyoshi 2017, The February Revolution, Petrograd, 1917: The End of the Tsarist Regime and the Birth of Dual Power, Leiden: Brill.

Healey, Dan 2001, Homosexual Desire in Revolutionary Russia: The Regulation of Sexual and Gender Dissent, Chicago: Chicago University Press, 2001.

Hyer, Janet 1985, Pre-Revolutionary Rabotnitsa: A Study of Bolshevik Policy towards Working Women, unpublished M.A. thesis, Carleton University, Ottawa. 116 pp.

Kaplan, Temma 1985, "On the Socialist Origins of International Women's Day", Feminist Studies, Vol. 11, No. 1, pp. 163171.

Kautsky, Karl 1906, «Le droit de suffrage pour les femmes : doit-on leur accorder immédiatement et sans transition ? ", La revue socialiste, tome XLIV, N 260, Août 1906, pp. 145-166. Disponible online en Gallica gallica.bnf.fr/

Kerensky, Alexander F. 1961, The Russian Provisional Government 1917: Documents, selected and edited by Robert Paul Browder and Alexander F. Kerensky, Stanford, Calif.: Stanford University Press, Vol. I: The February Revolution: Toward a Democratic Order.

Kirchner, Jürgen 1983, Herausbildung und Gescbicbte der Sozialistischen Fraueninternationale und $₹ u$ den Anfängen des Internationalen 
Frauentages. Ein Beitrag zur Geschichte der II. Internationale, Dresden, Pädagogische Hochschule, Diss. B.

Koenker, Diane P. 1981, Moscow Workers and the 1917 Revolution, Princeton University Press.

Kollontai, Alexandra 1910, "Bericht über die Arbeiterinnenbewegung in Russland", en Berichte an die zweite Internationale Konferenz sozialistischer Frauen zu Kopenhagen am 26. und 27. August 1910, pp. 73-76.

Kollontai, Alexandra 1915, "Staatliche Mutterschaftsversicherung", Die neue Zeit, 33. 1914-1915, 1. Bd. (1915), H. 11/12, S. 363-371.

Kollontai, Alexandra 1919, Women Workers Struggle for Their Rights, London: Falling Wall Press, 1971.

Kollontai, Alexandra 1920, "Towards a History of the Working Women's Movement in Russia", in Kollontai, Selected Writings, Translated with an introduction and commentaries by Alix Holt, Westport, Conn.: Lawrence Hill Co., Publishers, Inc., 1978, pp. 39-57. [А. Комлонтай. «К истории Авижения работниц в России». Харьков, 1920, стр. 3-11.]

Kollontai, Alexandra 1921a, "Aus meinem Leben und aus meiner Arbeit", Proletarskaja Rewoluzija, Nr. 3 (mit dem Titel "Autobiographischer Abriss"), in Kollontai, „Ich babe viele Leben gelebt": Autobiographische Aufzeichnungen, Berlin: Dietz Verlag, 1980, S. 115-163. [Kollontai, Alexandra 1921, "De mi vida y de mi trabajo", Revolución proletaria, $\mathrm{N}^{\mathrm{o}} 3$ (publicado originalmente con el título "Bosquejo autobiográfico"), en Kollontai, "He vivido muchas vidas": Apuntes autobiográficos, Berlin: Dietz Verlag, 1980, pp. 115-163.] https://sites.google.com/site/sozialistischeklassiker2punkt0/alexand ra-kollontai/alexandra-kollontai-ich-habe-viele-leben-gelebt

Kollontai, Alexandra 1921b, "Prostitution and ways of fighting it", in Selected Writings of Alexandra Kollontai, Translated with an introduction and commentaries by Alix Holt, Westport, Conn.: Lawrence Hill Co. Publishers, Inc., 1978, pp. 261-275. (Versión castellana: "La prostitución y cómo combatirla", disponible online en Marxists Internet Archive).

Kollontai, Alexandra 1921c, La mujer en el desarrollo social, Barcelona: Editorial Guadarrama/Omega, 1976.

Kollontai, Alexandra 1921d, L'ouvrière et la paysanne dans la République soviétique, Paris: Librairie de L'Humanité, 1921. [Комлонтай A.M., Работнича и крестьлнка в Советской России. Госиздат, Майноябрь 1921 г.] 
Kollontai, Alexandra 1927, "Die ersten Schritte zum Mutterschutz", in Kollontai, „Ich habe viele Leben gelebt": Autobiographische Aufzeichnungen, Berlin: Dietz Verlag, 1980, S. 348353. [Kollontai, Alexandra 1927, "Los primeros pasos para la protección de la maternidad", en Kollontai, "He vivido muchas vidas": Apuntes autobiográficos, Berlin: Dietz Verlag, 1980, pp. 348-353.]

Kollontai, Alexandra 1937, "Die Frauen im Jahre 1917", Rabotnitsa, Nr. 31, November 1937, S. 12-13, in Kollontai, „Ich babe viele Leben gelebt": Autobiographische Aufreichnungen, Berlin: Dietz Verlag, 1980, S. 348-353. [Kollontai, Alexandra 1921, "Las mujeres en el año 1917", La trabajadora, No 3 Nr. 31, November 1937, pp. $12-$ 13, en Kollontai, "He vivido muchas vidas": Apuntes autobiográficos, Berlin: Dietz Verlag, 1980, pp. 348-353.]

Kollontai, Alexandra 1976, Autobiografía de una mujer emancipada. La juventud y la moral sexual. El comunismo y la familia. Plataforma de la Oposición Obrera, Barcelona: Editorial Fontamara, 1976.

Kollontai, Alexandra 1984, Selected Articles and Speeches, Moscow: Progress Publishers, 1984. Disponible online en el Marxists Internet Archive.

Krupskaya, Nadezhda 1984, Lenin, su vida, su doctrina, Buenos Aires: Editorial Rescate. El título real de este libro es Recuerdos de Lenin, Moscú: Partizdat, 1933 (Воспоминания о Аенине, Москва: Партиздат, 1933).

Lamarche Marrese, Michelle 2006, "Gender and the legal order in Imperial Russia", in The Cambridge History of Russia, Vol. 2: Imperial Russia, 1689-1917, Cambridge University Press, pp. 326-343.

Lenin, V.I. 1899, "Protesta de los socialdemócratas de Rusia”, publicado por primera vez en diciembre de 1899 en una separata de la revista Rabocheye Dyelo, No. 4-5, en Lenin, Obras completas, Madrid: Akal Editor, 1976, Tomo IV: 1899-abril de 1901, pp. 169-184.

Lenin, V.I. 1913, "El capitalismo y el trabajo de la mujer", Pravda, No. 102, 5 de mayo de 1913, en Obras completas, Madrid: Akal, 1971, tomo 19, pp. 277-279.

Lenin, V.I. 1917, "Materiales sobre la revisión del programa del partido", abril-mayo de 1917, en Obras completas, Madrid: Akal, 1977, tomo 25 , pp. 439-464.

Lewin, Moshe 2005, The Soviet Century, London: Verso.

Marie, Jean-Jacques 2017, Les femmes dans la révolution russe, Paris: Éditions du Seuil.

Porter, Cathy, Alexandra Kollontai: A Biography, London: Virago Press, 1980. 
Mandel, Mark-David, The Petrograd Workers and the Soviet Seizure of Power: From July Days 1917 to July 1918, London: Macmillan, 1984.

Marie, Jean-Jacques 2010, "De Lenin a Stalin, la sección femenina del Komintern", en Christine Fauré (dir.), Enciclopedia histórica y politica de las mujeres: Europa y América, Madrid: Akal, 2010, pp. 449-465.

McDermid, Jane and Anna Hillyar 1999, Midwives of the Revolution: Female Bolsheviles and Women Workers in 1917, London: UCL Press.

McNeal, Robert H. 1972, Bride of the Revolution: Krupskaya and Lenin, Ann Arbor, Michigan: The University of Michigan Press.

Noonan, Norma C. and Carol R. Nechemias (eds.) 2001, Encyclopedia of Russian Women's Movements, Westport, Conn.: Greenwood Press.

Pannekoek, Anton 1914, "The Collapse of the International" (20-22 October 1914), en Richard B. Day and Daniel Gaido (eds.), Discovering Imperialism: Social Democracy to World War I, Leiden: Brill, 2011, pp. 775-790.

Quigley, John 1991, "The Dilemma of Prostitution Law Reform. Lessons from the Soviet Russian Experiment", 29 American Criminal Law Review 1197 (1991-1992), pp. 1197-1234.

Porter, Cathy 1980, Alexandra Kollontai: A Biography, London: Virago Press.

Rabinowitch, Alexander, The Bolsheviks in Power: The First Year of Soviet Rule in Petrograd, Bloomington: Indiana University Press, 2007.

Radkey, Oliver H., Russia Goes to the Polls: The Election to the All-Russian Constituent Assembly, 1917, Cornell University Press, 1990.

Ruthchild, Rochelle Goldberg 2001, "Liga ravnopraviia zhenshchin (League for Women's Equal Rights) (1907-1917)", in Norma C. Noonan and Carol R. Nechemias (eds.), Encyclopedia of Russian Women's Movements, Westport, CT: Greenwood Press, 2001, pp. 38-41.

Ruthchild, Rochelle Goldberg 2010, Equality and Revolution: Women's Rights in the Russian Empire, 1905-1917, Pittsburgh: University of Pittsburgh Press.

Schneider, Graziela (ed.) 2107, A Revolução das Mulheres. Emancipação Feminina na Rússia Soviética. Autoras: Aleksandra M. Kollontai, Anna A. Kalmánovitch, Ariadna V. Tirkóva-Williams, Ekaterina D. Kuskova, Elena A. Kuvchínskaia, Inessa F. Armand, Konkórdia N. Samóilova, Liubov I. Guriévitch, Maria I. Pokróvskaia, 
Nadiéjda K. Krúpskaia, Olga A. Chapír. Tradução de Cecília Rosas. São Paulo: Boitempo Editorial.

Scholze, Siegfried 2001, Der Internationale Franentag einst und beute. Geschichtlicher Abriss und weltweite Tradition vom Entstehen bis zur Gegenwart, Berlin: Trafo.

Serge, Victor 1930, El año I de la revolución rusa, Madrid: Siglo XXI, 1999.

Stites, Richard 1978, The Women's Liberation Movement in Russia: Feminism, Nibilism, and Bolshevism, 1860-1930, Princeton University Press.

The Labor Laws of Soviet Russia. Fourth edition. With a supplement on The Protection of Labor in Soviet Russia, by S. Kaplun, of the Commissariat of Labor. New York: Russian Soviet Government Bureau, 1921. https://archive.org/details/laborlawsofsovie00russ [Кодекс законов о http://www.hist.msu.ru/Labour/Law/kodex_18.htm]

The Marriage Laws of Soviet Russia; Complete Text of First Code of Laws of the Russian Socialist Federal Soviet Republic dealing with Civil Status and Domestic Relations, Marriage, the Family and Guardianship. New York: Russian Soviet Government Bureau, 1921. https://archive.org/details/marriagelawsofso00sovi

Trotsky, León 1936, La revolución traicionada ¿Qué es y adónde va la URSS?, Madrid: Fundación Federico Engels, 2001.

Walters, Elizabeth 1992, "Victim or Villain: Prostitution in Post-Revolutionary Russia," in Linda Edmondson, Women and Society in Russia and the Soviet Union, Cambridge University Press, pp. 160177.

Wood, Elizabeth A. 1997, The Baba and the Comrade: Gender and Politics in Revolutionary Russia, Bloomington: Indiana University Press.

Zakuta, Olga 1917, "How in the revolutionary time the AllRussian League for Women's Equal Rights won suffrage for Russian women", translated by Rochelle Goldberg Ruthchild, Aspasia: The International Yearbook of Central, Eastern, and Southeastern European Women's and Gender History, Vol. 6 (2012), pp. 117-24. [Закута О. Как в револючионное время Всероссийская Аига Равноправия Женщин добилась избирательныхх прав для русских женщин // Женщины в сочиальной истории России. Тверь, 1997. С. 97-105.] https://studfiles.net/preview/460589/

Zetkin, Clara 1896, "Nur mit der proletarischen Frau wird der Sozialismus siegen!", 16. Oktober 1896, Rede auf dem Parteitag der Sozialdemokratischen Partei Deutschlands zu Gotha, in Protokoll 
über die Verhandlungen des Parteitages der Sozialdemokratischen Partei Deutschlands. Abgehalten zu Gotha vom 11. bis 16. Oktober 1896, Berlin 1896, S. 160-168.

Zetkin, Clara 1907, Zur Frage des Franenwahlrechts, bearbeitet nach dem Referat auf der Konferenz sozialistischer Frauen zu Mannheim, Dazu drei Anhänge: I. Resolution der Konferenz sozialistischer Frauen zu Mannheim, das Frauenwablrecht betreffend; II. Entwicklung des Frauenwablrechts ; III. Eine sozialistische Enquete über die sofortige Einführung des Franenwablrechts, Berlin: Buchhandlung Vorwärts, 1907. 87 pp.

Zetkin, Clara 1920, „Richtlinien für die kommunistische Frauenbewegung“, Die Kommunistische Internationale, 1920/21, Nr. 15, S. 530-555.

Zetkin, Clara 1976, La cuestión femenina y la lucha contra el reformismo, Barcelona: Anagrama.

\section{Referencias en ruso}

Айвазова, Светлана Григорьевна 1998, Русские женщины в мабиринте равноправия: очерки политической теории и истории : документальные материалы, М.: РИК Русанова. [Aivazova, Svetlana Grigorievna 1998, Las mujeres rusas en el laberinto de la igualdad: Ensayos sobre teoría politica e historia: Materiales documentales, Moscú: RIK http://www.owl.ru/win/books/rw/index.htm

АрманА, Инесса 1917, "Работница и Всероссийский Женский СъезА”, Жизнь работничьл, 1917, N. 1, С. 5-6 / / Статьи, речи, письма - Москва: Политиздат, 1975, С. 36-38. [Inessa Armand, "La trabajadora en el Congreso de Mujeres de Toda Rusia", La vida de las trabajadoras, abril de 1917, N. 1, pp. 5-6, en Armand, Artículos, discursos, cartas, Moscú: Politizdat, 1975, pp. 36-38.] http://books.e-heritage.ru/book/10089772

Артюхина, Александра, В. Голубева, С. Аюбимова, Всегда с вами. Сборник, посвященный 50-летию журнала «Работница» (1914-1964), Москва: Правда, 1964. [Aleksandra Artiujina, V. Golubeva, S. Lyubimov, Siempre contigo: Una colección dedicada al 50 aniversario de la revista 'Rabotnitsa' (1914-1964), Moscú: Pravda, 1964. 542 pp.]

Бессонова, А.Ф., К истории издания журнала «Работница»: Аокументы Института Маркса-Энгельса-АенинаСталина при ЦК КПСС. 1913-1914 // Исторический архив. 1955 гоА, № 4, С. 25-53. [Bessonova A.F., "Sobre la historia de la publicación de la revista Rabotnitsa: Documentos del Instituto Marx- 
Engels-Lenin-Stalin adscritos al Comité Central del PCUS", Archivo histórico (Moscú), 1955, n 4, pp. 25-53.]

Бобылев, Ольга 1917. Привет русской работнице // Правда № 5. 10 марта [23 марта] 1917 г. С. 8-9. [Olga Bobyleva, "Saludos a la trabajadora rusa", Pravda, No. 5, 10 de marzo (23 de marzo) de 1917, pp. 8-9.] http://istmat.info/node/28027

Великий хень // Правда № 2 Вторник 7 марта [20 марта] 1917 г. [“Un Gran Día”, Pravda, martes 7 de marzo (20 de marzo) de 1917.] http://istmat.info/node/28027

Всероссийский центральный исполнительный комитет (ВЦИК): Кодекс законов об актах гражАанского состояния, Брачном, Семейном и Опекунском праве. (22 октября 1918 года.) [Comité Ejecutivo Central Panruso (VTsIK): Código de leyes sobre actos de estado civil, matrimonio, familia y derecho custodio. (22 de octubre de 1918).] http://istmat.info/node/31624

ГАебов, Н. 1917, Женщина в рабочем Авижении // Правда № 26. 7 апреля [20 апреля] 1917 г., C. 1-2 [Glebov, N. 1917, "La mujer en el movimiento obrero", Pravda, No. 26. No. 26.7 (20) de abril de 1917, pp. 1-2.] http://istmat.info/node/28027

Аекрет Совета Народных Комиссаров: О восьмичасовом рабочем Ане) [29 октября 1917 г.] [Decreto del Consejo de Comisarios del Pueblo: Sobre la jornada laboral de ocho horas (29 de octubre de 1917)] http:// constitution.garant.ru/history/act1600-1918/5306/

Женский митинг // Правда № 9. 15 марта [28 марта] 1917 г. C. 10. [“Asamblea de mujeres", Pravda, No. 9, 15 de marzo [28 de marzo] de 1917, p. 10.] http://istmat.info/node/28027

Кальманович А., Женское Авижение и отношение партий к нему // Светлана Г. Айвазова, Русские женщины в мабиринте равноправия: очерки политической теории и истории: Аокументальные материалы, М.: РИК Русанова, 1998. [Anna Kalmanovich, "El movimiento de las mujeres y la actitud de los partidos hacia él", reproducido en Svetlana G. Aivazova, Las mujeres rusas en el laberinto de la igualdad: Ensayos sobre teoría política e historia: Materiales documentales, Moscú: RIK Rusanova, 1998.] Disponible online: http://www.owl.ru/win/books/rw/t2_3.htm

Карпецкая, Надежда Аенисовна 1974, Работницы и Великий Октябрь, ИзА-во Аенинградского университета, 1974. 135 п. [Nadezhda Denisovna Karpetskaya, Las trabajadoras y la gran revolución de octubre, Editorial de la Universidad de Leningrado, 1974. 135 p.] 
Каюров, Василий Николаевич 1923, Шесть Аней Февральской революции // Пролетарская револючия. 1923. № 1 (23), c. 157-170. [Vasily Nikolaevich Kayurov, "Seis días de la Revolución de Febrero", Revolución proletaria, 1923, No 1 (23), pp. 157-170.]

Кодекс законов о труде 1918 года [Código de Trabajo de la República Socialista Federativa Soviética de Rusia, 1918] http://www.hist.msu.ru/Labour/Law/kodex_18.htm

Комлонтай Александра 1908, Женщина-работница в современном обществе // Светлана Г. Айвазова, Русские женщины в мабиринте равноправия: очерки политической теории и истории: Аокументальные материалы, М.: РИК Русанова, 1998. [Alexandra Kollontai, "La mujer trabajadora en la sociedad contemporánea", reproducido en Svetlana G. Aivazova, Las mujeres rusas en el laberinto de la igualdad: Ensayos sobre teoría politica e historia: Materiales documentales, Moscú: RIK Rusanova, 1998.] Disponible online: http://www.owl.ru/win/books/rw/t4_2.htm

Колмонтай, Александра 1909, Сочиальные основъ женского вonpoca. СПб.: ИзА. т-ва "Знание", 1909. [Alexandra Kollontai, Fundamentos sociales de la cuestión de la mujer, San Petersburgo: Editorial "Conocimiento", 1909. 437 pp.]

Колмонтай, Александра 1913, “Женский Аень”, Правда, № 40 (244), 17 февраля 1913 г. // Избранные статьи и речи, Москва: Издательство политической митературы, 1972, С. 109110. [Alexandra Kollontai, "El Día de la Mujer", Pravda, No. 40 (244), 17 de febrero de 1913, en Kollontai, Artículos y discursos seleccionados, Moscú: Editorial de Literatura Política, 1972, pp. 109-110.] ontay.pdf

https://bataillesocialiste.files.wordpress.com/2007/09/koll

Комлонтай, Александра 1916, Общество и материнство. I. Государственное страхование материнства. Пг.: Жизнь и Знание, 1916. [Alexandra Kollontai, Sociedad y maternidad. I. Seguro de maternidad estatal, Petrogrado: Vida y conocimiento, 1916.]

Колмонтай, Александра 1917a, Работницы и Учредительное Собрание. // Правда № 14. 21 марта [3 апреля] 1917 г. C. 2-4. [Alexandra Kollontai, "Las trabajadoras y la Asamblea Constituyente", Pravda, No. 14, 21 de marzo [3 de abril] de 1917, pp. 2-4.] http://istmat.info/node/28027

Комлонтай, Александра 1917b, Аемонстрация солдаток // Правда № 30 Среда 12 апреля [25 апр.] 1917 г. С. 5-6 [Alexandra Kollontai, "Manifestación de mujeres de soldados", 
Pravda, № 30, miércoles 12 de abril [25 de abril] de 1917, pp. 5-6.] http://istmat.info/node/28027

Комлонтай А.М., “Как мы созвали Первый Всероссийский съезА работниц и крестьянок”, Коммунистка, 1923, № 1b. C. 3-8. [Kollontai Kollontai, "Cómo convocamos el Primer Congreso de toda Rusia de Obreras y Campesinas", La Comunista, 1923, Número 1b, pp. 3-8.]

Крупской, Надежды 1899, Женщина-работнича // Педагогические сочинения. Том I. Автобиографические статьи. Аореволючионные работы, Москва: ИзАательство Академии педагогических наук, 1957, С. 71-102. [Nadezhda Krupskaya, La mujer trabajadora (1899), reproducido en Krupskaya, Obras pedagógicas, Vol. I: Articulos autobiográficos. Obras prerrevolucionarias, Moscú: Editorial de la Academia de Ciencias Pedagógicas, 1957, pp. 71-102.] http://publ.lib.ru/ARCHIVES/K/KPSS/_KPSS.html

Крупской, Надежды 1920, "Война и деторождение", Коммунистка, 1920, o. 1-2 // Педагогшческие сочинения. Том 06: Аошкольное воспитание; Вопросы семейного воспитания и быта, Москва: ИзАательство Академии педагогических наук, 1957, С. 7-12. [Nadezhda Krupskaya, "La guerra y el parto" Kommunistka, 1920, No. 1-2, reproducido en Krupskaya, Textos pedagógicos. Vol. 6. La educación preescolar. Cuestiones de educación y de vida familiar, Moscú: Editorial de la Academia de Ciencias Pedagógicas, 1959, pp. 7-12.].

Куделли, Прасковья Ф., Работница в 1905 г. в С.Петербурге. Сборник статей и воспоминаний. Сост. П. Ф. Кудемли. АенинграА : Рабочее издательство "Прибой", Сектор "Работница и крестьянка", 1926. - 88 с. [Kudelli, Praskovia F., La mujer trabajadora en 1905 en San Petersburgo: Colección de artículos y memorias. Comp. P. F. Kudelli. Leningrado: Editorial de trabajo Priboy, Sector "Trabajadora y mujer campesina", 1926. 88 p.]

Кускова Е., Женщины и равноправие, Союз женщин, 1908 г., № 12. // Светлана Г. Айвазова, Русские женщины в мабиринте равноправия: очерки политической теории и истории: Аокументальные материалы, М.: РИК Русанова, 1998. [Ekaterina Kuskova, "La mujer y la igualdad", Unión de mujeres, 1908, № 12, reproducido en Svetlana G. Aivazova, Las mujeres rusas en el laberinto de la igualdad: Ensayos sobre teoría política e historia: Materiales documentales, Moscú: RIK Rusanova, 1998.] Disponible online: http://www.owl.ru/win/books/rw/s1_14.htm

Мирошниченко, Мария И. 2011, “Женская Проституция на Урале в 1920-1935 гг. И борьба с ней: обзор митературы 1920-х-начала 1930-х гг,” Исторические, 
философские, политические и юридические науки, культурология и искусствоведение. Вопросы теории и практики, 2-1, C. 122-125. [Maria I. Miroshnichenko, "La prostitución de la mujer en los Urales en 1920-1935 y la lucha contra la misma: Revisión de la literatura de la década de 1920 y principios de 1930", Ciencias históricas, filosóficas, políticas y legales: Cuestiones de teoría y práctica, No. 2-1, pp. 122-125.]

Мирошниченко, Мария И. 2013, “Создание советов по борьбе с проституцией в начаце 1920-х годов,” Вестник ЮжнУральского государственного университета. Серия: Сочиальногуманитарныге науки, 13, 1, C. 41-45. [Maria I. Miroshnichenko, "La creación de Soviets para combatir la prostitución en la década de 1920", Boletin de la Universidad Estatal del Ural Sur. Serie: Ciencias Sociales y Humanas, Vol. 13, No. 1, pp. 41-45.]

Носах, Виктор Иванович 2001, Профсоюзы СанктПетербурга (1905-1930), Санкт-Петербургский гуманитарный университет профсоюзов. [Viktor Ivanovich Nosach, Los sindicatos de San Petersburgo (1905-1930), Universidad Humanitaria de Sindicatos de San Petersburgo, 2001.]

Покровская М. Как женщины должны бороться с проституцией // Светлана Г. Айвазова, Русские женщины в мабиринте равноправия: очерки политической теории и истории: документальные материалы, М.: РИК Русанова, 1998. [Maria Pokrovskaia, "Cómo deberían las mujeres luchar contra la prostitución", reproducido en Svetlana G. Aivazova, Las mujeres rusas en el laberinto de la igualdad: Ensayos sobre teoría política e historia: Materiales documentales, Moscú: RIK Rusanova, 1998.] Disponible online: http://www.owl.ru/win/books/rw/t5_1.htm

Резолюции // Правда № 18. 26 марта [8 апреля] 1917 г. C. 9. ["Resoluciones", Pravda, No. 18. 26 de marzo [8 de abril] de 1917, p. 9.] http:/ / istmat.info/node/28027

Трудыг Первого Всероссийского женского съезда при Русском женском обществе в Санкт-Петербурге, 10-16 декабря 1908 г. СПб., 1909. [Actas del Primer Congreso de Mujeres de toda Rusia en la Sociedad de Mujeres Rusas en San Petersburgo, del 10 al 16 de diciembre de 1908. San Petersburgo, 1909].

Трудвг первого всероссийского съезда по борьбе с торгом женшинами и его причинами, происходившего в С.-Петербрге с 21 nо 25 Aпреля 1910 года. С.-Петербург: Типо-Аитография С.Петербургской ОАиночной Тюрьмы, 1911. [Actas del Primer Congreso de toda Rusia sobre la lucha contra la trata de mujeres y sus causas, que tuvo lugar en San Petersburgo del 21 al 25 de abril de 1910. San 
Petersburgo: Typo-litografía de la prisión única de San Petersburgo, 1911.] http://istmat.info/node/37476

Уголовный Кодекс РСФСР реАакции 1926 [El Código Penal de la República Socialista Federativa Soviética de Rusia de 1926] https://coollib.com/b/124310/read

ШАяпников, Александр 1923, Канун семнадиатого года. Т.

2: Семнадуатый год, М.: Гос.изА-во полит.литературы, 1992, С. 173. [Alexander Shliapnikov, La víspera del decimoséptimo año. T. 2: El decimoséptimo año, Moscú: Editorial estatal de literatura política, 1992, p. 173.] 
A fines del siglo XIX, las socialistas alemanas, como parte del movimiento obrero, adoptaron una política de "separación tajante" de las feministas, como movimiento policlasista, y fijaron la postura de que no existía una única "cuestión de la mujer" sino varias, correspondientes a la necesidades de las mujeres de las principales clases de la sociedad capitalista (la burguesía, la clase media y el proletariado). En términos programáticos, llamaron a abandonar la noción de igualdad en la legislación y a adoptar leyes laborales protectoras del trabajo femenino y de las mujeres embarazadas y lactantes, así como a levantar la bandera del sufragio universal femenino como consigna en torno a la cual podian movilizar y organizar a las mujeres trabajadoras. Esta política se transformó en la línea oficial de la Internacional de Mujeres Socialistas creada en 1907 en Stuttgart, la cual estableció la celebración de un Día Internacional de la Mujer en su segunda conferencia celebrada en Copenhague en 1910. Dicha decisión jugaría un rol crucial en la historia de Rusia. Este trabajo analiza la historia del dichos debates y esfuerzos organizativos que, progresivamente, se fueron transformando en una lucha por el apoyo de las mujeres proletarias entre la principal organización feminista rusa (la Liga por la Igualdad de los Derechos de las Mujeres) y el ala revolucionaria de la socialdemocracia rusa, el Partido Bolchevique. 